\title{
DESIGN AND OPERATION OF MECHANICAL AND HYDRAULIC BIT RELEASES
}

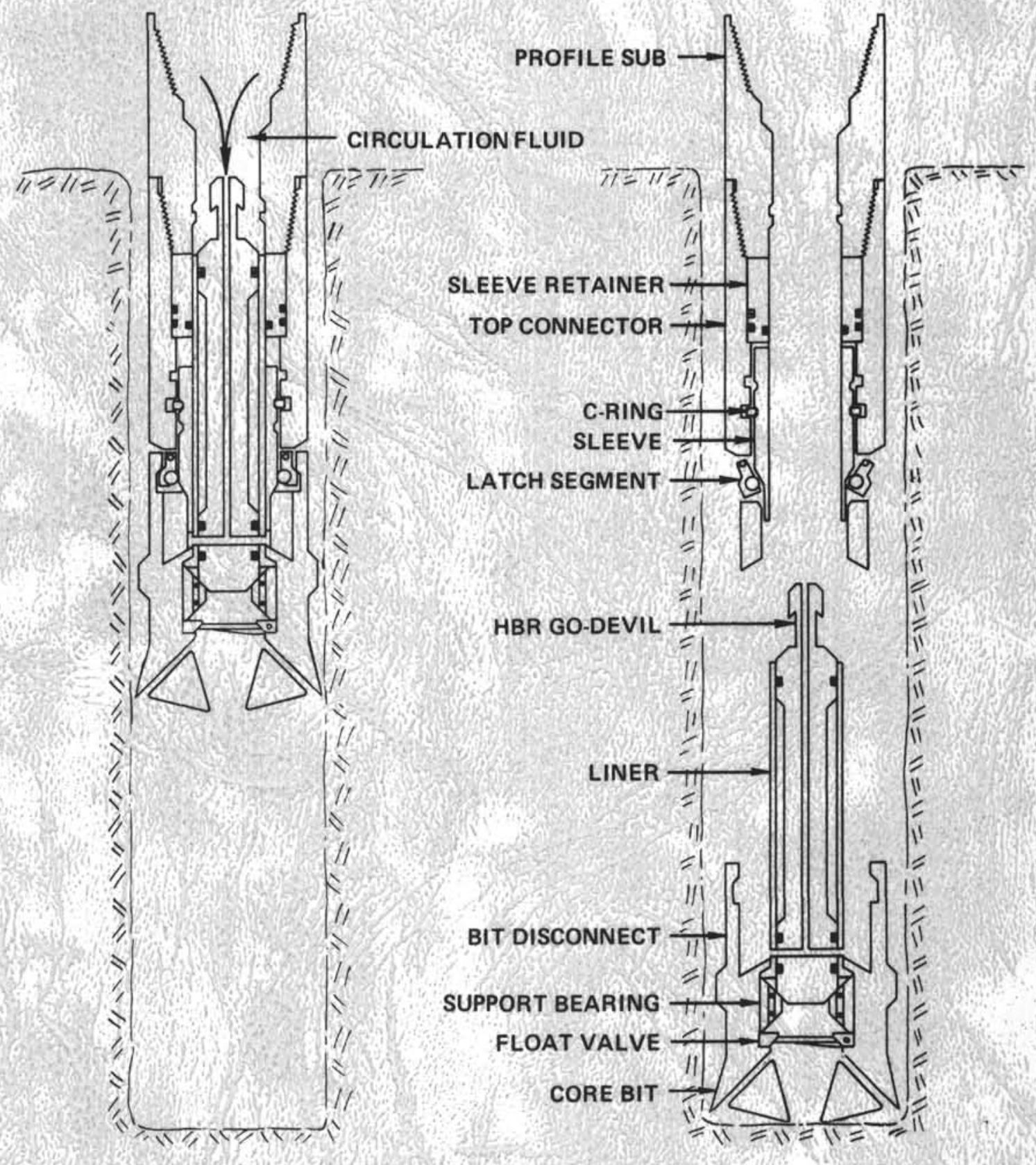

HYDRAULIC BIT RELEASE 
DISCLAIMER

This report was prepared by the Deep Sea Drilling Project, University of California, San Diego, as an account of work sponsored by the United States Government's National Science Foundation. Neither the University nor any of their employees, nor any of their contractors, subcontractors, or their employees, makes any warranty, express or implied, or assumes any legal liability or responsibility for the accuracy, completeness or usefulness of any information, apparatus, product or process disclosed, or represents that its use would not infringe privately owned rights. 


\section{THE COVER ILLUSTRATION}

A simplified presentation of the operation of the latest Hydraulic Bit Release (HBR-Mod. IV) appears on the cover. At the left, the Go-devil has been pumped down the drill string and landed at the support Bearing to align in the HBR mechanism where the circulation fluid is diverted to activate the Release sleeve. At the right, the sleeve has shifted up, allowing the Latch Segments to swing in releasing the bit and other expendable components. 
TECHNICAL REPORT NO. 17

Design and Operation of Mechanical

and Hydraulic Bit Releases

\author{
Prepared for the \\ National Science Foundation \\ National Ocean Sediment Coring Program \\ Under Contract $\mathrm{C}-482$ \\ by the \\ University of California \\ Scripps Institution of Oceanography \\ Prime Contractor for the Project
}

February 1984

W.A. Nierenberg, Director

Scripps Institution of Oceanography
M.N.A. Peterson

Principal Investigator and Project Manager

Scripps Institution of Oceanography 


\section{INTRODUCTION}

\section{DEEP SEA DRILLING PROJECT}

The Deep Sea Drilling Project (DSDP) began coring in August, 1968, under the auspices of the National Science Foundation's (NSF) Ocean Sediment Coring Program to increase man's knowledge of the earth's development through the exploration of the ocean floor. The prime contract for the Project was executed in 1966 between NSF and the Board of Regents of the University of California (UC). Scripps Institution of Oceanograhy in La Jolla, California, which is part of the UC system, is responsible for the management and operation of the Project. Global Marine, Inc. (GMI) of Los Angeles, owner, designer, and builder of the GLOMAR CHALLENGER, subcontracted with Scripps to provide the drilling vessel for the drilling and coring program.

To plan the scientific objectives of the program, major oceanographic institutions in the United States (including Woods Hole Oceanogrtaphic Institution, Lamont-Doherty Geological Observatory of Columbia University, Rosenstiel School of Marine Sciences of the University of Miami, the University of Washington and Scripps), joined in an agreement to mutually support such a program of deep ocean drilling. This association is called the Joint Oceanographic Institutions for Deep Earth Sampling (JOIDES) and provides scientific guidance for the Deep Sea Drilling Project. The group was later enlarged to include nine American institutions.

\section{INTERNATIONAL PHASE OF OCEAN DRILLING}

Prompted by the vast scientific and technical successes of the first seven years, the Project increased the scope of the coring program to include even deeper penetrations into the ocean floor. International interest in the Project increased. Several foreign scientific institutions, excited by past scientific results and confident of future successes, were interested in becoming members of JOIDES. These institutions were willing to contribute financially to the project in exchange for a greater role in the scientific planning. In 1975, the "International Phase of Ocean Drilling", known as IPOD, was born. IPOD was an initial threeyear Deep Crustal coring Program supported both scientifically and financially by the governments of France, Germany, Japan, England and Russia. 
The GLOMAR CHALLENGER, with its unique coring procedures, has long been recognized as a major technical achievement in its own right. The 10,500 metric ton drillship utilizes an advanced onboard computer and dual bow and stern thrusters to dynamically position itself. The CHALLENGER has operated as far north as 76 degrees latitude; as far south as 77 degrees latitude and has the capability to maintain its station in 30-knot winds and 7-10 foot seas. Similar to conventional drillships, the vessel incorporates a 43-meter derrick amidship with a hookload capacity of 450 metric tons and can deploy a $7000 \mathrm{~m}$ drill string. The CHALLENGER utilizes an automatic pipe racker capable of handing 7,300 meters of $5-i n c h$ S- 135 drill pipe, and is equipped with a drill pipe heave compensation system.

Most coring operations are conducted in very deep water and all sites are carefully screened to ensure that there is no possibility of encountering gas or hydrocarbons. For these reasons no riser or blow prevention equiipment is used. Circulation while coring is provided by two National 1600 mud pumps and consists of seawater without return circulation. Core barrels are retrieved by wireline utilizing a coring winch equipped with up to $7900 \mathrm{~m}$ of 6 × 16 wire rope. Well equipped shipboard scientific laboratories are utilized to conduct comprehensive core analyses.

ABSTRACT/TECHNICAL REPORT NO. 17

This Deep Sea Drilling Project Technical Report documents the history, incentives and development details of the bit release technology used aboard the GLOMAR CHALLENGER. Descriptions of the most current models and operational guidelines for both the earlier Mechanical Bit Release (MBR) and the later Hydraulic Bit Release (HBR) are included. Operational deployments of both systems are summarized. Appendices are included with certain significant engineering calculations and machine drawings.

The need for electronic well logging in open holes prompted development of bit release capability by DSDP as early as 1969. Logging tools slightly less than four inches in diameter were available from the oil industry and could be deployed down the CHALLENGER' $S$ drill string but could not pass through the restriction at the core bit. The successful development of two different Bit Release mechanisms literally opened the door for the acquisition of hundreds of well logs in DSDP holes worldwide.

Continuous evolution and development of DSDP downhole coring tool technology, including the advent of radically new tools such as the Wireline Pressure Core Barrel and the Hydraulic Piston Corer, required that the Bit Releases be modified or operational compromises be determined to maintain logging capability in concert with the many different coring programs. Comments on Bit. Release compatibility with the various DSDP coring systems are 
included in this report. The latest developments to make logging possible in cases where open throat core bits tended to preclude use of either type of bit release are discussed in a section on through-the-bit logging techniques.

Both the MBR and $H B R$ remain viable tools to achieve open ended pipe for a variety of downhole logging programs and other open hole experiments. With proper selection and use the bit release technology developed by DSDP offers significant capabilities to any future CHALLENGER-type drilling or coring operations in the deep ocean. 


\section{ACKNOWLEDGEMENTS}

The Mechanical Bit Release (MBR) was originally conceived by Mr. Valdemar "Swede" Larson of DSDP as a modification of existing oilfield disconnect and safety joint technology. The original model of the MBR was produced for DSDP by Rotary 0il Tool Company. Continued adaptation of the MBR to the requirements of driling and coring operations aboard the GLOMAR CHALLENGER were carried out by Mr. Larson and Mr. Patrick G. Thompson of DSDP.

Mr. Thompson also was instrumental in the design, development and testing of the early versions of the Hydraulic Bit Release (HBR) system which evolved from the lessons learned using the MBR. The original HBR Project Engineer was Mr. Michael Storms of DSDP. The reliability analysis and Mod. IV re-design of the HBR were done by Mr. David Huey of DSDP who also prepared this technical report.

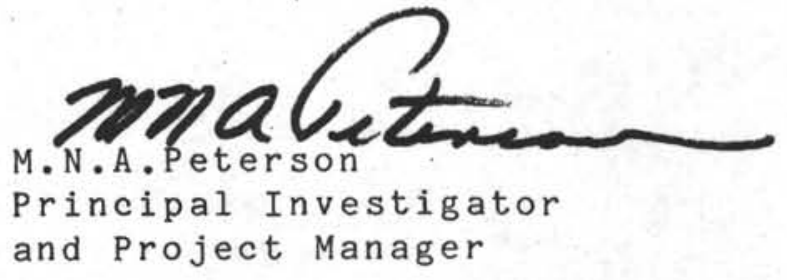


I. Background/Goals....................... 1

II. Engineering Development.................. 3

A. Design-Mechanical Bit Release (MBR).......... 3

B. Design-Hydraulic Bit Release (HBR) ........... 6

II. Current System Descriptions and Operation......... 14

A. Mechanical Bit Release (MBR)............... 14

1. Description .................... 14

2. Assembly Instructions ................ 15

3. Deck Testing.................... 16

4. Downhole Release Instructions .......... 16

B. Hydraulic Bit Release (HBR) ............. 17

1. Description .................... 17

2. Assembly Instructions $\ldots \ldots \ldots \ldots \ldots \ldots \ldots \ldots$

3. Deck Testing....................... 19

4. Downhole Release Instructions........... 21

C. Compatibility With Coring Systems........... 22

D. Through-The-Bit Deployment of Logging Tools..... 23

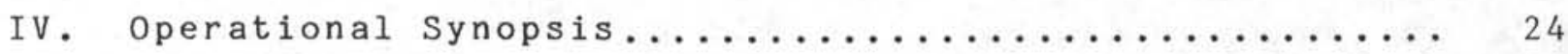

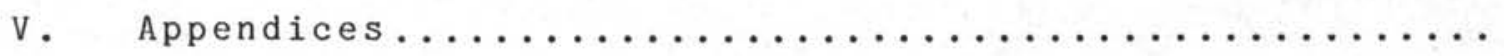

A. Sample Calculations, C-Ring Stresses, Latch Segment, Frictional Analyses......... 45

B. Current MBR Machine Drawings.............. 61

C. Current HBR Machine Drawings.............. 71

D. Past MBR/HBR Machine Drawings and

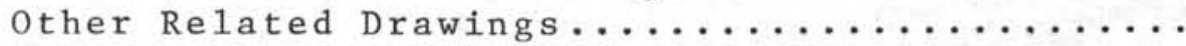




\section{LIST OF FIGURES}

$\underline{\text { Page }}$

1. Prototype Mechanical Bit Release (MBR).

Produced in 1970 by Rotary 011 Tool Co. .......... 31

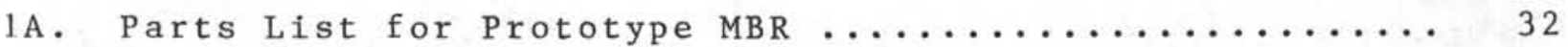

2. Improved MBR. Introduced in 1976 for

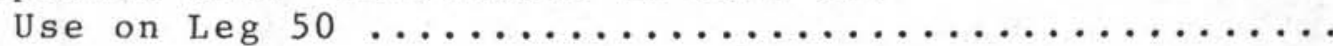

3. Hydraulic Bit Release (HBR) as Used From

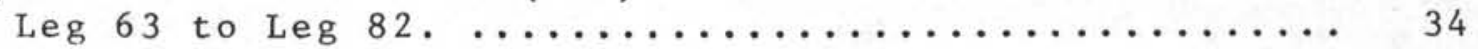

4. Early Mode1 HBR with Asymmetrical Latch

Segments Showing Actuation Forces and

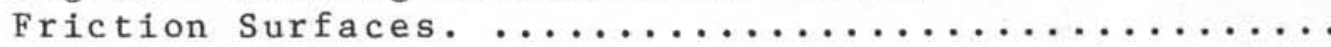

5. HBR Working Parts Showing One of Several

Ear1y Modified Versions of Latch Segments ........ 36

6. HBR Working Parts Showing Later Modifications

Including Modified Latch Segments and

"Toggled" Release Sleeve .................. 37

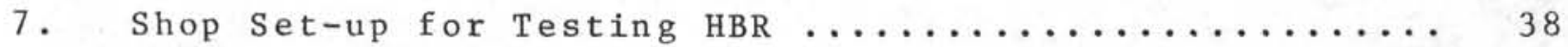

8. HBR Latch Segment Free-Body Diagram ............ 39

9. Pivoting Latch Segment Tested on HBR.

Not successful .......................... 40

10. Trunnion-rotter Latch Segment Incorporated

in Mod. IV HBR ...................... 41

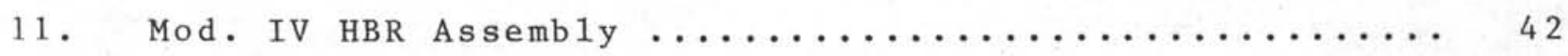

12. Deck Test Set-up for Mod. IV HBR ............. 43 


\section{BACKGROUND/GOALS}

In January 1970, the electronic well logging capability aboard the GLOMAR CHALLENGER was evaluated in view of the scientific goals of DSDP. The ability to provide the best possible downhole logs in most DSDP holes was considered essential for three reasons:

1) To provide missing data in uncored sections and zones of poor or intermittent core recovery;

2) To generate accurate data about in situ, sediment properties, and;

3) To measure general formation properties beyond the physical boundaries of the borehole itself.

The common oilfield practice of choosing logging tools with diameters to match borehole sizes as closely as practical was not possible in DSDP holes since any logging tool would be required to pass through the drill pipe and bottomhole assembly (BHA) before entering open hole. Both through-the-pipe logging and use of "slim" tools capable of passing through the throat of DSDPstandard (nominally 2-1/2" diameter) core bits had been attempted earlier in the Project (Legs 3-8) with generally unsatisfactory results.

Removal of the core bit to allow passage of larger logging tools, up to 4" diameter, was an obvious necessity. Tripping the drill string in order to remove the bit on deck would be self-defeating in single bit holes and excessively time consuming in re-entry holes. (Pipe round trips in deep water can easily require a full day.) A bit release mechanism which could be actuated remotely with the drill string in the hole was required.

The Rotary oil Tool Co., a division of Baker oil Tools, was approached to do a market survey of oil industry suppliers to determine if any suitable downhole release mechanism existed which could be modified to meet Deep Sea Drilling Project requirements. At that time Rotary produced a mechanically actuated downhole shifting device operated by a wireline shifting tool. That particular shifting tool was already used aboard the CHALLENGER in conjunction with the re-entry system. After surveying twenty or more potential suppliers and finding no appropriate tool, Rotary $0 i l$ Tool was given the job of designing and fabricating one prototype Mechanical Bit Release (MBR) based on their existing Disconnect Apparatus. The design was modified to allow a minimum inside diameter of 4-1/8 inches and the threaded connections were made compatible with the DSDP standards so that the MBR could be inserted in the BHA directly above the core bit in place of the standard Bit Crossover Sub. 
This 1970-version was never field tested as no logging program was funded and initiated aboard the CHALLENGER until Leg 48 in June 1976. By that time, the 1970 prototype model had become obsolete because it did not allow room for a Baker Float Valve which had since been added as a standard element to the BHA. In March 1976, Tri-State 0il Tool Industries was contracted to modify the design of the 1970-version prototype MBR and fabricate enough expendable parts to handle the requirements for the logging program planned for Leg 48.

The MBR was first deployed operationally during Leg 48 in June 1976. During its first two years of use four instances of unintentional, premature release occurred. These incidents resulted in the loss of the holes being drilled as well as the loss of ship's time associated with round tripping the pipe and drilling new holes. The problem was serious enough to merit a review of the Bit Release design philosophy. The root problem was thought to be the potential of accidently actuating the release mechanism during a normal core barrel retrieval operation rather than with the shifting tool. The solution proposed was the original conceptualization of the Hydraulic Bit Release (HBR).

An in-house development program for the HBR was begun at DSDP in March 1977. The goal was to utilize the better features of the MBR, which had proven itself to be functionally reliable except for the premature release tendencies, but change the actuation mechanism from mechanical to hydraulic so that an isolation liner could be added between the Release Sleeve and the coring tools which passed through the BHA. The HBR development continued intermittently over the next 14 months, including extensive laboratory testing. The first sea trial models were sent to the CHALLENGER in May 1978 . 


\section{ENGINEERING DEVELOPMENT}

A. Design-Mechanical Bit Release (MBR)

The initial requirements for a bit release mechanism were as follows :

1) The device had to fit into the standard DSDP bottom hole assembly (BHA) with a maximum outside diameter of 8- $1 / 4$ " and an inside diameter of 4-1/8" minimum to allow unobstructed passage of core barrels and downhole instruments;

2) It had to be rugged enough to withstand the rigors and abuse of downhole drilling conditions for up to several days and still function when called upon to release;

3) Release actuation had to be accomplished remotely from the rig floor in a minimum of time;

4) The release mechanism had to be able to remain inert through routine coring and sampling operations without the likelihood of inadvertent release;

5) The mechanism had to be hydraulically sealed prior to actuation to prevent drilling fluids from escaping to the hole and bypassing the bit;

6) The separating halves of the mechanism would be required to carry the normal drilling loads prior to release:

- torque - up to $12,000 \mathrm{ft} / \mathrm{lbs}$

- compression - weight of the BHA transmitted to the bit, up to 45,000 pounds

- tension - weight of bit and releasable components prior to release

- impact, inertial, vibration and wear loads.

7) After release, the down-looking end of the last component remaining attached to the drill string had to be rugged enough to withstand minor weight-on-bit load applications to ream hole and penetrate minor bridges, as well as provide a smooth profile to enable re-entry of the logging tools while protecting the logging E-M cable from snags and chafing. 
The prototype MBR designed and fabricated by Rotary 0il Tool Company based on their existing Disconnect Apparatus is shown in Fig. 1 along with the Shifting Tool (spear). The mechanism met all seven initial design requirements and proved acceptable in shore testing although no shipboard testing was ever done on this MBR version.

The mechanism was composed of four primary components: Top Connector, Disconnect, Release (Latch) Sleeve, and Latch Segments. The Top Connector and Disconnect were attached by means of four block-like Latch Segments which prevented separation and were adequate to hold the tensile load of the releasable components. Compression (weight-on-bit) loading was transmitted through shoulders on the Top Connector and Disconnect. Torque loads were handled by Torque Slipper pads welded to the Disconnect.

Release was accomplished by engaging the Dogs of the Shifting Tool in a special profile cut in the Release sleeve, then pulling the sleeve up with the sandline to unveil the Latch Segments. The Segments were then free to fall inward releasing the Top Connector and Disconnect. Safety against accidental shifting of the Sleeve was provided by a "C"-ring spring snapped into a detent on the sleeve. Sufficient upward pull on the sleeve to overcome the locking action of the "C"-ring was required before the sleeve could move. Three 0-rings were included to seal the possible fluid paths around the sleeve and out the Latch segment windows so that all pumped flow was directed to the bit.

The next design modifications were accomplished by Tri-State 0il Tool Industries at the direction of DSDP prior to the first at sea deployment of the MBR during Leg 48. The Disconnect was lengthened to allow room for a Baker Float Valve which had been added to the standard BHA to control well back flow. During lab testing of the prototype MBR, problems had been encountered with overstressing the "C"-ring during installation. To alleviate this a re-engineered "C"-ring was added (see actual calculation in Appendix).

Following Leg 48, the torque transmission capability of the Slipper Pads was questioned and they were discarded in favor of a hex spline drive arrangement between the Top Connector and Disconnect. This adaptation proved to be $100 \%$ reliable over the seven years that the MBR was used thereafter. The male hex measures 6.186 inches across the flats and mates with the female with $0.064 / 0.100$ inches diametral clearance and 3.375 inches lengthwise engagement. Compression loads continued to be carried via 60 degree conical mating shoulders between the Top Connector and Disconnect.

The improved MBR made its debut on the CHALLENGER during Leg 50 in the version which appears in Fig. 2. Later improvements which were made were all minor. The most significant of these involved slimming of the Latch Segments so that a band could be welded over the windows in the Disconnect. The welded band plus an 0- 
ring partially sealing between the Disconnect and Top Connector above the Latch Segments were added in an attempt to shield the Latch Segments and Release Sleeve from contamination and jamming by drill cuttings and detritus. On at least two occasions fine sand had packed off around the segments of the MBR so that either the sleeve could not be shifted or, once shifted, the segments were effectively locked in place preventing separation of the Top Connector and Disconnect. The gland for the additional 0-ring had to be provided with bypass grooves in order to prevent a perrect seal around the annulus occupied by the segments. If all four brings in the vicinity were allowed to seal completely, an atmospheric chamber would be created which would tend to lock up under the influence of high hydrostatic pressures encountered in service. The combination of a partially bypassed final seal and a heavy grease pack around all the moving parts succeeded in excluding detritus effectively enough to lend a high degree of reliability to the MBR mechanism even under adverse downhole coneditions.

$-5-$ 
B. Design-Hydraulic Bit Release (HBR)

Unlike the Mechanical Bit Release, which was an adaptation of an oil industry tool with engineering development done by industrial suppliers, the HBR was designed entirely by the DSDP Development Engineering Department. Development of the HBR was based on the desire to achieve three improvements over the MBR:

a) The MBR had experienced sporadic instances of premature release when drilling debris and /or sand became wedged between a core barrel and the Release Sleeve. When the barrel was retrieved, the sleeve was pulled up and inadvertent release occurred. The HBR would have a Liner attached to the Disconnect which physically separated the Release Sleeve from core barrels. Only hydraulic pressure diverted to the bottom of the sleeve through holes in the Liner would be able to shift the Sleeve up.

b) A Go-devil with seals would be used to divert the rig pump hydraulic pressure to the Release Sleeve. Since it could be pumped down without requiring the sandline, round trip time for the wireline shifting tool would be eliminated, thus consuming less rig time for the bit release operation.

c) In order for the Go-devil to align itself accurately in the HBR Liner it was designed to land on the support Bearing where it packed off the flow to the bit. In doing so, it acted as a piston which exerted a significant downward thrust (up to 40,000 lbs at 2800 psi pump pressure) on the support Bearing, Core Bit and other releasable components. This action was expected to help "shoot" the bit off if it hung up slightly. In addition, sudden release of the pressure required to shift the sleeve and release the bit would provide positive indication of release at the rig floor.

The HBR, in its initial version, used many of the concepts and components proven in the MBR design. Figure 3 shows the HBR as it was used aboard the CHALLENGER from Leg 63 to Leg 82. Minor modifications were made throughout that period but no consistent improvement in reliability resulted. The major functional elements from the MBR were repeated in the HBR design: Top Connector, Bit Disconnect, Release Sleeve, and four block Latch Segments. A "C"-ring was again used to lock the Shifting Sleeve prior to release actuation. An expendable tubular Liner was added which was fixed to the Bit Disconnect and served to physically shield the inside of the Release Sleeve.

A Go-devil, carrying Chevron seals, was designed to be deployed by pumping it down the drill pipe until it landed at the support Bearing. At that point the seals would seal off the Liner diverting the drilling fluid (sea water) to ports in the Liner. 
Another set of seals, between the Liner and Release Sleeve, isolated the upper and lower halves of the sleeve so that pressure acting on the underside would ultimately lift the sleeve allowing the blocks to fall inward. The bit, Disconnect, Liner, and Godevil were then free to move down under the influence of the pressure acting from above.

Shop tests to determine force requirements to overcome the locking effect of the "C"-ring on the MBR showed that an axially applied force of 1450 to 1650 pounds was needed to "jump" the "C"-ring. With the MBR this force was applied by pulling up on the Shifting Tool with the sandline. The HBR used hydraulic pressure applied to the bottom of the sealed Release sleeve. The annular working area between the inner and outer seals was calculated by:

$$
\begin{aligned}
A_{S}=\pi / 4 \quad\left(D_{0}^{2}-D_{i}{ }^{2}\right) & \text { where the outer seal diameter, } \\
& \begin{array}{l}
D_{0}=4.621 \text { in. and the inner seal } \\
\text { diameter, } D_{i}=4.250 \text { in. }
\end{array}
\end{aligned}
$$

Thus $A_{S}=2.58$ sq.in.

Therefore, the pressure required to jump the "C"-ring was 1450 to 1650 pounds divided by the $2.58 \mathrm{sq}$. in. working area yielding 560 to 640 psi.

Early lab tests on the prototype HBR demonstrated that the mechanism did not function exactly as expected. Results were inconsistent and failure to release took several forms: in some cases the sleeve would not shift even at pressures up to 1800 psi, in many cases the sleeve would shift as expected but the Latch segments would not budge. In some tests release occurred quite easily.

It became apparent that the downward force exerted hydraulically on the Go-devil and transmitted via the support Bearing to the Disconnect and other releasable components resulted in a considerable change in characteristics of the moving parts that had previously been reliable in MBR service. Fig. 4 shows the problem. As pressure is built up to shift the sleeve past the "C"ring at say, $600 \mathrm{psi}$, the Go-devil acts as a piston forcing down on the Support Bearing. The Go-devil "piston" area is $A_{G}=\frac{\pi}{4}$. $(3.875)=11.79 \mathrm{sq}$. in. the minimum downward force is then $\mathrm{F} 1{ }^{4}=$ $600(11.79)=7075$ lbs. The minimum load, F2, on each of the four Latch Segments is thus $7075 / 4=1769 \mathrm{lb}$ (if the loads are evenly distributed) and a reaction force, F3, at the bottoms of the windows in the Top Connector of an equal amount exist before the Sleeve begins to move. The frictional forces, $f$, between the Sleeve and Latch Segments then tends to resist movement of the Sleeve and requires a greater pressure to overcome the combined resistance of the Latch Segment friction and "C"-ring. The magnitude of the frictional forces exerted on and by the Latch Segments depends on the normal force at those surfaces which, in 
turn, depends on the angles of the two working sides of the segments relative to the direction of application of the forces, F2 and F3.

To combat the problem, several combinations of angles were tested for the surfaces of the Latch segments until an optimum combination was selected as shown in Fig. 5. (See Appendix for example calculations). To avoid the simultaneous combined influence of Latch Segment friction drag and "C"-ring resistance, a toggle mechanism was added to the Release Sleeve design as shown in Fig. 6. This enabled the sleeve to jump the "C"-ring before trying to move out from under the segments.

With these improvements, a series of lab tests were conducted during which the mechanism was operated in a variety of conditions simulating, to some degree, actual operating conditions. After passing all tests, including pressuring up against a completely plugged bit and releasing after contamination with sand, the HBR was sent to the CHALLENGER for sea trials.

Results of deployments at sea from Leg 63 to Leg 82 showed that although the HBR had the potential to be a superior tool to the MBR, its reliability was poor. Numerous failures, lost rig time, and unintentional releases occurred during that period. In hopes of improving reliability minor changes were continuously incorporated. Modifications were also made to simplify the system for ease of assembly, ease of fabrication or reduction of fabrication costs. The majority of these changes were made on the basis of designer's judgement without exhaustive testing since ship's operating time was not generally available for Engineering Development testing and shore-based tests could not authentically simulate true downhole conditions (i.e., sand ingress, impact and fatigue loading, temperature and hydrostatic pressure).

Among the modifications made during this period were:

a) Changing seal types on the Go-devils.

b) Re-design of Latch Segments and mating surface on Release Sleeves.

c) Closing Segment windows from outside access.

d) Altering stiffness (spring rate) of "C"-rings.

e) Revamping clearances between moving parts.

f) Incorporation of "trash" or wiper seals to reduce sand contamination.

Recognition of the fact that the downward thrust on the support Bearing from the Go-devil was not necessarily desirable led to the development of a Drag Block Go-devil. It was designed to 
lock into the Profile Sub just above the Top Connector where it was properly aligned to divert the hydraulic pressure but would not produce a downward force on the Bit Release mechanism. This Go-devil was tested only once, at Site $516 \mathrm{~F}$ on Leg 72 . The results were inconclusive since the Go-devil seals were apparently stripped off during the trip to the bit and no seal was achieved. The Drag Block Go-devil was never again tested but had arguable technical merit in that it would have allowed the mechanism to operate and release in an unloaded manner similar to the MBR. A drawback which ultimately eliminated it from further testing, was that after a successful release a wireline trip would have been required to retrieve the Go-devil since it would not exit with the bit and other releasable components.

In September 1981, a major status appraisal and redesign of the HBR was undertaken with the aim of improving reliability. The HBR design at that time is shown in Fig. 3. Operational histories were studied and related to theoretical analyses with the goal of investigating, and finding a solution for, every possible way the HBR could be failing to function.

To apply some order to the analysis, possible failure modes for the HBR were grouped into three categories, according to the sequential events which take place when the tool operates normally.

$$
\begin{aligned}
& \text { Group } 1 \text { - Included dropping and sealing of the Go-devil } \\
& \text { and shifting of the release Sleeve. Premature } \\
& \text { releases were also included in this category. } \\
& \text { Group } 2 \text { - Included problems associated with shifting of } \\
& \text { the four Latch Segments. } \\
& \text { Group } 3 \text { - Included separation of the Bit Disconnect, Liner, } \\
& \text { and lower assembly components from the Top } \\
& \text { Connector and Release Sleeve. }
\end{aligned}
$$

Results of the investigation and technical analysis are as follows:

\section{Group 1}

Operational experience indicated that this phase of operation of the tool had adequate reliability. In the past the integrity of the Go-devil seals had been a problem. Often more than one Go-devil had been required to achieve bit release. (It is possible that in some cases where multiple Go-devils were used only the first was needed. Release delay could have been falsely attributed to bad Go-devil seals when actually other elements were momentarily preventing full release). Improved reliability of chevron seals on the Go-devils was achieved by reducing the rate at which the Go-devil is pumped down and adding metal V-spacers between elastomeric seals. A later modification employed Lynes 
wedge-type seals which were more resistant to stripping and thus more reliable. Go-devil failures were not considered to be the cause of recurring failures and general low reliability of the HBR.

In several cases of HBR failure the assembly had been recovered with the Release sleeve in the shifted position. operational experience did not reveal a single case where the Release Sleeve had failed to shift when the Go-devil had been able to achieve an adequate seal.

The four recorded premature releases up to that time had all occurred when the HBR was used during or immediately after heavy weather conditions. This phenomenon could be explained by a combination of inertial and vibration forces acting to jump the C-ring. One premature release occurred while the drill string was being lowered in open water prior to spudding Hole 555. The C-ring, originally designed with a solid cross-section, had been weakened in several modifications by scalloping its O.D. to achieve a release threshold pressure of about $450 \mathrm{psi}$. This apparently was low enough to enable the premature releases to occur. All other aspects of Group 1 operation of the HBR appeared highly reliable.

Group 2

It was demonstrated by a free-body static force analysis that Latch segments as designed at that time were subject to locking up be static friction. This could occur if the coefficient of friction between the lower surfaces of the Segments and the windows in the Top Connector exceeded 0.27 . This was a direct result of the 15 degree incline which the Segments were required to slide across and was independent of contact area or applied normal force. The coefficient of static friction for unlubricated steel-on-steel can commonly be as high as 0.7 . Running friction is often about 0.4 . This suggested that a minor amount of contamination on one or more Latch Segments would probably have impeded its movement and prevented disengagement from the Bit Disconnect.

\section{Group 3}

No probable scenario for bit release failure after the Latch Segments shifted was conceived. Several specific theoretical causes of failure in this category were analyzed but none could be supported by operational experience. They included:

a) Locking due to unbalanced hydrostatic pressure.

b) Frictional resistance of liner as it slid free, inhibited by Go-devil induced bulging, misalignment, unbalanced hydraulic pressures, or liner 
buckling.

c) Solidified grease.

d) 0-ring breakout friction.

In order to empirically verify the above evaluation one of the most recently modified HBR assemblies was set up for shop testing as shown in Fig. 7. Tests were run in a variety of conditions to isolate different parts of the release mechanism sequence. Ultimately a repeatable failure mode was achieved involving the Latch Segments which verified the static friction theory. All other potential failure modes and suspect weaknesses were found to be limited to isolated or special cases.

Redesign concentrated on devising Latch Segments which would function smoothly in spite of the fact that the hydraulic load caused a significant downward thrust on each segment before shifting could begin. Fig. 8 shows the situation. A single Latch segment is shown in a free-body diagram with the loads which would occur after the Release Sleeve had shifted out from underneath it. Four segments are in the mechanism but only one had to be stuck to prevent release. The segment is shown turned horizontally ("down" to the right) to match drawing conventions.

In a completely frictionless case, static equilibrium cannot be achieved and the segment will certainly move in the desired direction. After about 1/4" of movement of each of the Latch Segments the Disconnect is free to separate. The MBR Latch Segments functioned in a manner more or less simulating the frictionless case because the resultant surface loads $F$ and $R$ were quite small allowing lubrication to remain intact on the sliding surfaces.

In the case of the HBR, however, significantly greater surface loads on the Latch segments brought friction very much into the picture. In the free-body diagram it can be seen that even without the support of the Release Sleeve under the Segment static equilibrium (lock-up) can be achieved if the outward frictional components, $f 1$ and $f 2$, are sufficient to balance the inward components of $F$ and $R$. The force balance analysis (which appears in the Appendix) shows that the critical coefficient of friction for either working surface, $\mu_{c}$ is 0.42 . Any coefficient higher will result in a segment locked firmly in place. This effect was observed often in lab tests of the mechanism. Welllubricated steel on steel can exhibit a static coefficient of friction as low as 0.1 while in the unlubricated case the coefficient is commonly 0.7 or higher. Lab tests showed that well greased Segments shifted easily on the first attempt but failed when a repeat was tried without regreasing. It is not difficult to imagine that in actual use of the HBR downhole drilling conditions would often destroy the lubricant required between Latch Segments and mating surfaces until the coefficient of friction exceeded $\mu_{c}$ of 0.42 . 
An additional effect of the Segment design can be extracted from the free-body analysis. Resultant forces $F$ and $R$ can be seen to act non-colinearly thus a couple is induced which would promote rotation of the Segment as it tried to move in translation. Any significant rotation would break the sliding surfaces away from each other thus temporarily mitigating the frictional lock-up. This would allow some sliding until the flat surfaces mated again and the process would intermittently repeat leading to a somewhat unreliable "squirming" action. This phenomenon was observed in lab tests and also helps to explain why many operational deployments of the HBR achieved full release only after "working" the bit by rotation, tagging bottom and generally banging the mechanism around.

To circumvent the problem of uncontrollable static friction, a series of hinged or pivoting latch segments were analyzed and tested. The first candidate appears in Fig. 9. This design was not successful for two reasons. The counteracting frictional forces on the pivot pin could be ignored but the frictional force, f1, acting on the outer corner of the Segment had a long moment arm while force, $F$, had a short moment arm relative to the pivot point. This made it too easy for a small $f$ to overpower a large $F$ and cause the segment to rotate the wrong direction. A second problem involved frictional resistance caused by the pinch effect between the underside of the Segment and the moving portion of the Release Sleeve.

An improved Latch Segment hinged on trunnion ears is shown in Fig. 10. This design incorporated a roller at the contact point between the Segment and the Release Sleeve to eliminate the problem of friction at that surface. The free-body diagram and analysis of the force balance (which appears in the Appendix) shows that the geometry of the trunnion ear segment offers the optimum combination of maximizing forces and moments which tend to make the segment rotate in the proper direction while minimizing the counter-rotational moments caused by static friction. The critical coefficient of friction on the outer edge required to achieve static equilibrium (frictional lock-up) after the Sleeve has shifted up is 1.46. Even the worst case of lubrication (or lack of) cannot induce such a high coefficient, so the problem of frictional lock-up is eliminated.

Since the trunnion ears and Roller Axles were limited in diameter by space restrictions, their worst case load carrying ability was carefully analyzed. The Segments are not loaded by weight-on-bit compression or by drilling torque. The highest loads encountered by the Latch Segments is when maximum pump pressure is applied to a completely plugged bit. In such a case a downhole thrust of about 124,000 pounds forces the Release Mechanism apart and must be held by four Segments. The shear strengths of the Latch Segments and Roller Axles were thus chosen to allow for this condition and a safety factor was included by designing the parts so that only two of the four Latch segments could carry the full plugged bit load. Lab tests were successfully conducted to verify the analyses. 
Shop tests of the HBR assembly employing the new trunnion/roller Latch Segments (designated Mod IV) proved 100\% successful even under intentionally unlubricated conditions. Initial sea trials resulted in one routinely successful release, one failure to release, and two spontaneous releases during spud-in or coring. The release failure was traced to severe sand contamination brought on by the fact that the mechanism was inadvisedly oiled rather than greased packed prior to deployment. (Experience has proven that a full grease pack is the only means of sand and grit exclusion. Any Latch Segment, hinged or otherwise, can be locked in place with an aggressive sand contamination.) The spontaneous releases were eventually traced to a problem where the rollers on the Latch Segments were slipping down the ramp of the Release Sleeve prior to actuation. This was apparently caused by a combination of tolerance slop in the mating parts, vibrational effects and slightly out-of-spec dimensions.

The potential for the Release Sleeve working its way up, despite the "C"-ring, enough to allow the Latch segment rollers to slip over the edge was deemed real enough to warrant a final design modification. A Hold Down Spring was added above the Release Sleeve with a preload of 200 pounds to insure that the sleeve remained at the bottom of its cavity and fully under the Latch Segments until shifted by a hydraulic pressure greater than 97 psi. On the one occasion, when the Mod. IV HBR with the Hold Down Spring was used at sea, a routine release was successfully accomplished. The MOD IV HBR assembly appears in Fig. 11. 
A Mechanical Bit Release (MBR)

1. Description-MBR

The most current modification of the MBR (Fig 2) incorporates only a few improvements over the original version developed in 1976 by Tri-State 0il Tools. The assembly consists of four major components: the Top Connector (OL-1115) which remains attached to the drill string after release, the Bit Disconnct $(\mathrm{OL}-1350)$ which is the primary releasable component and crosses over to the core bit, four block-like Segments (01-1105) which attach the Top Connector and Disconnect, and the Latch Sleeve (OL-1120) which is shifted to allow the segments to full inward and effect release of the bit. (The Latch Sleeve is often called the Release sleeve. Both designations will be found in descriptions and figures both in this report and other DSDP documentation.)

A Sleeve Retainer $(\mathrm{OL}-1110)$ is threaded into the bottom of the Bit Disconnect to complete the assembly, a "C"-ring $(O L-1125)$ is used to lock the Latch Sleeve into the lower position before actuation of the mechanism is desired. Several fasteners and $0-r i n g s$ are required to complete the parts list.

The releasable (expended) components include the Bit, Bit Disconnect (including a Support Bearing, Float Valve and Bit Seal Assembly), and the four Segments.

Shifting the Latch Sleeve downhole is done with a "Rotary" Shifting Tool Assembly $(\mathrm{OL}-1400)$ which is run in on the sandline attached to the bottom of a standard inner core barrel assembly. The Shifting Tool consists of a Body (OL1405), a Landing Sub (OL-1409) and a pair of spring-loaded Shifting Dogs (OL-1406) which engage the Latch Sleeve.

The MBR assembly is included in the bottomhole assembly (BHA) in place of a Bit Crossover Sub whenever manual bit releasing capability is desired. When a combination Bit Sub Spacer $(O G-0621)$ and Bit Sub $(O L-1030)$ is replaced by a Head Sub or Profile Sub plus an MBR assembly, the overall change in spacing of that portion of the BHA is less than one-half inch. 
2. Assembly Instructions-MBR

a) Install a C-ring (OL-1125) in the provided groove in the Top Connector (OL-1115).

b) Grease and install one 0-ring (\$2-431) into the upper gland on inside of the Top Connector.

c) Slide the Latch Sleeve (OL-1120) into the Top Connector and force it past the C-ring detent far enough to uncover the windows for the segments. Several types of Latch Sleeves have been used and many may still be found in inventory. Earliest models have a 4-3/4-inch V-thread at the bottom to allow an installation tool to be screwed into the Sleeve. Parts with Revision (dash) numbers 1 through 3 have no threaded section for installation and Revision (dash) numbers 4 and 5 have a $4 "-8$ NPT, $3 / 4$ TPF thread. The pipe thread allows use of any handy piece of 4 " pipe as an installation aid.

d) Grease and install another 0-ring (\#2-431) into lower gland on inside the Top Connector.

e) Install the Sleeve Retainer (OL-1110) into the bottom of the Top Connector. Use Baker Lock compound on the Retainer thread.

f) Grease and install two 0-rings (\#2-442) into the glands around the windows on the inside of the Bit Disconnect $(\mathrm{OL}-1350)$.

g) Insert Top Connector into Disconnect and hold engaged until segments can be fixed in place.

h) Insert a Segment $(\mathrm{OL}-1105)$ into each window cavity and hold against the Disconnect by "pulling" with a permanent magnet over each window from outside the welded band. The void areas around each segment should be grease packed as thoroughly as possible.

i) While holding the Segments out, push or pull the Latch Sleeve down under the segments until it locks into place in the fully down position with the C-ring in the detent groove on the sleeve.

j) Pump grease into the two threaded ports ( $1 / 8$ NPT) over the C-ring and plug the ports. Also plug the three $3 / 8^{n}-24$ UNC threaded holes over the C-ring. These are used for jacking the C-ring out of its groove for disassembly. 
3. Deck Testing - MBR

Deck testing the Mechanical Bit Release prior to deployment has limited value. Thorough deck testing is recommended when new personnel, all new equipment or doubt about correct assembly is involved. Unfortunately, a nearly complete reassembly and a complete regreasing is required following any adequate deck test. Therefore, when a degree of confidence exists in correct assembly especially when reusing previously deployed hardware, deck testing is not considered essential.

Before deployment downhole the Rotary Shifting Tool which will be used should be checked for proper fit and engagement in the Latch Sleeve. This is most readily accomplished during the assembly procedure.

\section{Downhole Release Instructions-MBR}

The tendency toward premature release of the MBR brought about certain precautions concerning hole cleaning practices when coring with the MBR in the bottomhole assembly. The cases when the $M B R$ has been unintentionally released were thought to have been caused by sand and/or chunks of cuttings getting jammed between the Latch Sleeve and a core barrel. The sand or cuttings were able to get into the mechanism by backflowing from the outer barrel/hole annulus. Meticulous attention to hole cleaning reduces the amount of material in suspension in the annulus and reduces possibilities of premature release of the MBR.

Before attempting a release the bit should be off bottom and the hole adequately conditioned. A "Rotary" Shifting Tool is made up to a blank core barrel and either pumped to the bit or lowered on the sandline. Release is achieved by pulling up on the sandline to shift the Latch Sleeve. The sandline core reel weight indicator should show an increase of roughly 1000-1500 lbs. if the Shifting Tool dogs have engaged the profile in the Latch Sleeve. A sudden release of this overpull indicates the sleeve has shifted and the Shifting tool has pulled free. Verification that the bit has released is accomplished by lowering the Shifting Tool again and observing if it is able to go past the line flag at the previous location where the Tool landed on the Support Bearing.

When using the MBR, consideration should be given to means of avoiding plugging the end of the Top Connector with mud, clay or gumbo after releasing the bit. The MBR is especially susceptible to this problem and difficult to get clean because of the open windows on the side of the Top Connector above the plug. If possible, reaming the hole should not be done with the MBR Top Connector and the end of the pipe should be located in a part of the hole where sticky mud and clay are not thought to exist. 
B. Hydraulic Bit Release (HBR)

\section{Description - HBR}

The current version of the HBR (Fig. 11) is designated Mod. IV and utilizes a 3.875 inch I.D., Liner. (Another version, Mod. V with a 3.800 inch I.D. Liner was developed but has since been obsoleted.) The Mod. IV HBR consists of four major component sub-systems: the Top Connector (OL-1224) which remains attached to the drill string after release, the Bit Disconnect $(\mathrm{OL}-1225)$ the primary releasable part which connects to the core bit, the four Latch segment assemblies (OL-1226, 27, 28) which fix the Top Connector to the Disconnect prior to release and the Release sleeve (OLl-1229) which moves to allow the Latch Segments to unlock the mechanism and drop the bit and other releasable components.

Other significant elements include the Liner (OL-1236) which physically separates the Release Sleeve from coring tools and instruments passing through the BHA, a Sleeve Retainer (OL-1223) required for proper assembly, sealing and alignment, a "C"-ring (OL-1221) which locks the Release Sleeve in the down position until the release sequence begins, and a Hold Down Spring $(\mathrm{OL}-1247)$ which maintains the Release Sleeve in the down position before release in spite of slop in mating parts or vibration which may tend to shift the Sleeve prematurely. A set of fasteners and seals is required to complete the assembly. A special HBR Go-devil (OL-1274) with wedge-type seals is used to activate the mechanism by diverting circulation and hydraulically shifting the Release Sleeve. A Baker Float Valve, Support Bearing and. Bit Seal Assembly are normally included in the Bit Disconnect directly above the bit but are not components in the HBR system. A Profile Sub (01-1201) or Head Sub (OL1010) with a 5-inch long pin connection must be included above the Top Connector to mate properly with the sleeve Retainer. The releaseable (expended) components include the Bit, Bit Disconnect, Bit Seal, Float Valve, Support Bearing, Liner, and Go-devil.

2. Assembly Instructions - HBR

a) Piece together four Latch Segment Assemblies, each with:

$$
\begin{aligned}
& \text { ( } 1 \text { ea) Latch Segment (OL-1226), } \\
& (1 \text { ea) Roller Axle }(\mathrm{OL}-1227) \text {, } \\
& (1 \text { ea) Roller }(\mathrm{OL}-1228) \text {, } \\
& (1 \text { ea) } 1 / 8 \text { "Roll Pin }
\end{aligned}
$$

Apply grease to lubricate Roller on Roller Axle. During further assembly grease should be packed 
liberally into the Latch segment windows and around the Liner to exclude sand from moving parts.

b) Install a C-ring (OL-1221), in the provided groove in the Top Connector (OL-1224).

c) Insert the four Latch Segment Assemblies into the windows of the Top Connector so that the trunnion ears of the Latch Segments are engaged into the sockets in the sides of the windows.

d) Fit proper O-rings into grooves on Top Connector; $0-r i n g s$ required:

$$
\begin{aligned}
& (1 \text { ea }) \text { \#2-440, } \\
& (1 \text { ea) \#2-426, } \\
& (1 \text { ea) } \# 2-347
\end{aligned}
$$

e) Fit one 0-ring (非-347) into I.D. groove on the Release Sleeve (OL-1229).

f) Force the Release Sleeve into position from the top of the Top Connector so that the C-ring snaps into the first (lower) detent in the Release Sleeve. The Latch Segments should now be locked into the windows but free to swing.

g) Insert the Top Connector into the Bit Disconnect (OL-1225) and hold fully engaged while forcing the Release Sleeve down into the "locked" position so that the C-ring snaps into the second (upper) detent. The Latch Segments should now be locked in the "swung-out" position holding the Disconnect to the Top Connector.

h) Hold down the Release Sleeve with a rod or piece of tubing while inserting the Liner Assembly (OL1236) from the bottom of the Disconnect. The Liner is held in place finally by the support Bearing and Float Valve Assemblies.

i) Insert the Hold Down Spring (OL-1247) into the Top Connector on top of the Release Sleeve.

j) Install four O-rings in the Sleeve Retainer (OL1223); 0-rings required:

$$
\begin{aligned}
& (2 \text { ea }) \text { \#2-432, } \\
& (1 \text { ea }) \text { \#2-347, } \\
& (1 \text { ea }) \text { \#2-426, }
\end{aligned}
$$


k) Install the Sleeve Retainer into the top of the Top Connector into the annulus created by the top of the Liner. The Sleeve Retainer should seat firmly and be flush with the top of the Liner $1 / 16^{\prime \prime}$ after step m).

1) Place an 0-ring \#2-432 on top of the Sleeve Retainer before mating a Profile Sub (OL-1201) into the box thread on top of the Top Connector. The Profile sub presses down on the sleeve Retainer and partially compresses the Hold Down Spring as it is screwed into the Top Connector.

m) Pump grease into threaded ports over C-ring and plug the ports. These threaded ports are later used to jack the C-ring out of its groove for disassembly.

\section{Deck Testing - HBR}

Deck testing has proven to be a vital element in promoting reliability when using the HBR. Several approaches to deck testing have been used with various levels of difficulty in accomplishing the test, contrasting with the effectiveness of the test at proving proper assembly and operational readiness.

The most thorough deck test involves complete assembly and lubrication of the HBR, followed by installation to a drilling joint and appropriate crossovers in the derrick. A test release sequence can then be accomplished at the rig floor by applying pressure with the rig pumps. The drawbacks to this type of test are:

a) During the test release grease which had been packed into cavities around the moving parts as a sand exclusion medium is extruded out of place and cannot be repacked when the mechanism is reset unless disassembly is done. This would partially negate the value of the deck test,

b) Testing on the rig floor takes up valuable rig time,

c) Rig pump pressure gages at the driller's console are not highly accurate so actual release pressure cannot be determined,

d) Pressuring up with the HBR attached to a drilling joint or drill collar does not allow for proper air bleeding so that trapped air at high pressure can present a pneumatic hazard. 
Deck testing in the mudroom or other convenient assembly location is an alternative to rig floor testing. Generally a sprague pump or similar high pressure low volume, positive displacement pump must be used to apply pressure for release. This allows for accurate monitoring of pressure and observation of the release action but often minor seal leakage cannot be overcome with the very limited flow rates available. Also, grease extrusion from critical locations occurs when a full release is accomplished.

To eliminate the grease extrusion problem when deck testing a two-part deck test in the mudroom can be done. The HBR is assembled lightly lubricated, but not grease-packed, in an arrangement as shown in Fig 12. A normal test release is then done by applying pressure to the pressure cap. This demonstrates that all mechanical elements are correctly fabricated and assembled. The mechanism is then disassembled far enough to hand pack grease into the Latch segment and Release sleeve cavities before being reassembled. Forward and reverse pressures are then applied with vents closed (as described below) to check that no seals have been dislodged or damaged by the test or disassembly procedures.

The selection of the type of deck test to be done depends on how much of the HBR being used is new hardware, whether or not rig time is readily available and what level of confiedence operations and rig personnel have in seals and assembly procedures.

The following is a detailed description of the mudroom type deck test.

a) Set up the test apparatus as shown in Fig. 12. A standard Go-devil is firmly seated in place. The bottom pressure line goes to the $1 / 4$ NPT threaded outlet port in the bottom of the Go-devil.

b) The volume above the Go-devil is filled slowly with water while air is vented off through the upper vent valve.

c) Close both upper and lower vent valves and apply hydraulic pressure through the upper line to 1000 psi. No flow should occur. This checks the integrity of the hydraulic system and internal HBR seals.

d) Vent the pressure from the upper line first then close the upper vent valve and open the lower vent valve.

e) Release the Disconnect by applying pressure through the upper line. Release actuation should occur at 500-600 psi. Do not allow the Disconnect 
to separate from the Top Connector more than three inches to avoid dislodging upper most 0-ring \#2347 (** Fig. 12) in Sleeve Retainer when resetting.

f) Reset is done by first manually closing the Disconnect back onto the Top Connector. Shuttle the Release Sleeve back to its lower position by applying hydraulic pressure to the tapped outlet port in bottom of Go-devil while the vent on the upper line is open. After reset is completed, the assenmbly should hold pressure. Steady flow indicates a damaged or dislodged 0-ring.

After partial disassembly to apply grease packs to the Latch segment cavities, perform forward and reverse leakage tests as follows to verify integrity of all critical seals.

g) Forward Leakage Test

Repeat steps a), b), and c) above. No flow should be observed. Be sure to release pressure by opening upper vent valve first.

h) Reverse Leakage Test

Apply hydraulic pressure not exceeding 500 psi to lower line. No flow should be observed. Doing this step last assures that the Release sleeve is shifted completely to the lower, or locked, position when the HBR is deployed.

\section{Downhole Release Instructions - HBR}

No special criteria exists for drilling or coring operations when the HBR is in the bottomhole assembly. When release is desired, the hole shold be conditioned as appropriate for the logging or downhole operation to be carried out.

The Go-devil is then pumped to the bit and a rise in pressure at the rig floor with flow dropping to zero indicates that the Go-devil has properly seated. In the ideal case pressure is slowly increased until a sudden release of pressure from some point $600 \mathrm{psi}$ or greater indicates that the Bit has been disconnected. If the pressure exceedes 1500$2000 \mathrm{psi}$ and holds without evidence of release, successful actuation can sometimes be achieved by alternate cycles of tagging bottom, releasing pressure, rotating the drill string and repressuring. When various combinations of these have been attempted without apparent success, the Go-devil should be retrieved and inspected. If no evident problem can be identified, a second Go-devil should be pumped down and the release sequence repeated. 


\section{Compatibility with Coring Systems}

The continued development of a variety of DSDP coring systems ultimately led to cases where compatibility between certain coring systems and either the HBR or MBR became limited. The following chart defines those limits:

\begin{tabular}{|c|c|}
\hline CORING SYSTEM IN USE & BIT RELEASE COMPATIBILITY \\
\hline Standard Rotary Core & $\begin{array}{l}\text { Both MBR and HBR compatible without } \\
\text { modifications }\end{array}$ \\
\hline $\begin{array}{l}\text { Variable Length } \\
\text { Hydraulic Piston Corer }\end{array}$ & $\begin{array}{l}\text { Mechanical Bit Release } \\
\text { Compatible only if Collet Seal sleeve } \\
\text { (OL-1006) is deployed after bit re- } \\
\text { leased (this technique now considered } \\
\text { obsolete), or Rotary Shifting Tool } \\
\text { modified to pass through } 3.800 \text { inch } \\
\text { diameter Seal/Latch Sleeve (OL-1014). } \\
\text { Hydraulic Bit Release } \\
\text { Compatible only if using Collet Seal } \\
\text { Sleeve (OL-1006). (Obsolete) }\end{array}$ \\
\hline Pressure Core Barrel & $\begin{array}{l}\text { Both MBR and HBR compatible without } \\
\text { modifications. }\end{array}$ \\
\hline $\begin{array}{l}\text { Advanced Hydraulic } \\
\text { Piston Corer }\end{array}$ & $\begin{array}{l}\text { Mechanical Bit Release } \\
\text { Compatible only if Rotary Shifting } \\
\text { Tool is modified to pass through } \\
3.800 " \text { diameter Seal Bore Drill Collar } \\
\text { (OL-1044) and spaced to land on Landing/ } \\
\text { Saver Sub (OG-0621). Not able to lower } \\
\text { Shifting Tool for release verification. } \\
\text { Hydraulic Bit Release } \\
\text { Not compatible unless special } 3.800 \text { inch } \\
\text { diameter Liner and matching Go-devil } \\
\text { used. (Obsolete) No support bearing } \\
\text { available to land Go-devil when APC used } \\
\text { in combination with XCB. }\end{array}$ \\
\hline $\begin{array}{l}\text { Extended Core Barrel } \\
\text { (XCB) } \\
\text { when used in combination } \\
\text { with VLHPC. }\end{array}$ & $\begin{array}{l}\text { VLHPC restrictions apply. Collet seal } \\
\text { Sleeve not compatible. }\end{array}$ \\
\hline $\begin{array}{l}\text { Extended Core Barrel } \\
\text { (XCB) } \\
\text { when used in combination } \\
\text { with APC. }\end{array}$ & APC restrictions apply. \\
\hline
\end{tabular}


D. Through-the-Bit Deployment of Logging Tools

The advent of the combination Advanced Piston Corer (APC)Extended Core Barrel (XCB) coring system has led to an operational technique whereby logging can be achieved without the necessity of dropping the core bit. The minimum inside diameter in the BHA for the XCB system, including the throat of the bit, is 3.800 to 3.840 inches, thus a suite of logging tools with a maximum diameter not exceeding $3-3 / 4$ inches can be deployed through the BHA and out the end of the pipe into open hole without releasing the bit. Use of this techbnique is not universal since it requires deleting the Baker Float Valve from the BHA. In certain upper sediments there is no particular disadvantage to operating without the Float Valve but in over-pressured formations or where chert, basalt rubble, large cuttings or significant quantities of sand may be encountered the Float Valve becomes more important.

Through-the-bit logging or instrument runs offer several significant advantages over the more conventional technique involving a bit release. First, there is no bit release mechanism in the BHA thus no possibility of either a premature release or failure to release on command. Secondly, no rig time is wasted on release operations which can often be lengthy. Third, the bit remains on the string for further coring which opens the door to a whole new approach to intermediate (rather than end-of-hole) logging. The hole is not junked by the released components. The bit is also available for wiper runs, breaking through bridges or drilling out fill prior to or during the logging operation. Also, if, following logging, a repeat hole is desired for spot coring hiatuses or heavily sampled intervals the operation can begin immediately without a pipe trip for a new bit.

Through-the-bit logging was successfully accomplished on Legs 95 \& 96 with complete success. The Schlumberger logging tools used were all checked to assure that they could pass through a 3-3/4" ring gage and the only minor modifications required were to the bow spring centralizers on the Caliper Tool. 
IV. OPERATIONAL SYNOPSIS

The Mechanical Bit Release (MBR) was first used in June 1976 on Leg 48 and deployed as needed through the remainder of the Project until Leg 96. The Hydraulic Bit Release (HBR) was introduced to the CHALLENGER during Leg 63 in october 1978. It was used, redesigned and deployed again over the remainder of the Project until its final deployment in its Mod. IV version on Leg 89 in November 1982.

A detailed account of all operational deployments of both types of bit release is included later in this section. Deployments in which a bit release was included in the BHA but no release was attempted do not appear in the listing.

The following table capsulizes the results of all bit release experience in the history of DSDP.

\section{TABLE I}

DSDP BIT RELEASE DEPLOYMENT SUMMARY

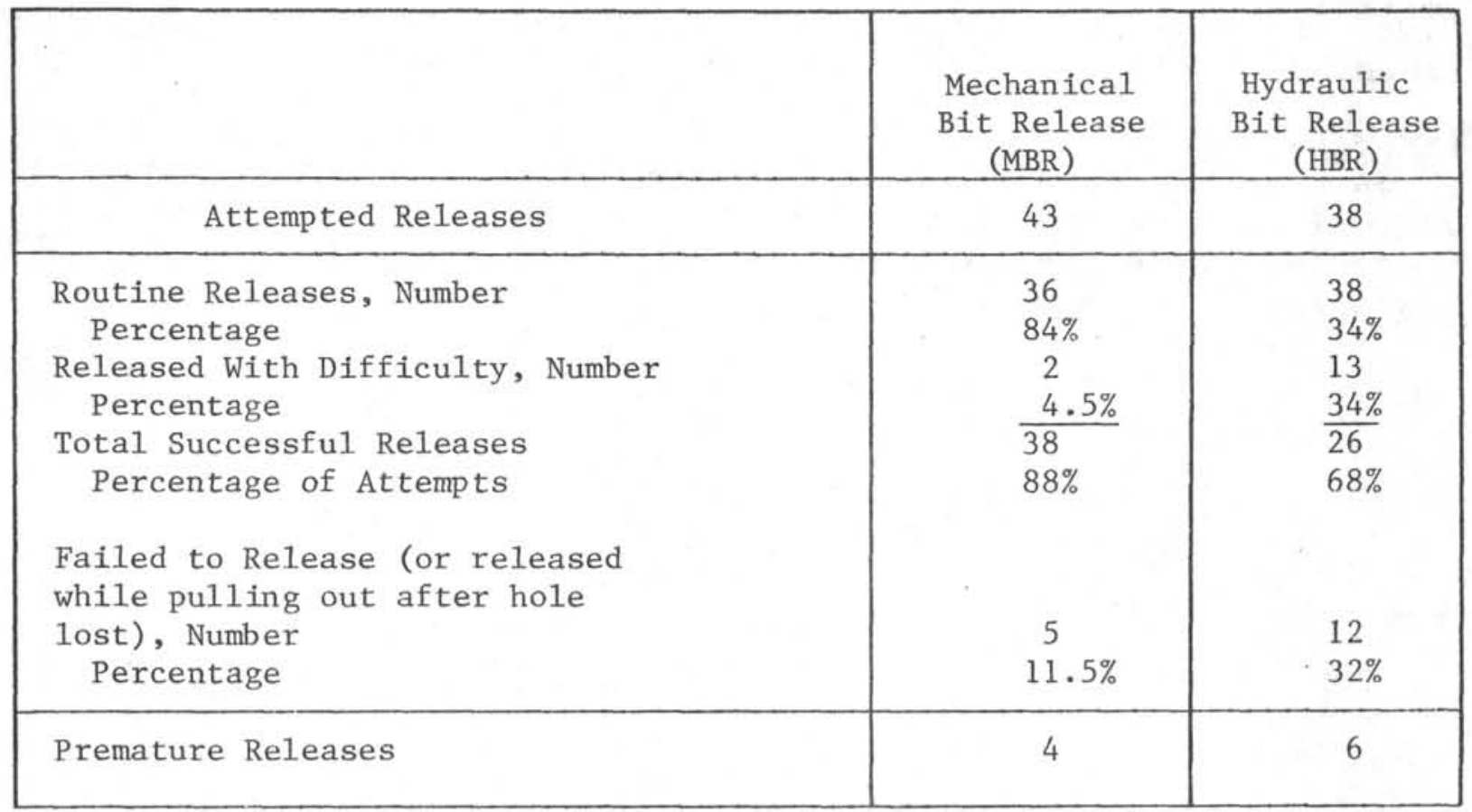


A first glance at the table would apparently indicate that the MBR is distinctly more reliable than the HBR. Both have been deployed enough times to have been given a fair test. The MBR has enjoyed a superior track record in total percentage of successful releases, percentage of trouble-free releases and a lower fraction of unsuccessful releases. Premature releases must be rated as a percentage of occurrences vs the number of times the device was included in any BHA. The number of instances of premature releases is documented but the actual number of times each bit release was deployed down hole is not known. It is reasonable to guess that the MBR and HBR have both been deployed about the same number of times. Thus, the HBR appears to have displayed about a $50 \%$ greater tendency toward premature release than the MBR. These statistics do not reveal the whole story, of course, and should not be taken out of context.

The MBR may well have exhibited a great many more premature releases had not its troublesome tendencies been recognized and accounted for. After the four instances of premature release occurred in the first six legs on which the MBR was used the tool was never again deployed in the kind of rubble or sand prone formations which were thought to pose the greatest danger. In many such cases, following Leg 63, the HBR was used instead without premature releases.

On the other hand, two of the six recorded cases of premature release by the HBR were caused by a design and fabrication oversight in the first deployment of the Mod. IV version. The cause was found and easily corrected. The HBR must, therefore, still be considered significantly less susceptible to premature release than the MBR. Premature release is the most serious failure mode for any bit release since it results in a lost hole and lost time spent in repeat drilling. Failure to release is less damaging since only logging is lost and a re-entry hole would not be lost at all.

The HBR has an additional advantage over the MBR from an operational standpoint. After the bit is released, the terminating component on the BHA is the Top Connector. When the MBR is actuated the Top Connector is left with four large holes on the sides formerly occupied by the Latch Segments. These holes allow circulation to escape out the sides causing minor washouts and making the MBR susceptible to being plugged off by mud and clay. When the lower end of the Top Connector becomes plugged, the logging tools often cannot be made to exit the pipe and the plug cannot be cleared by pumping. Logging plans have been curtailed on numerous occasions over DSDP history because of plugged MBR Top Connectors.

The problem is much less pronounced when using the HBR because the Latch segment windows are not left open after the bit is released. When mud or clay plugs occur with the HBR, cleaning out by vigorous circulation normally is successful. 
DEEP SEA DRILLING PROJECT

BIT RELEASE OPERATIONAL HISTORY

\begin{tabular}{|c|c|c|c|c|}
\hline DATE & LEG & HOLE & TYPE & RESULTS \\
\hline $6 / 76$ & 48 & 401 & MBR & Routine release. \\
\hline $6 / 76$ & 48 & 402 & MBR & Routine release. \\
\hline $6 / 76$ & 48 & 403 & MBR & Routine release. \\
\hline $7 / 76$ & 48 & 405 & MBR & Routine release. \\
\hline $7 / 76$ & 48 & 406 & MBR & Premature release. Logging completed anyway. \\
\hline $9 / 76$ & 50 & 415 & MBR & Routine release. \\
\hline $11 / 76$ & 50 & $416 \mathrm{~A}$ & MBR & $\begin{array}{l}\text { Release okay but Top Connector jammed with } \\
\text { cuttings \& rock. No logging. }\end{array}$ \\
\hline $11 / 76$ & 50 & $416 \mathrm{~A}$ & MBR & Twelth re-entry. Routine release. \\
\hline $12 / 76$ & $51 \mathrm{~A}$ & $417 \mathrm{~A}$ & MBR & $\begin{array}{l}\text { Unintentional release while pulling pipe after } \\
\text { thruster failure. }\end{array}$ \\
\hline $3 / 77$ & 52 & 417D & MBR & $\begin{array}{l}\text { Routine release in re-entry hole. Geophone } \\
\text { experiment run. }\end{array}$ \\
\hline $10 / 77$ & 57 & $438 \mathrm{~A}$ & MBR & Routine release. \\
\hline $10 / 77$ & 57 & 439 & MBR & Routine release. \\
\hline $11 / 77$ & 57 & $440 \mathrm{~B}$ & MBR & $\begin{array}{l}\text { Premature release probably while pulling on } \\
\text { wedged core barrel. }\end{array}$ \\
\hline $11 / 77$ & 57 & $441 \mathrm{~A}$ & MBR & $\begin{array}{l}\text { Release successful after knocking off with } \\
\text { weighted junk barrel. }\end{array}$ \\
\hline $3 / 78$ & 60 & 453 & MBR & Routine release. \\
\hline $4 / 78$ & 60 & $454 \mathrm{~A}$ & MBR & Routine release. \\
\hline $4 / 78$ & 60 & 456A & MBR & Routine release. Pipe later stuck \& severed. \\
\hline $5 / 78$ & 60 & $459 B$ & MBR & Routine release. \\
\hline $5 / 78$ & 60 & 460 & MBR & Spontaneous release. Cause unknown. \\
\hline $6 / 78$ & 61 & 462 & MBR & Routine release. \\
\hline $10 / 78$ & 63 & 467 & MBR & Routine release. \\
\hline $10 / 78$ & 63 & 468B & HBR & $\begin{array}{l}\text { Successful release after aborted attempt to } \\
\text { retrieve Go-devil. }\end{array}$ \\
\hline $10 / 78$ & 63 & 469 & HBR & $\begin{array}{l}\text { Failed to release. Caused by excessively tight } \\
\text { fit between Top Connector \& Disconnect. }\end{array}$ \\
\hline $11 / 78$ & 63 & $470 \mathrm{~A}$ & MBR & Routine release. \\
\hline $11 / 78$ & 63 & 471 & HBR & Routine release. \\
\hline $11 / 78$ & 63 & 473 & MBR & Routine release. \\
\hline $12 / 78$ & 64 & $474 \mathrm{~A}$ & HBR & $\begin{array}{l}\text { Successful release after multiple pressure-up } \\
\text { and tag bottom cycles. Second Go-devil. } \\
\text { never landed. }\end{array}$ \\
\hline $12 / 78$ & 64 & 476 & HBR & $\begin{array}{l}\text { Failed to release. Mechanism jammed with sand } \\
\text { and cuttings. }\end{array}$ \\
\hline $12 / 78$ & 64 & $477 \mathrm{~A}$ & MBR & Routine release. \\
\hline $12 / 78$ & 64 & 478 & MBR & Routine release. \\
\hline $12 / 78$ & 64 & 479 & MBR & Routine release. \\
\hline $1 / 79$ & 64 & $481 \mathrm{~A}$ & MBR & Routine release. \\
\hline
\end{tabular}


DEEP SEA DRILLING PROJECT

BIT RELEASE OPERATIONAL HISTORY

(Continued)

\begin{tabular}{|c|c|c|c|c|}
\hline DATE & LEG & HOLE & TYPE & RESULTS \\
\hline $1 / 79$ & 65 & $482 \mathrm{~B}$ & MBR & $\begin{array}{l}\text { Release attempted. Crossover between overshot } \\
\text { and sinker bars parted. Pipe stuck and } \\
\text { ultimately severed. }\end{array}$ \\
\hline $2 / 79$ & 65 & $482 \mathrm{C}$ & MBR & Routine release. \\
\hline $2 / 79$ & 65 & 483 & MBR & Routine release. \\
\hline $3 / 79$ & 65 & 485A & HBR & Successful release with second Go-devil. \\
\hline $4 / 79$ & 66 & $489 \mathrm{~A}$ & MBR & $\begin{array}{l}\text { Failure to release. Barrel with shifting tool } \\
\text { stuck. Sandline parted. }\end{array}$ \\
\hline $4 / 79$ & 66 & 490 & HBR & $\begin{array}{l}\text { Failed to release. Two Go-devils used. } \\
\text { Mechanism probably jammed with sand. }\end{array}$ \\
\hline $4 / 79$ & 66 & 491 & MBR & $\begin{array}{l}\text { Failed to release after three attempts. } \\
\text { Sandline parted. }\end{array}$ \\
\hline $4 / 79$ & 66 & 492 & HBR & $\begin{array}{l}\text { Failed to release. Mechanism probably jammed } \\
\text { with sand. }\end{array}$ \\
\hline $4 / 79$ & 66 & 493 & HBR & $\begin{array}{l}\text { Failed to release with two Go-devils. Probable } \\
\text { sand jam. }\end{array}$ \\
\hline $4 / 79$ & 66 & 492B & MBR & $\begin{array}{l}\text { Failed to release after three attempts. Probable } \\
\text { sand jam. }\end{array}$ \\
\hline $5 / 79$ & 67 & $494 \mathrm{~A}$ & HBR & Routine release. \\
\hline $5 / 79$ & 67 & 495 & HBR & Routine release. \\
\hline $6 / 79$ & 67 & 497 & HBR & Routine release. \\
\hline $6 / 79$ & 67 & 498A & MBR & $\begin{array}{l}\text { Failed to release on two attempts. Second attempt } \\
\text { hampered by line tar build-up. Sandline } \\
\text { eventually parted. }\end{array}$ \\
\hline $6 / 79$ & 67 & 499C & HBR & $\begin{array}{l}\text { Failed to release. Chevron seals stripped off } \\
\text { Go-devil. }\end{array}$ \\
\hline $6 / 79$ & 67 & 499D & MBR & Routine release. \\
\hline $7 / 79$ & 68 & 501 & $\mathrm{HBR}$ & $\begin{array}{l}\text { Successful release after tagging bottom and } \\
\text { repressuring. }\end{array}$ \\
\hline $10 / 79$ & 69 & $505 B$ & HBR & Routine release. \\
\hline $10 / 79$ & 69 & $504 \mathrm{~A}$ & $\mathrm{HBR}$ & Routine release on second pressure-up. \\
\hline $12 / 79$ & 70 & $504 \mathrm{~B}$ & HBR & $\begin{array}{l}\text { Release attempted out of re-entry hole. } \\
\text { Two Go-devils used. No apparent release. } \\
\text { Pipe pulled. Bit released during pipe trip. }\end{array}$ \\
\hline $12 / 79$ & 70 & $504 \mathrm{~B}$ & $\mathrm{HBR}$ & $\begin{array}{l}\text { Successful release out of re-entry hole after } \\
\text { two pressure-ups and vigorous rotation of the } \\
\text { pipe. }\end{array}$ \\
\hline $1 / 80$ & 71 & 511 & $\mathrm{HBR}$ & $\begin{array}{l}\text { Unintentional release during or after through- } \\
\text { the-pipe logging and heavy seas. }\end{array}$ \\
\hline $3 / 80$ & 72 & $516 \mathrm{D}$ & HBR & Premature release after $90 \mathrm{~m}$ coring. Cause unknown. \\
\hline $3 / 80$ & 72 & $516 \mathrm{~F}$ & HBR & $\begin{array}{l}\text { Successful release using old Go-devil after repeat } \\
\text { pressure-up and tagging bottom. New Drag Block } \\
\text { Go-devil failed when seals stripped off. }\end{array}$ \\
\hline $\begin{array}{l}4 / 80 \\
5 / 80\end{array}$ & 73 & $\begin{array}{l}520 \\
524 \mathrm{~A}\end{array}$ & $\begin{array}{l}\mathrm{HBR} \\
\mathrm{HBR}\end{array}$ & Routine release after tagging bottom. \\
\hline $5 / 80$ & 73 & $524 \mathrm{~A}$ & HBR & Routine release after tagging bottom. \\
\hline
\end{tabular}


DEEP SEA DRILLING PROJECT

BIT RELEASE OPERATIONAL HISTORY

$$
\text { (Continued) }
$$

\begin{tabular}{|c|c|c|c|c|}
\hline DATE & LEG & HOLE & TYPE & RESULTS \\
\hline $6 / 80$ & 74 & $525 \mathrm{~A}$ & HBR & $\begin{array}{l}\text { Failed to release. One Go-devil stripped off } \\
\text { down-looking seals, second stuck in bit. }\end{array}$ \\
\hline $7 / 80$ & 74 & 527 & HBR & $\begin{array}{l}\text { Successfu1 release after multiple pressure-up } \\
\text { and bottom tag cycles. }\end{array}$ \\
\hline $7 / 80$ & 74 & 528 & HBR & Routine release. \\
\hline $8 / 80$ & 75 & $530 \mathrm{~A}$ & HBR & $\begin{array}{l}\text { Successful release on third pressure-up and } \\
\text { bottom tag sequence. }\end{array}$ \\
\hline $10 / 80$ & 76 & $533 \mathrm{~A}$ & HBR & $\begin{array}{l}\text { Unintentional release beneath keel after Go-devil } \\
\text { stuck at bit. }\end{array}$ \\
\hline $1 / 81$ & 77 & 540 & HBR & $\begin{array}{l}\text { Failed to release. Sleeve shifted, Go-devil } \\
\text { jammed, Latch Segments packed with sand. }\end{array}$ \\
\hline $2 / 81$ & $78 \mathrm{~A}$ & 541 & HBR & Successful release after 20 minutes of working pipe. \\
\hline $3 / 81$ & $78 \mathrm{~A}$ & $543 \mathrm{~A}$ & MBR & Routine release. \\
\hline $3 / 81$ & $78 \mathrm{~B}$ & $385 \mathrm{~A}$ & MBR & Routine release. \\
\hline $6 / 81$ & 80 & $548 \mathrm{~A}$ & HBR & Successful release after some working of pipe. \\
\hline $6 / 81$ & 80 & 549 & HBR & $\begin{array}{l}\text { Successful release after working pipe then } \\
\text { attempted retrieval of Go-devil. }\end{array}$ \\
\hline $7 / 81$ & 80 & $550 \mathrm{~B}$ & HBR & $\begin{array}{l}\text { Successful release after two Go-devils failed, } \\
\text { additional core cut, then third Go-devil used. }\end{array}$ \\
\hline $8 / 81$ & 81 & $553 \mathrm{~A}$ & HBR & $\begin{array}{l}\text { Spontaneous release during or after instrumented } \\
\text { drill string (IDSS) run. }\end{array}$ \\
\hline $8 / 81$ & 81 & 555 & HBR & Premature release during pipe trip in. \\
\hline $9 / 81$ & 81 & 555 & MBR & Routine release. \\
\hline $9 / 81$ & 82 & 556 & HBR & Routine release after tagging bottom. \\
\hline $10 / 81$ & 82 & 558 & HBR & $\begin{array}{l}\text { Successful release after two Go-devils and } \\
\text { six hours consumed. }\end{array}$ \\
\hline $10 / 81$ & 82 & 563 & HBR & Spontaneous release while working stuck pipe. \\
\hline $10 / 81$ & 82 & 564 & HBR & Routine release after tagging bottom. \\
\hline $1 / 82$ & 84 & $566 \mathrm{C}$ & MBR & Routine release. \\
\hline $2 / 82$ & 84 & $567 \mathrm{~A}$ & MBR & Routine release. \\
\hline $2 / 82$ & 84 & 568 & MBR & Routine release. \\
\hline $2 / 82$ & 84 & 570 & MBR & Routine release. \\
\hline $6 / 82$ & 86 & 581 & HBR & Routine release (Mod. IV version). \\
\hline $6 / 82$ & 87 & 582 & HBR & $\begin{array}{l}\text { Spontaneous release while running in or spudding } \\
\text { (Mod. IV). }\end{array}$ \\
\hline $7 / 82$ & 87 & $582 \mathrm{~B}$ & HBR & Failed to release. Packed with sand (Mod. IV). \\
\hline $7 / 82$ & 87 & $583 \mathrm{~F}$ & HBR & Spontaneous release during coring (Mod. IV). \\
\hline $8 / 82$ & 87 & $584 \mathrm{~A}$ & MBR & Routine release. \\
\hline $9 / 82$ & 88 & $581 \mathrm{C}$ & MBR & Routine release. \\
\hline $11 / 82$ & 89 & $586 \mathrm{C}$ & HBR & (Mod. IV with Hold Down Spring) \\
\hline $3 / 83$ & 92 & $597 \mathrm{~B}$ & MBR & Routine release. \\
\hline $9 / 83$ & 95 & $603 \mathrm{~F}$ & MBR & Routine release. \\
\hline $10 / 83$ & 96 & 620 & MBR & Routine release. \\
\hline
\end{tabular}


ROTARY OIL TOOL COMPANY

DEEP SEA DRILLING BIT DISCONNECT

PARTS LIST

\begin{tabular}{|c|c|c|}
\hline ITEM & DESCRIPTION & QUANTITY \\
\hline 1 & Top Connector & 1 \\
\hline 2 & Button Head Cap Screw & 3 \\
\hline 3 & Latch Sleeve & 1 \\
\hline 4 & O-Ring & 2 \\
\hline 5 & C-Ring & 1 \\
\hline 6 & Grease Fitting & 2 \\
\hline 7 & Segments & 4 \\
\hline 8 & O-Ring & 1 \\
\hline 9 & Sleeve Retainer & 1 \\
\hline 10 & Torque Slipper & 2 \\
\hline 11 & $\begin{array}{l}\text { Bit Disconnect (complete with Item } 10 \\
\text { welded in place) }\end{array}$ & 1 \\
\hline 12 & Socket Head Cap Screw (1960 Series) & 4 \\
\hline 13 & Internal Tooth Lock Washer & 4 \\
\hline 14 & Compression Spring (stainless steel) & 4 \\
\hline 15 & Cam Latch & 4 \\
\hline 16 & Pin-Camlatch & 4 \\
\hline 17 & Spear & 1 \\
\hline
\end{tabular}

FIG. 1A

PARTS LIST FOR PROTOTYPE MBR 


\section{DEEP SEA DRILLING BIT DISCONNECT \\ SIZE $8 \frac{1}{4}$}

SPECIAL $3 \frac{1 / 4-5}{\text { TPI }}$

STUB ACME $3 / .8$ TPI

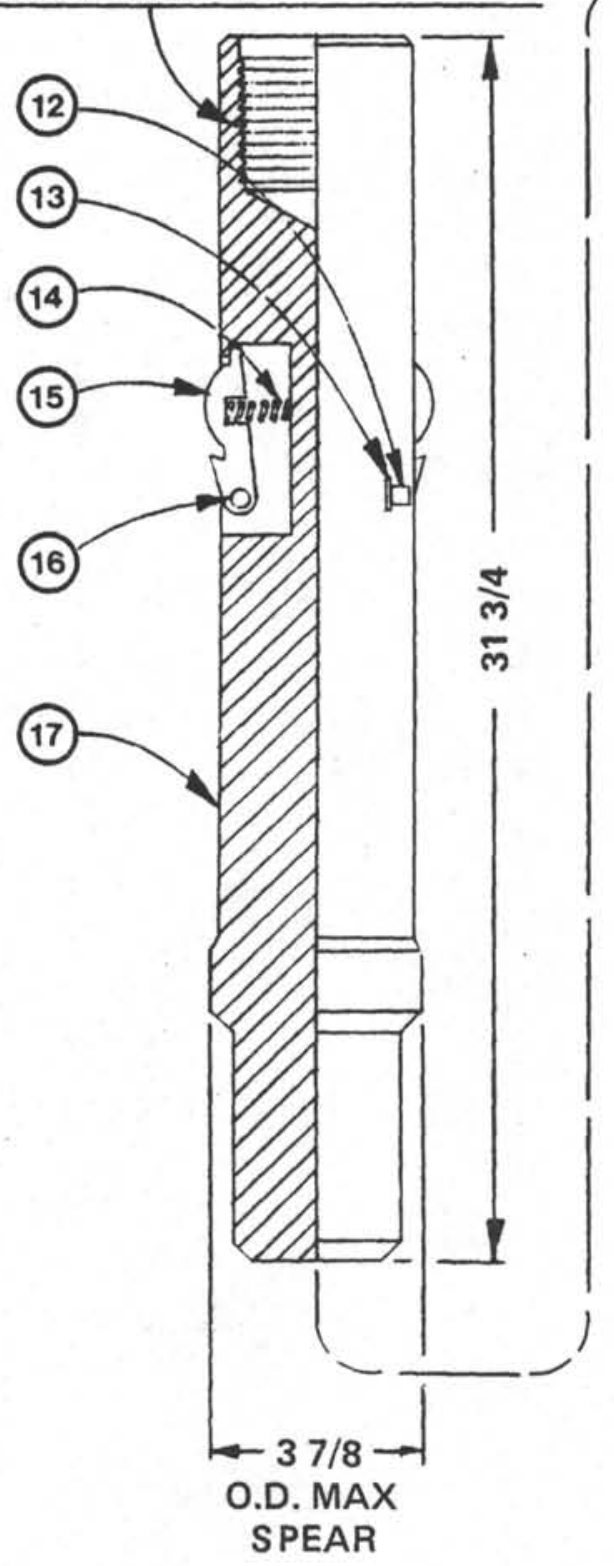

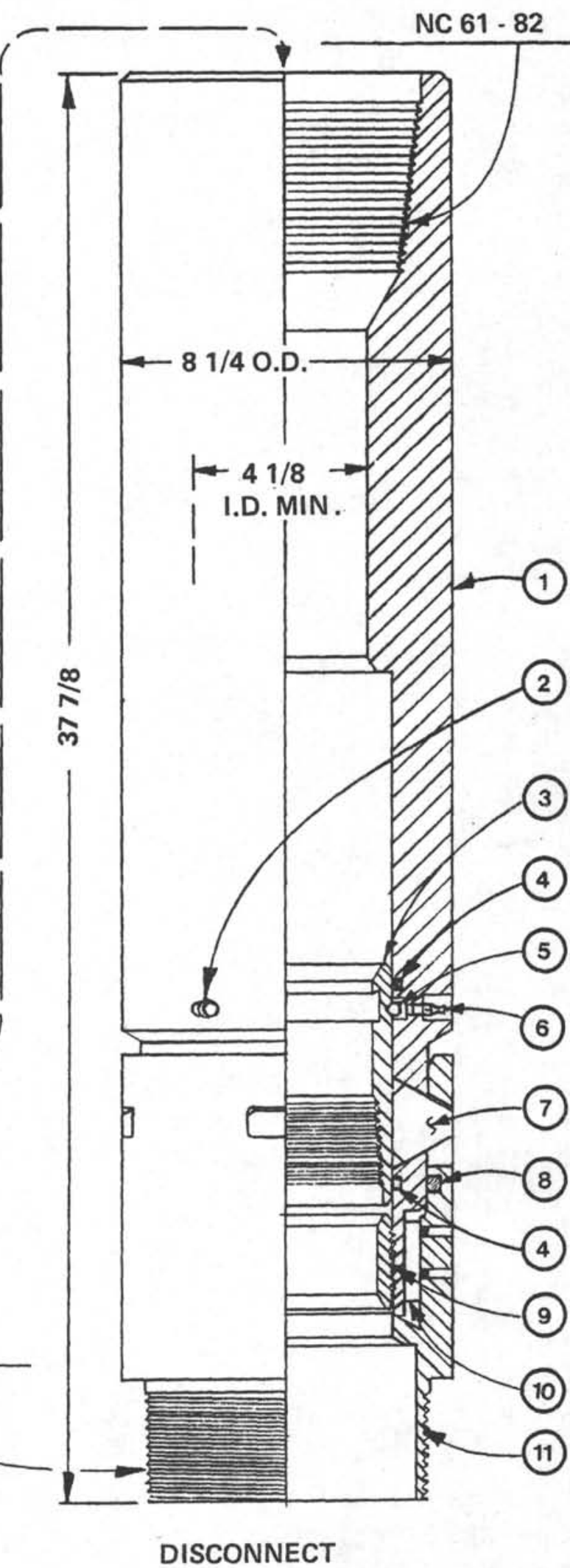

FIG. 1 


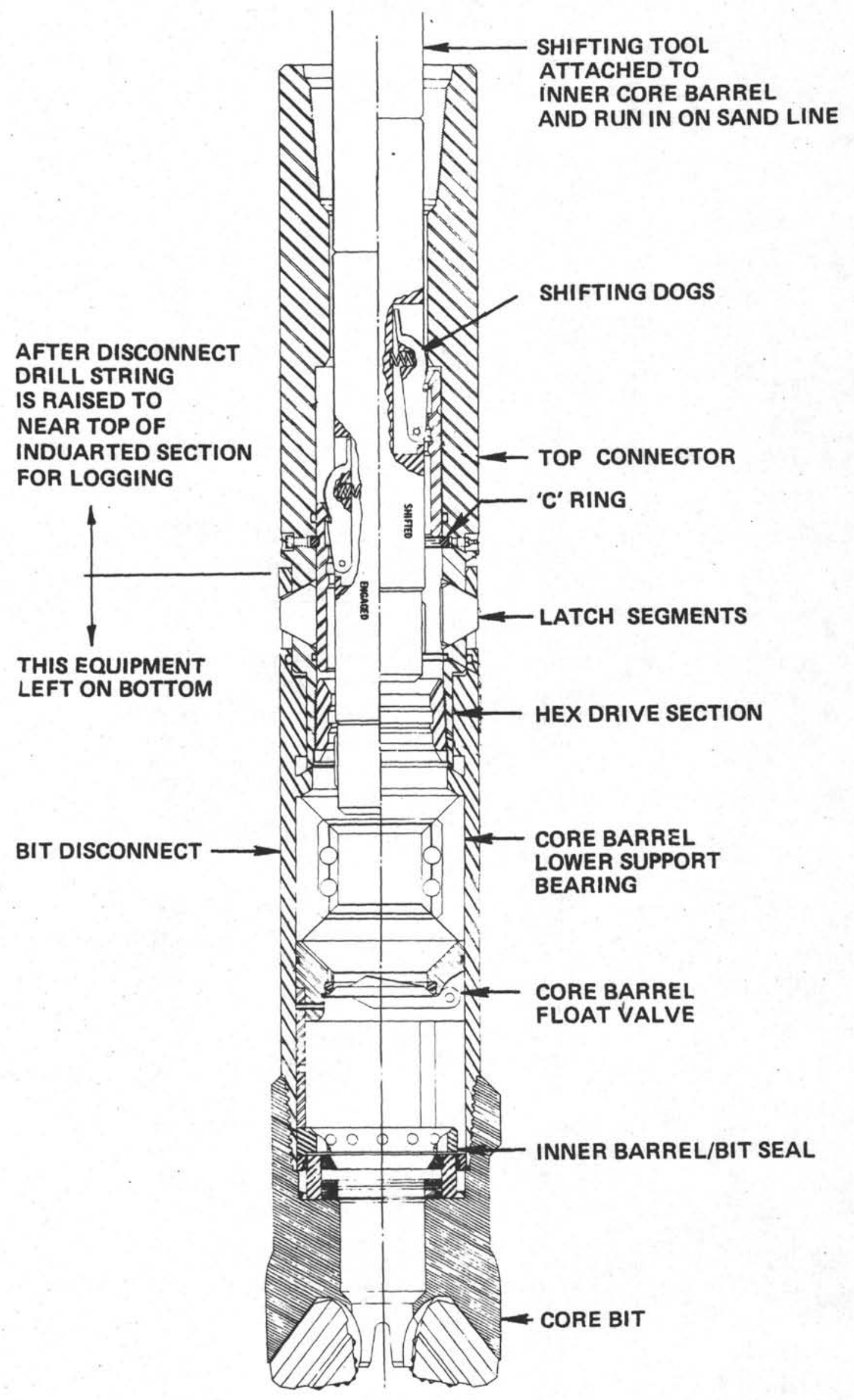

FIG. 2

IMPROVED MBR. INTRODUCED IN 1976 FOR USE ON LEG 50. 


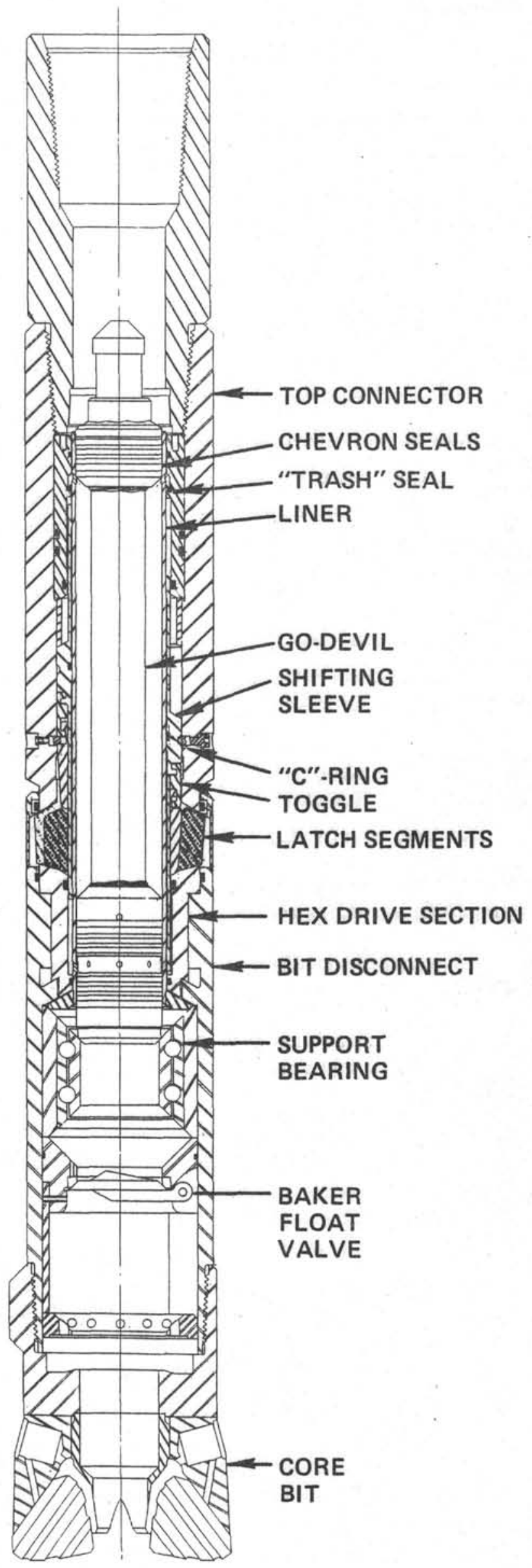

FIG. 3

HYDRAULIC BIT RELEASE (HBBR) AS USED FROM LEG 63 TO LEG 82. $-34-$ 


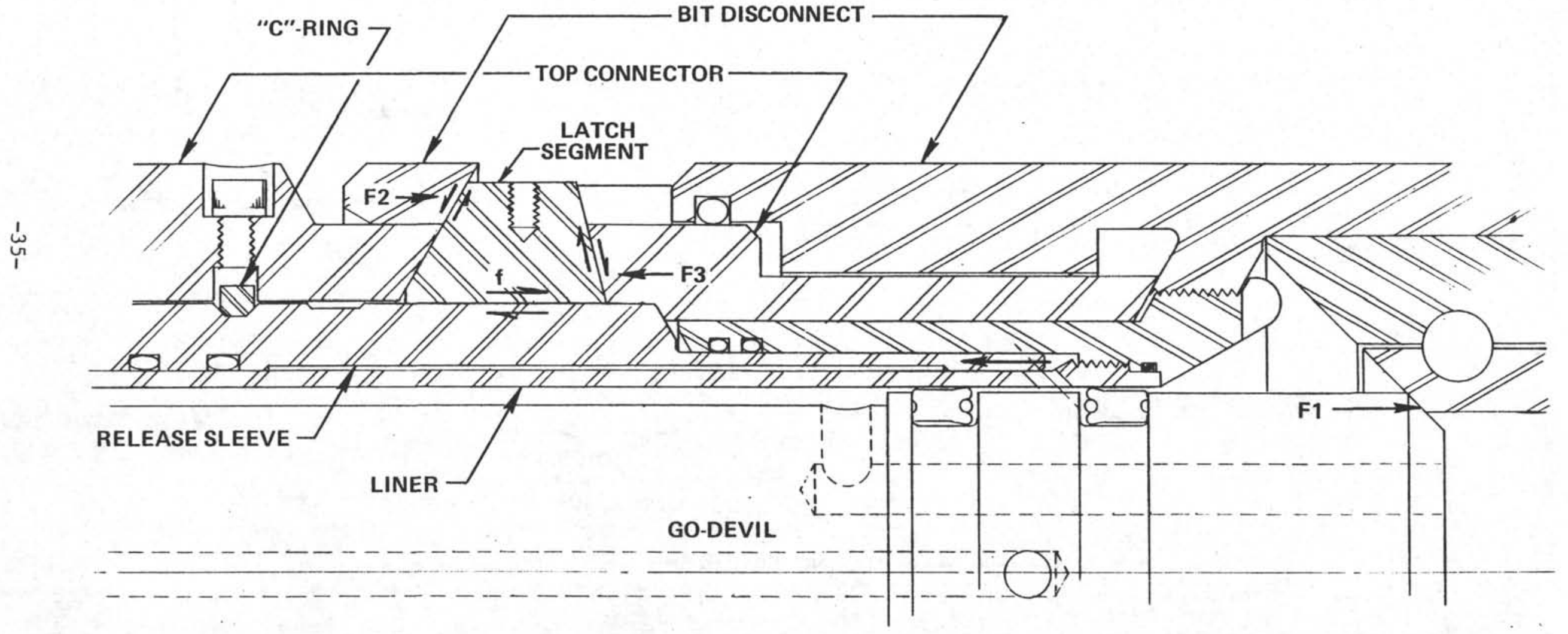

FIG. 4

EARLY MODEL HBR WITH ASYMMETRICAL LATCH SEGMENTS SHOWING ACTUATION FORCES AND FRICTION SURFACES. 


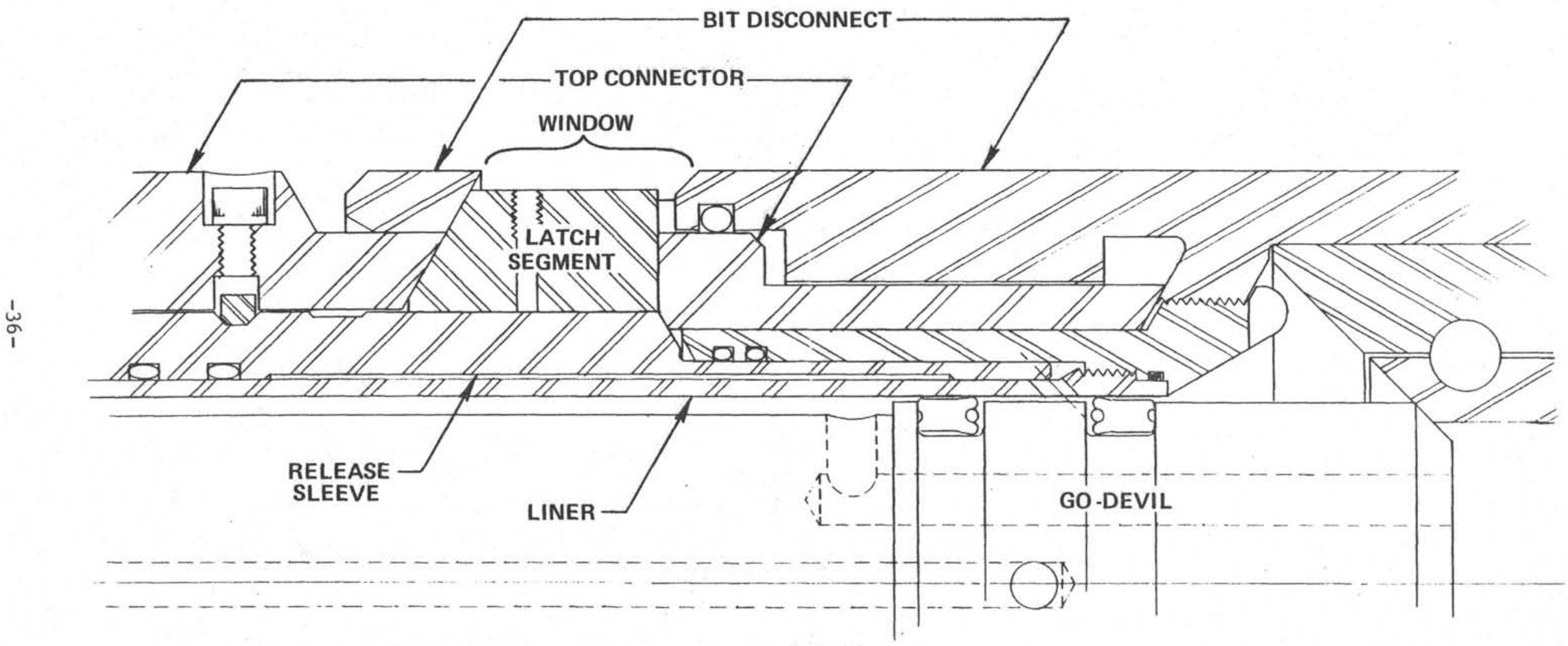

FIG. 5

HBR WORKING PARTS SHOWING ONE OF SEVERAL EARLY MODIFIED VERSIONS OF LATCH SEGMENTS. 


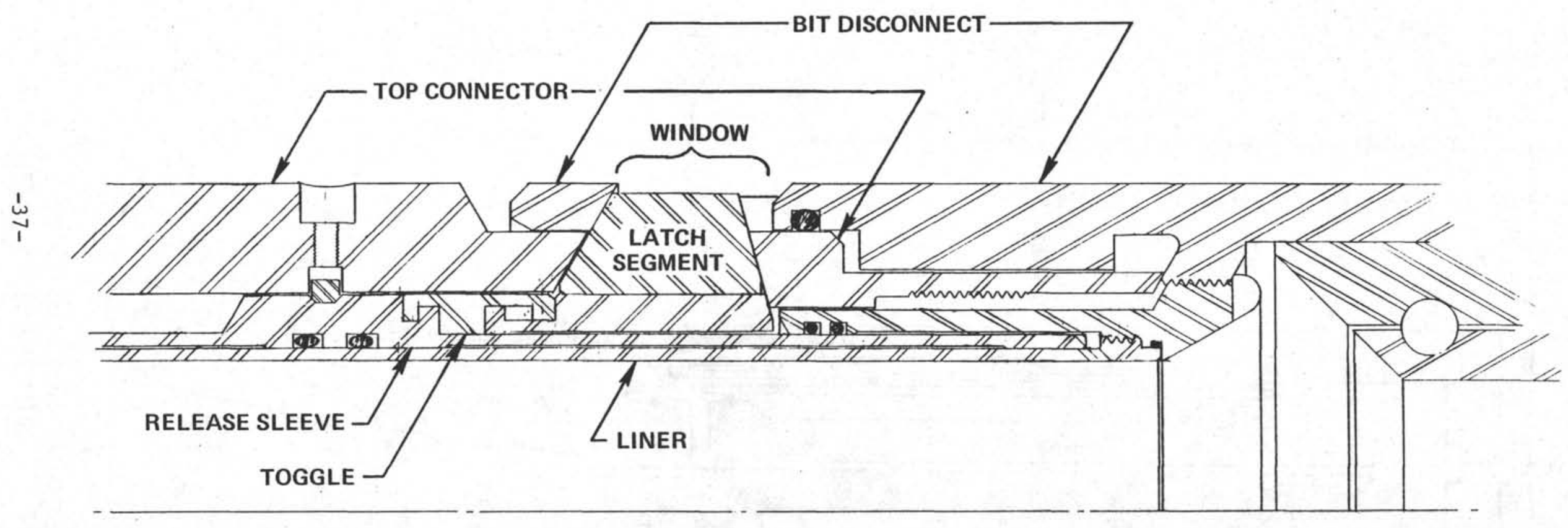

FIG. 6

HBR WORKING PARTS SHOWING LATER MODIFICATIONS INCLUDING MODIFIED LATCH SEGMENTS AND “TOGGLED” RELEASE SLEEVE. 


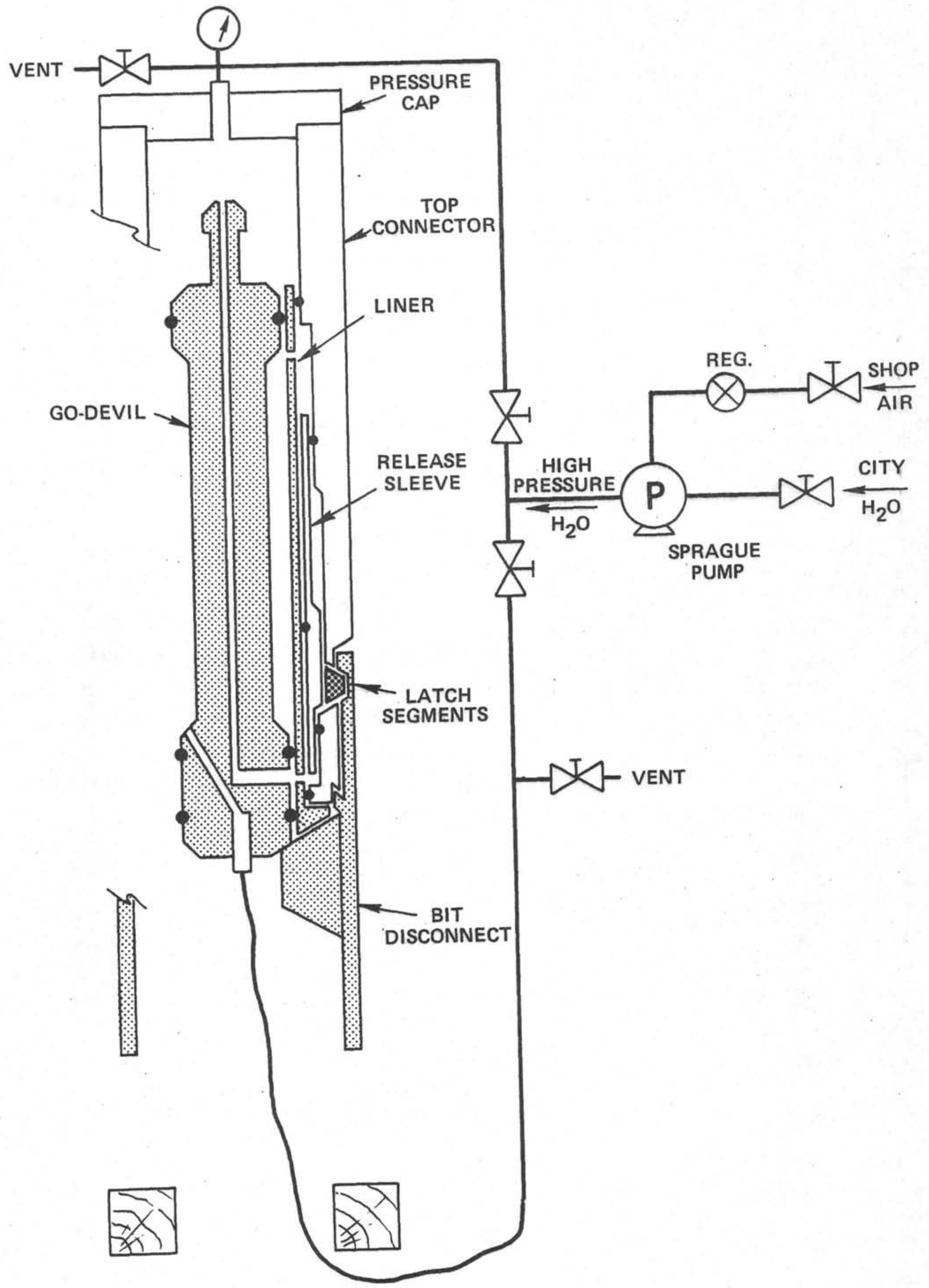

FIG. 7

SHOP SET-UP FOR TESTING HBR. 


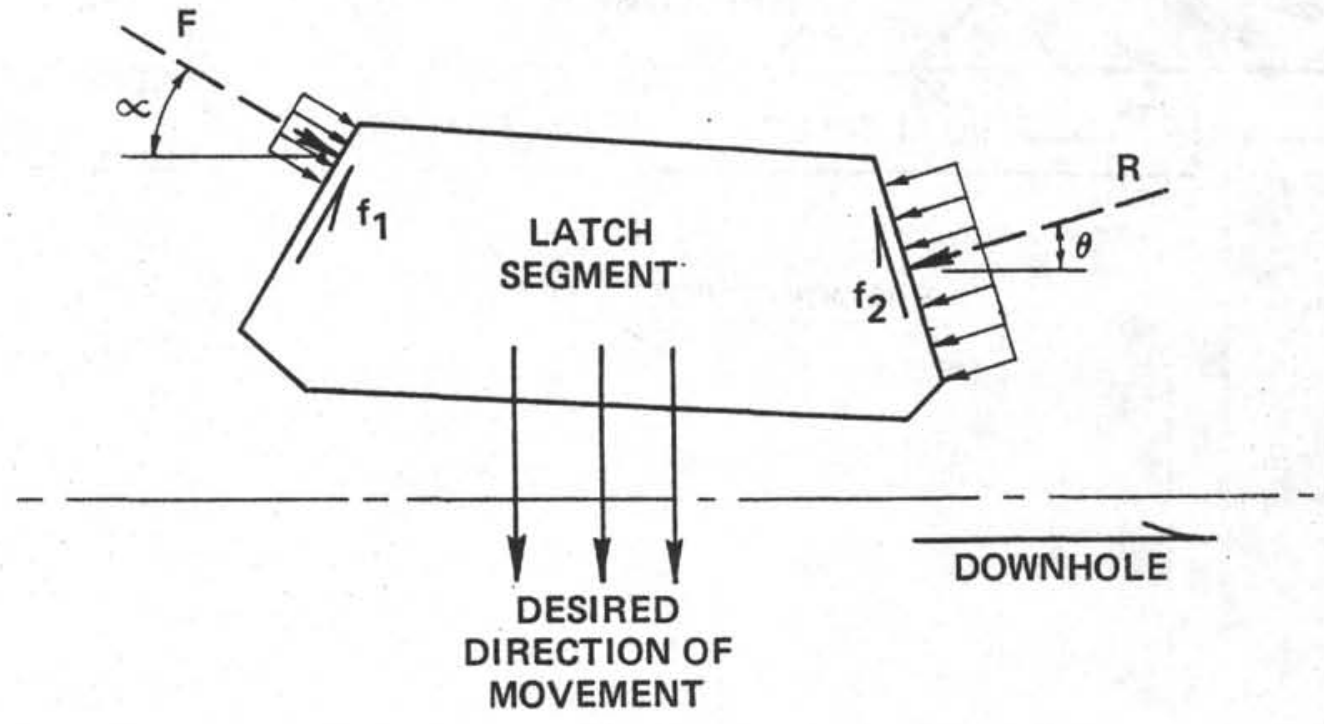

$$
\begin{aligned}
& f_{1}=\mu_{1} F \\
& f_{2}=\mu_{2} R
\end{aligned}
$$

FIG. 8

HBR LATCH SEGMENT FREE-BODY DIAGRAM. 


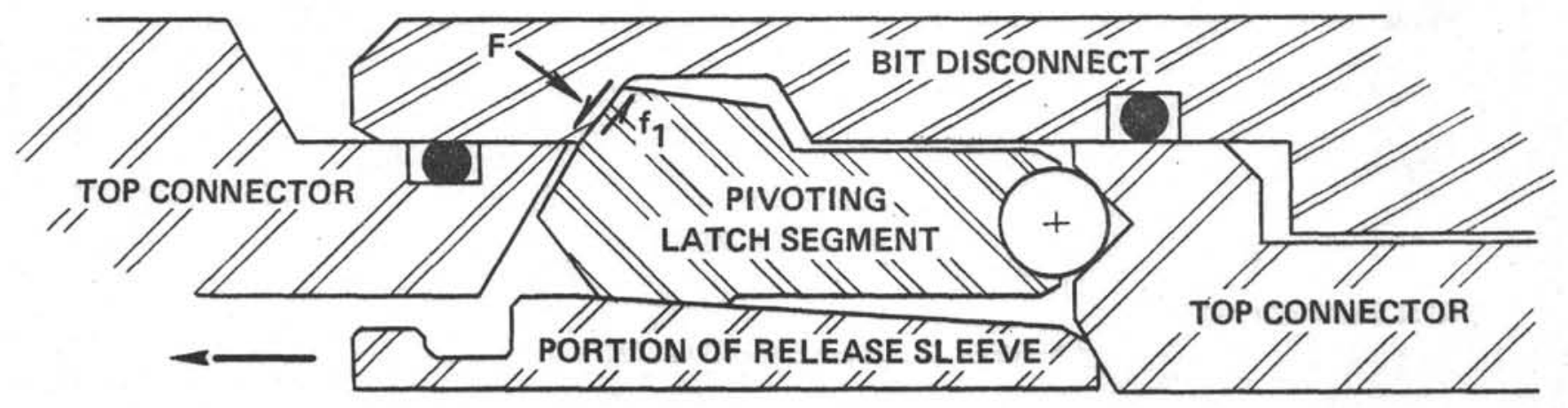

\section{LOCKED POSITION}

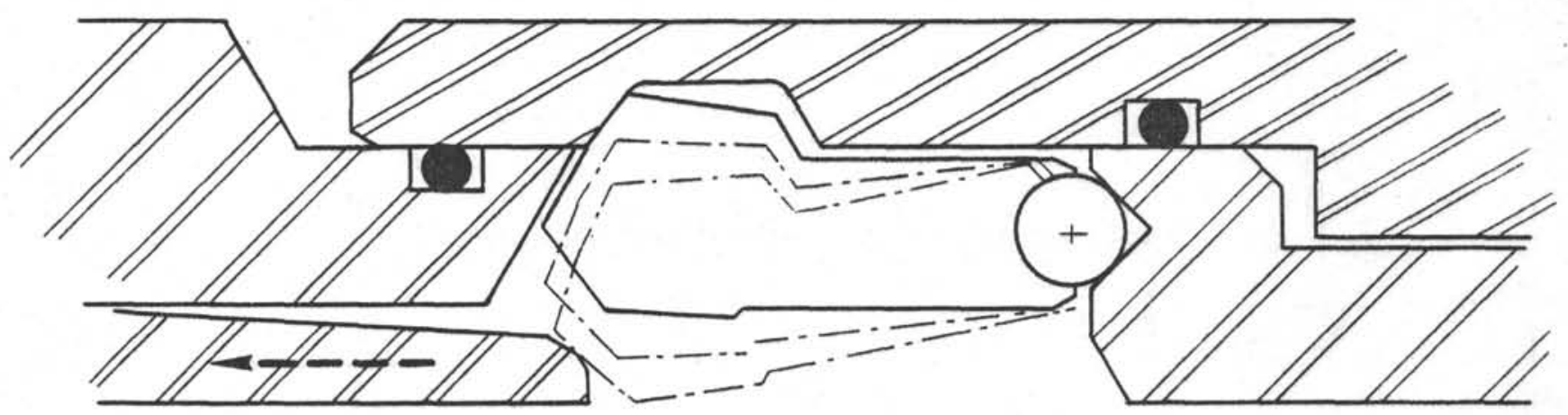

RELEASE ACTION

FIG. 9

PIVOTING LATCH SEGMENT TESTED ON HBR. NOT SUCCESSFUL. 

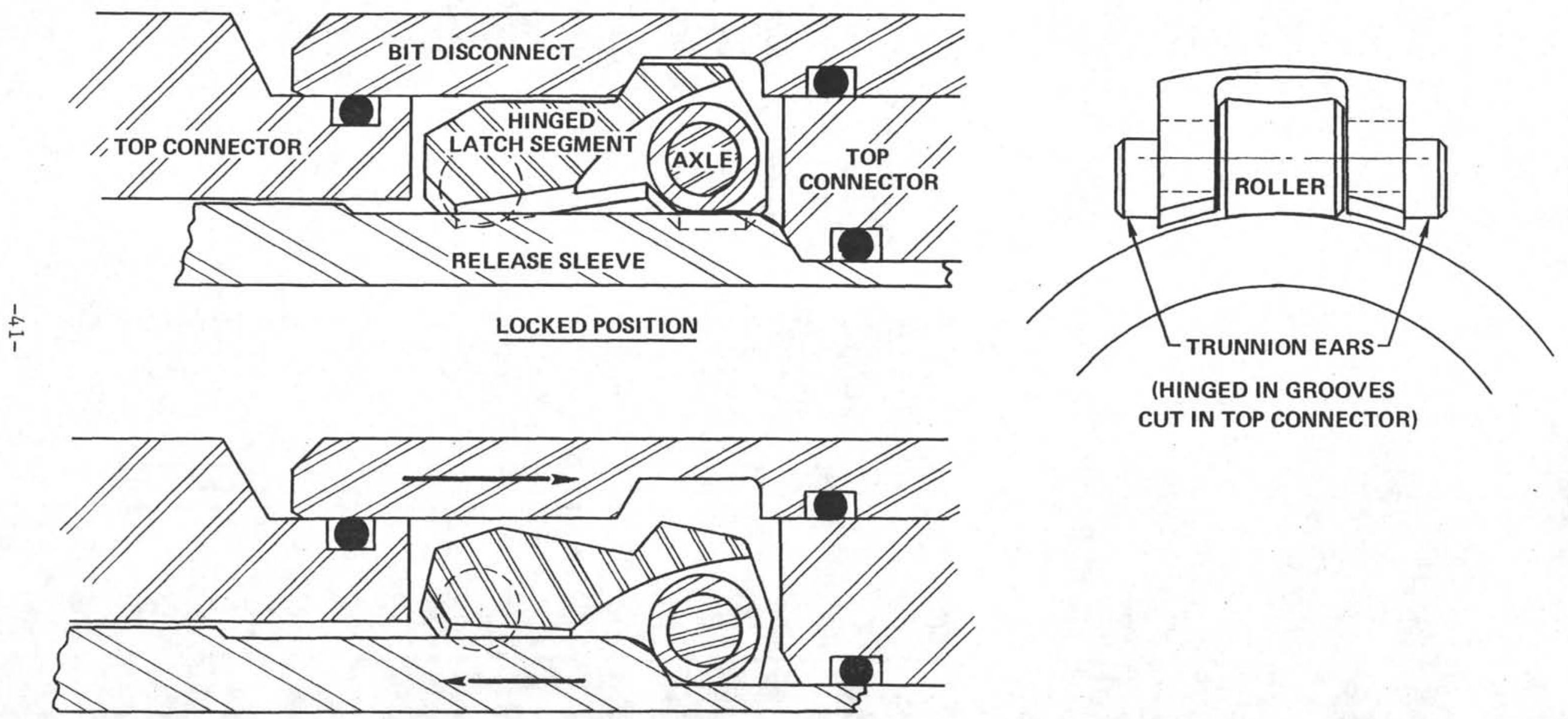

\section{RELEASED POSITION}

FIG. 10

TRUNNION-ROLLER LATCH SEGMENT INCORPORATED IN MOD. IV HBR. 


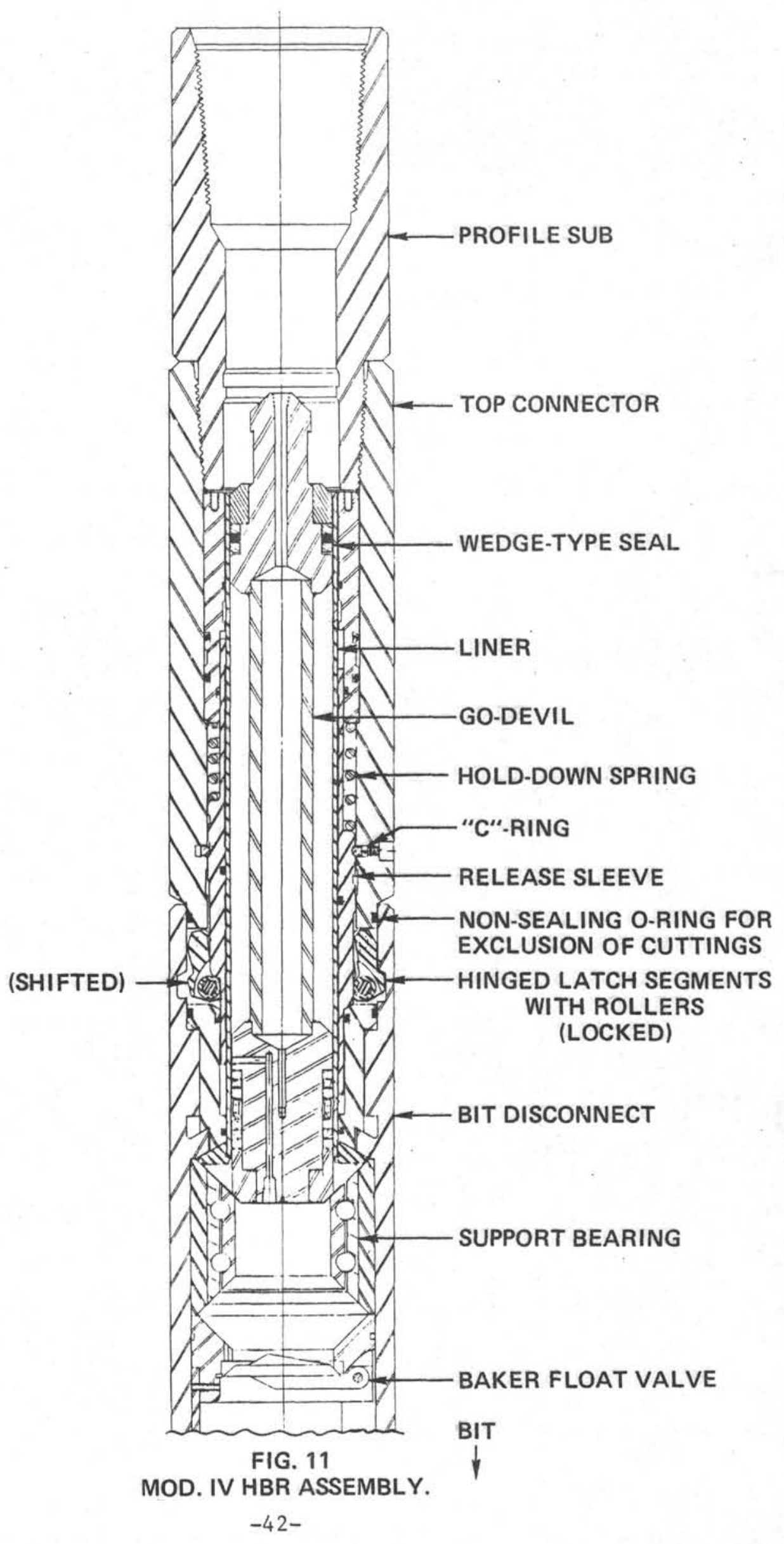




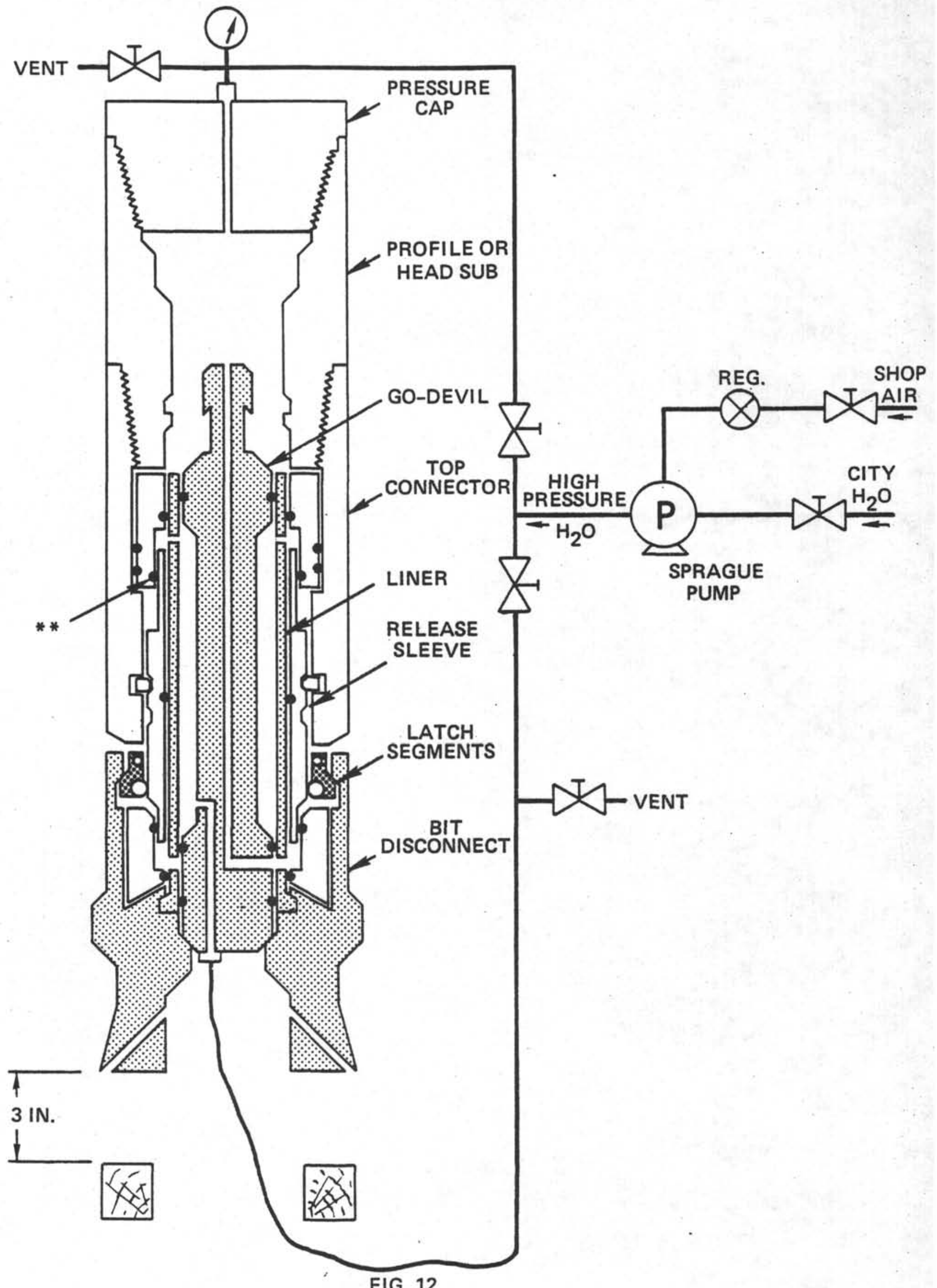

FIG. 12

DECK TEST SET-UP MOD. IV HBR. 
APPENDIX A

MECHANICAL BIT RELEASE/HYDRAULIC BIT RELEASE REPORT 


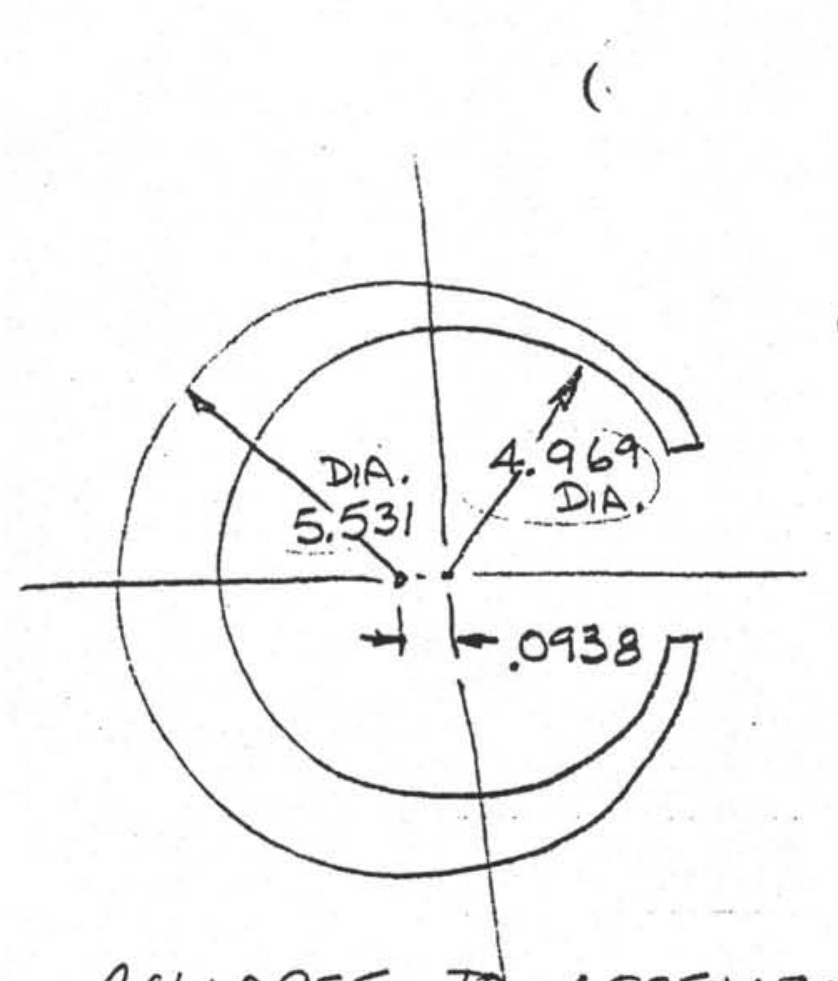

C-RING 303915

$$
\begin{aligned}
5.531 \div 2 & =2.7655 R \\
& +\frac{.0938}{2.8593} \\
4.969 \div 2 & =\frac{-2.4845 R}{375=h} \\
5.531 & C^{\prime} \text { RINT O.D. }
\end{aligned}
$$

Collapse to assemble

$$
\begin{array}{rlrl}
S & =\frac{f E K}{n}=\frac{(281)(30 \times 106)(007)}{.375} & .281=f \\
& =157,360 \mathrm{PSI} & K=.007
\end{array}
$$

Expand to operate 5.250 sLEEVE O.D. 4.969 'C' RING 1.D.
$.281=0$

$$
S=\frac{f E K}{h}=\frac{(281)\left(30 \times 10^{6}\right)(-007)}{.375}=157,360 P_{51}
$$


LAT' + SEOUIJT ANALYSK HYURAULIC EIT REIEISE
Nuv3, :77, ir.?. SHEET NO. 1

HYDRAULIE FOPCE DONN

ARE: $4,623 \overline{N N . D T A} \bar{A}=16.791 \mathrm{~N}^{2}$ (a) 1,500 FSI $F=25,178$ LES

SINCE LOAD IS DISTRIE. OVER 4 DOGS. FORCE FER DOG $-6,295$
$F_{1}=6,295$

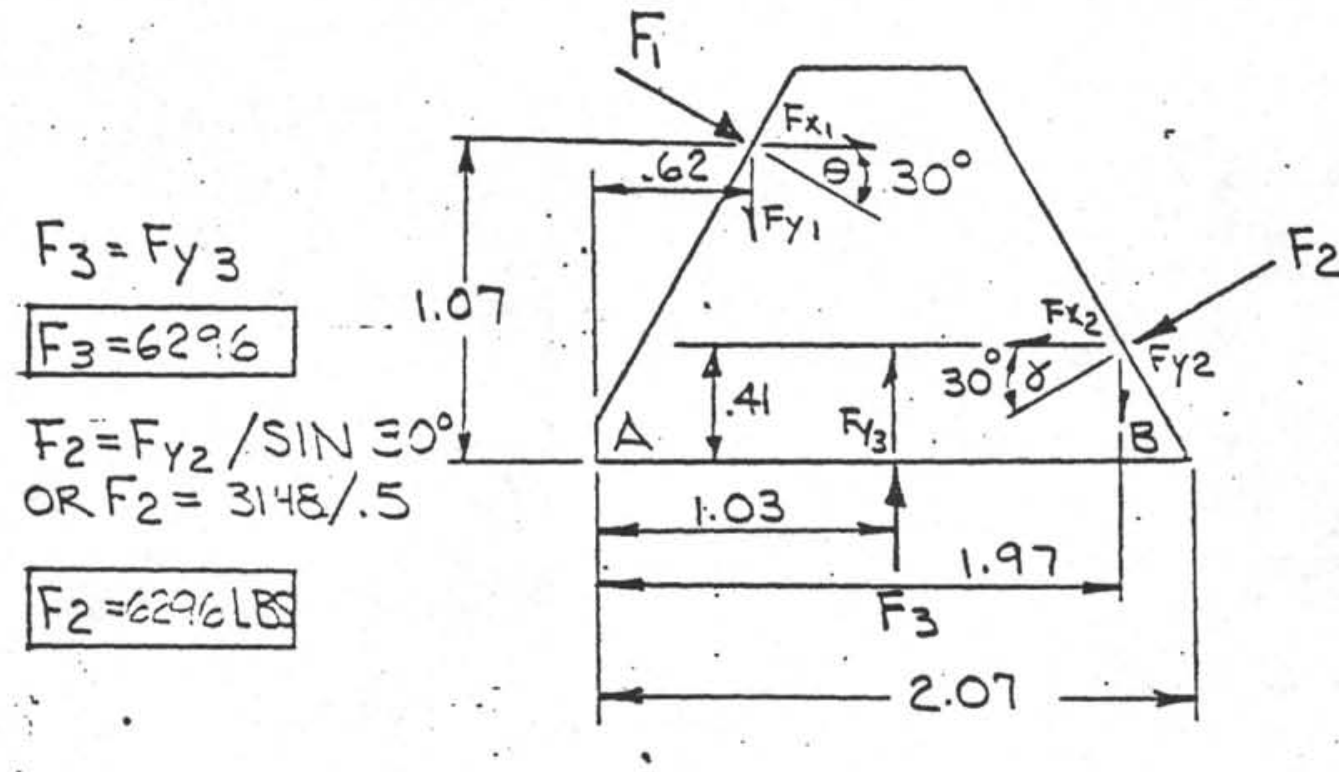

$\sum F_{x}=0$

$\therefore \sum F_{x}=F_{x_{1}}-F_{x_{2}}=0$ SINCE $\theta=30^{\circ}$

AND $F_{1}=6295$ LBS

THEN $F_{x_{1}}=F_{1} \cos 30^{\circ}$

OR $F x_{1}=6295 \operatorname{LSS}\left(.2 x_{0}\right)$

$$
F_{X_{1}}=5452 \text { LES }
$$

AND $F_{x_{e}}=5452 L B S$

$\sum F_{y}=0$
$\sum F_{y}=F_{y_{1}}+F_{y_{2}}-F_{y_{3}}$

SINCE $\gamma=30^{\circ}$

$A_{N_{D}} F_{X_{2}}=5452 \mathrm{LBS}$

THEN $F_{Y_{2}}=F_{x_{2}}$ TAN $30^{\circ}$ $0.2 \quad F_{Y_{2}}=5452(.5 .79)$

$F_{y_{2}}=3148$ L?:

$F_{y_{1}}=F_{1} \operatorname{SIN} 30^{\circ}$

$F_{Y_{1}}=(6295 !-23)(0.5)$

$F_{y_{1}}=3148$ L是

THEN $F_{y_{3}}=F_{1 / 2}+F_{y_{1}}$

or $F_{Y_{3}}=3: 43 L 3 S+3148$ LES

$F_{Y_{3}}=: \therefore=9 E L B S$ $\left(E M_{A}=F_{y_{1}}(\therefore=2)+F_{x_{1}}(1.07):\right.$
$F_{y_{2}}(1.97)-F_{y_{3}} 1,03 ;-$ $F_{x_{2}}(.41)=3267 \mathrm{IN}-\mathrm{L3S}$ DISTAN:E $A B=2.07 \mathrm{~N}$. SO RE:-T:ON@"B" $F_{B}=32: 12.07$

$1 F_{B}=25 \div \div \operatorname{LBS}$

$\left\langle\sum M_{3}=F_{x_{1}}(1.07)+\right.$ $F_{y}\left(3,(1.03)-F y_{1}\right.$
$(1.45)-F x_{2}(.41)$ $-F_{2}(0.1)^{2}=$ 5204 IN-LZS SOREACTION: इ" $A$ " $F_{A}=520 \div 12.07$

$\rightarrow F_{A}=2 B: \div \angle B S$ 
LAT CU SEGMENT ANALYSIS NOV E, 1977 MIA. HYURAULIC BIT RELEFI:- SHEET NOT

HYDRAULIC FOE CE DOL ,N

ARE: $\angle, 6 \overline{C E}$ IN. DIR $\bar{A}=16.791 \mathrm{~N}^{2}$ @ 1,500 PSI $F=25,178$ LBS

SINCE LOAD IS DI.STRIE. OVER 4 DOGS. FORCE FER DOG $=6,295$

$\because \quad F_{1}=6,295$

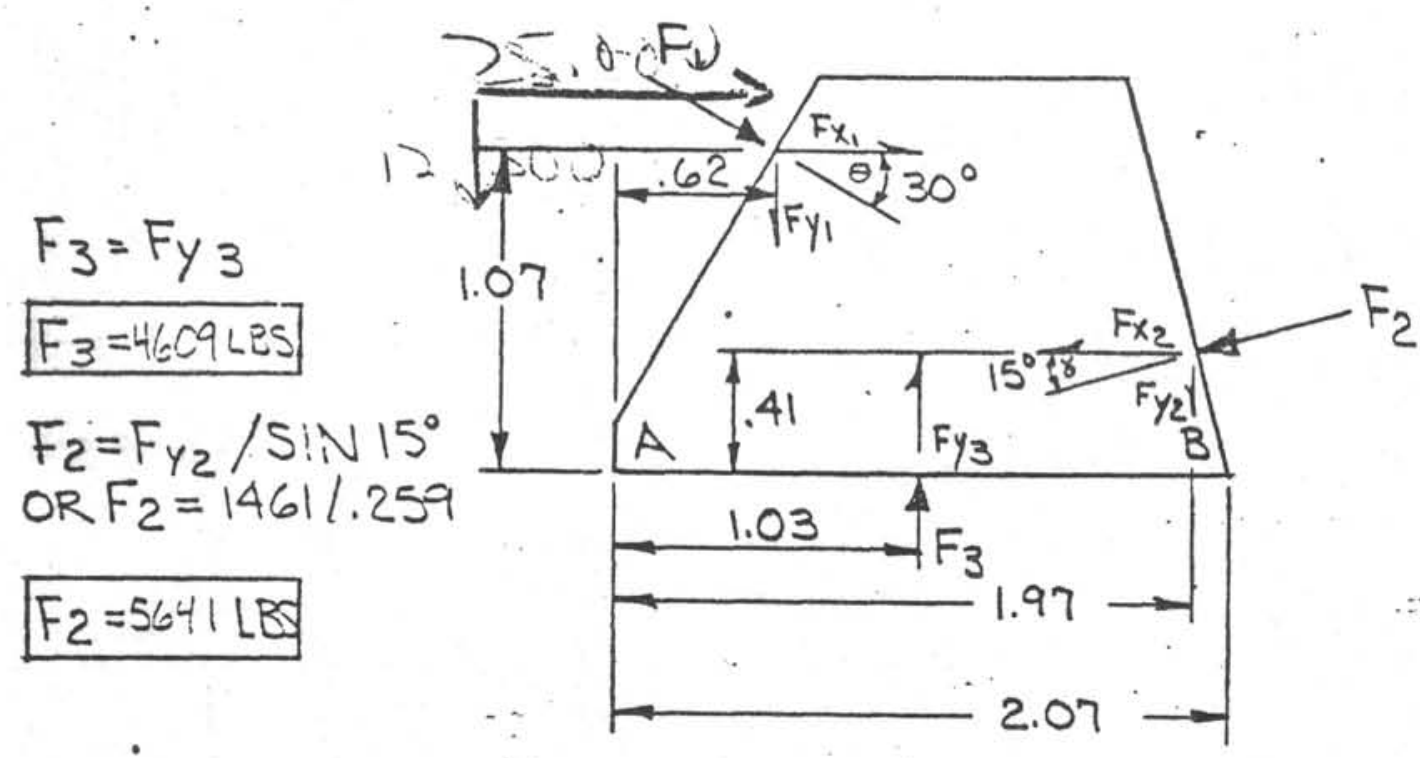

$\sum F_{x}=0$

$\sum F x_{x}=F_{x_{1}}-F_{x_{2}}=0$

SINCE $\theta=30^{\circ}$

$A_{N D} F_{1}=6295$ LBS

THEN $F_{X_{1}}=F_{1} \cos 30^{\circ}$

OR $F x_{1}=6295$ LBS (866)

$F_{X_{1}}=5452$ LES

AND $F x_{2}=5452 \angle B S$

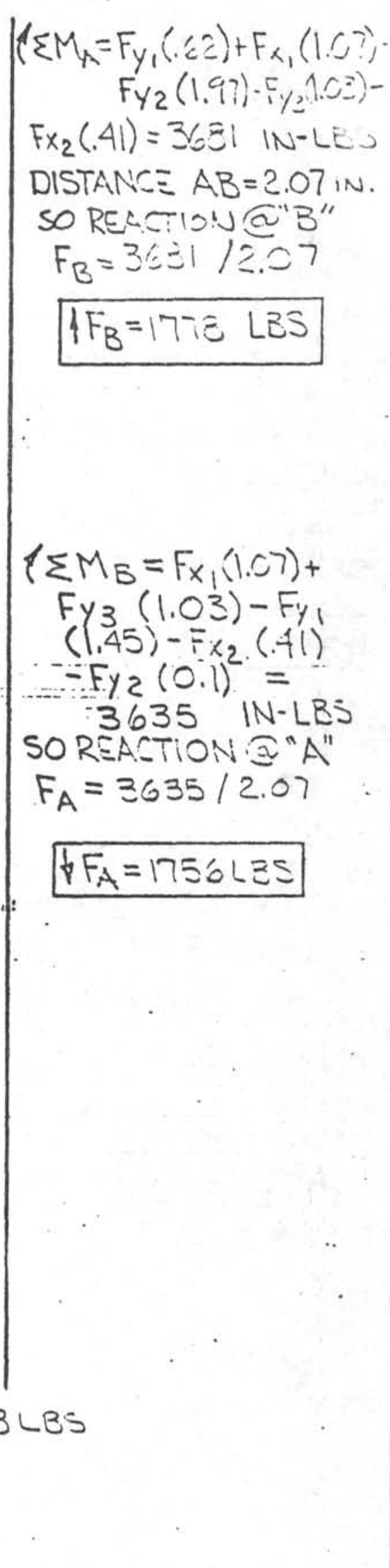

$F_{y_{1}}=F_{1} \operatorname{SIN~} 30^{\circ}$

$F_{Y_{1}}=(6295 \mathrm{LBS})(0.5)$

$F_{y_{1}}=3143$ LR

THEN F $F_{3}=F_{y_{2}}+F_{y_{1}}$

OR $F_{Y_{3}}=1461$ LBS +3148 LBS

$F_{Y_{3}}=4609$ LBS

$-50-$ 
LAT rH SEGMENT ANALYSIS HI URALIC BIT RELEASe-
NOV 3,1977 MAS. SHEET NO 4

HYDE AULIC FORCE DONN

ARE: 4,623 INDIA $\bar{A}=16.791 \mathrm{~N}^{2}$

@ 1,500 PSI $F=25,178$ LBS

SINCE LOAD IS DISTRIB. OVER 4 DOGS FORCE PER DOG $=6,295$ $F_{1}=6,295 \mathrm{~V}$
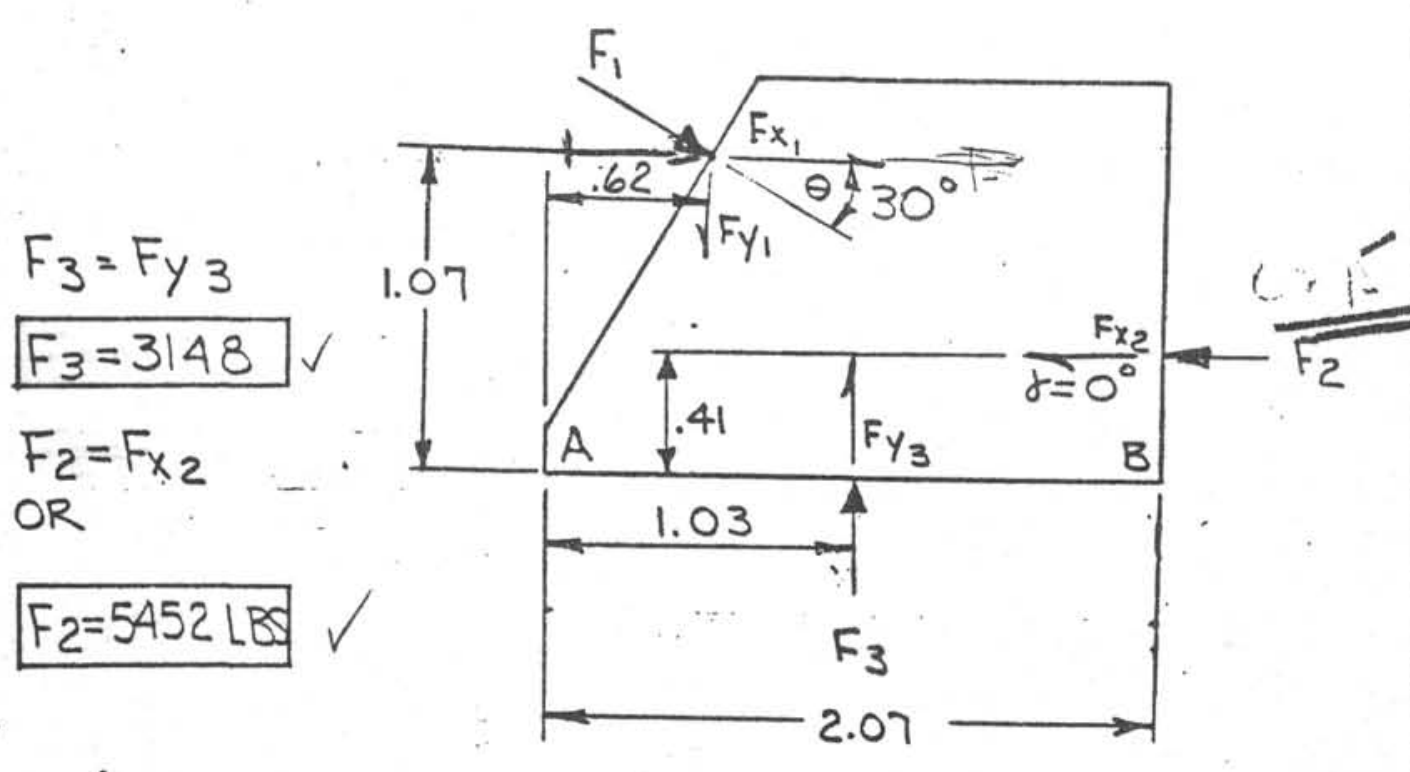

$$
\begin{aligned}
& R \in M_{A}=F_{y_{1}}(0.5)+F_{x_{1}}(1.0) \\
& -F_{y_{3}}(1.03)- \\
& F_{x_{2}}(41)=19301 \mathrm{~N}-L \text { LS } \\
& \text { DISTANCE } A B=2.07 \mathrm{in} \\
& \text { SO REACTION@"B" } \\
& F_{B}=1930 / 2.07 \\
& 4 F_{B}=932 \mathrm{LBS}
\end{aligned}
$$

$$
\begin{aligned}
& 1 \sum M_{B}=F_{X_{1}}(1.07)+ \\
& \begin{array}{l}
F_{y_{3}}(1.03)-F_{y_{1}} \\
(1.45)-F_{x_{2}}(41)
\end{array} \\
& =-2276 \text { IN-LBS. } \\
& \text { SOREACTION@"A } \\
& F_{A}=2276 / 2.07 \\
& \downarrow F_{A}=1100 \text { LBS }
\end{aligned}
$$

AND $F_{x_{2}}=5452 \angle B S=F_{2}$

$$
\begin{aligned}
& F_{y_{1}}=F_{1} \operatorname{SIN}\left(30^{\circ}\right) \\
& F_{y_{1}}=(6295 \text { LBS })(0.5) \\
& F_{y_{1}}=3148 \text { LBS } \\
& \text { THEN } F_{y} 3=F_{y_{1}} \\
& \text { OR } \\
& F_{y_{3}}=3: 48 \text { LBS } \\
& -52-
\end{aligned}
$$


SURMIARY

HYDRAULIC BIT RELEASE்

LATCH SEGMENT AVALYSIS

\begin{tabular}{|c|c|c|c|c|}
\hline $\begin{array}{l}\text { UPPER }(\theta) / \\
\text { LOWER }(\gamma) \\
\text { ANGLE ON } \\
\text { SEGRENT } \\
\text { (DEGREES) }\end{array}$ & $\begin{array}{c}\text { ACTION } \\
\text { TAKEN/RECONMIENDED } \\
\end{array}$ & $\begin{array}{l}\text { REACTION FORCE } \\
\text { ? "B" DUE TO } \\
\text { SUNNATION OF } \\
\text { FORCES ABOUT } \\
\text { POINT "A" }\end{array}$ & $\begin{array}{l}\mathrm{F}_{3} \text { REACTION } \\
\text { FORCE NORNAL } \\
\text { TO SLEEIE }\end{array}$ & $\begin{array}{l}\because \text { REDUCTION } \\
\text { IN FORCE } \\
\text { "B" FRON } \\
\text { ORIGI.NAL }\end{array}$ \\
\hline $30^{\circ} / 30^{\circ}$ & ORIGINAL DOG DESIGN & 2544 LBS & 6296 LBS & NA \\
\hline $30^{\circ} / 15^{\circ}$ & PRESENT STATE OF FABRICATION & 1778 LBS & 4609 LBS & $30 \%$ \\
\hline $15^{\circ} / 15^{\circ}$ & REJECTED ALTERVATIVE & 2065 LBS & 3260 LBS & $19 \%$ \\
\hline $30^{\circ} / 0^{\circ}$ & RECOMRENDED DESIG MODIFICATION & 932 LBS & 3148 LBS & $63 \%$ \\
\hline
\end{tabular}

NOTE: SUMMARY OF FORCES ARE FOR INDIVIDUAL SEGIENT ONLY FOUR (4) SEGIENTS ARE UTILIZED IN EACH ASSEMBLY 
ABR:

PJ.1

Latch Segment load Analysis

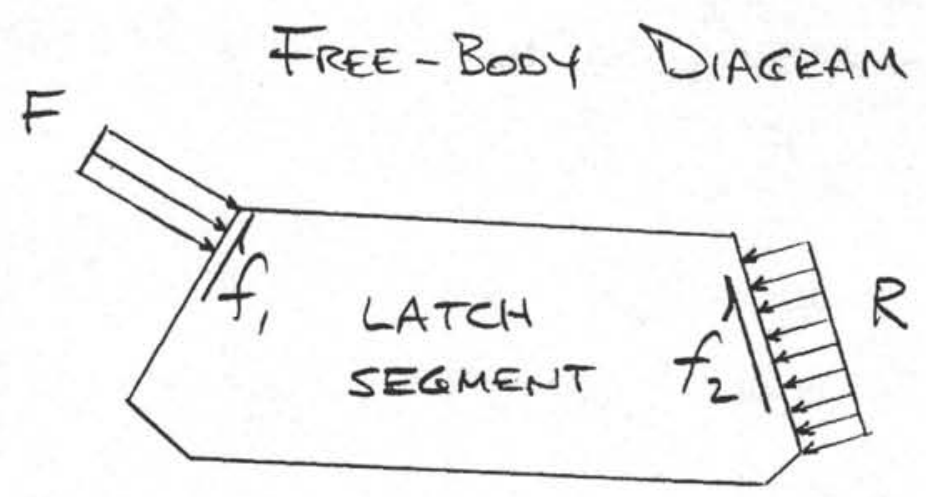

$f_{1}=\mu_{1} F$

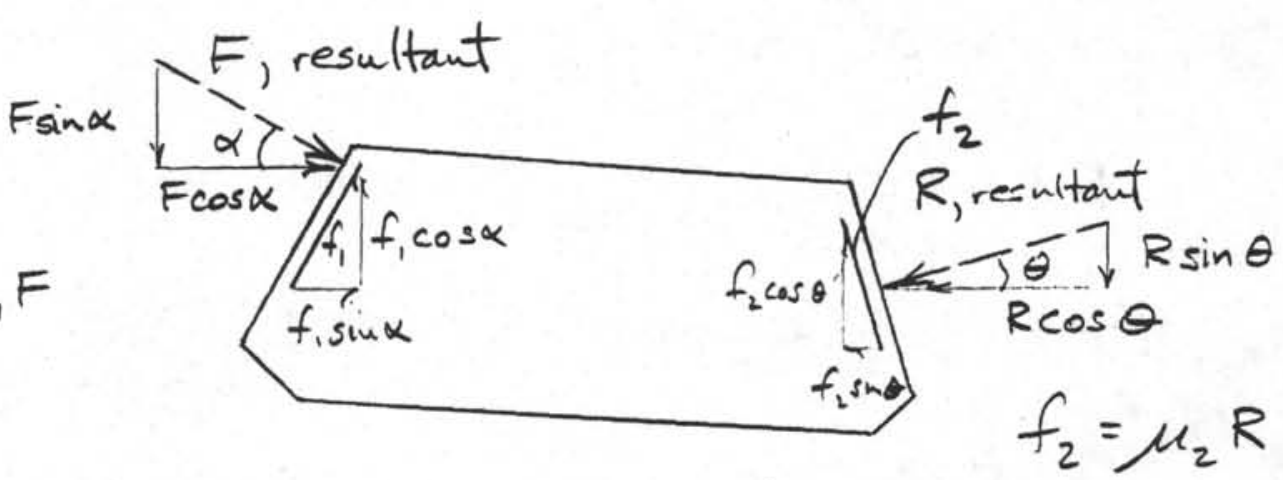

frictionless case

$\alpha=30^{\circ}, \theta=15^{\circ}$

With release sleeve removed, segment must move under influence of $F \sin \alpha+$ $R \sin \theta$. Also, rotation is possible depending ON PIVOT POINTS.*

WITH FRICTION

Calculate critical friction coefficient, $\mu_{C}$, WHICH WILL ESTABLISH STATE EQUILIBRIUM OF SEGMENT.

* ie rotation occurs, friction surfaces will BREAK MOMENTARILY LEADiNG TO "SQUIRMING", 


$$
\begin{aligned}
& \sum F \uparrow=0 \\
& f_{1} \cos \alpha+f_{2} \cos \theta=F \sin \alpha+R \sin \theta \\
& f_{1}=\mu_{1} F, f_{2}=\mu_{2} R \\
& \mu_{1} F \cos \alpha+\mu_{2} R \cos \theta=F \sin \alpha+R \sin \theta \\
& F \sin \alpha-\mu_{1} F \cos \alpha=\mu_{2} R \cos \theta-R \sin \theta \\
& F\left(\sin \alpha-\mu_{1} \cos \alpha\right)=R\left(\mu_{2} \cos \theta-\sin \theta\right)
\end{aligned}
$$

$\operatorname{Pg} .2$

for $\alpha=30^{\circ}, \theta=15^{\circ}$

$$
F\left(.5-.866 \mu_{1}\right)=R\left(.966 \mu_{2}-.259\right)
$$

$F \cos \alpha=R \cos \theta$ from load application

$$
\begin{aligned}
& .866 F=.966 R \\
& \text { and reaction geometry } \\
& F=1.115 R \\
& 1.115 R\left(.5-.866 \mu_{c}\right)=R\left(.966 \mu_{c}-.259\right) \\
& \mu_{c}=0,42
\end{aligned}
$$

WHEN $\mu \geq 0.42$ BLOCK-TYPE LATCH SEGMENT DOES NOT MOVE

$-56-$ 
Max. LOAD CONDITION:

WITH ONLY (Z) SEGMENTS ENGAGED $=$.

2

BIT PLUGGED AT 3000 PSI, GO-DEVIL ARE E $A=41.2 \mathrm{in}^{2}$

$$
\begin{aligned}
& F_{\text {total }}=123,600 \mathrm{lb} . \\
& F_{s}=61,800 \mathrm{kf} / \text { segment }=N_{x} \\
& N_{y}=N_{x} \tan 30^{\circ}=35,680 \mathrm{k} / \text { segment } \\
& k=1.178 \quad b=.822 \quad m=1.760
\end{aligned}
$$

$$
\begin{aligned}
35,680 & +2 H_{y}=R \\
61,800 & =2 H_{x} \\
R(1.761) & =61,800(.822)+35,680(1.178) \\
R & =52,7451 b_{f}
\end{aligned}
$$

$$
\begin{aligned}
2 H_{y}=R-35680 & =52,745-35,680 \\
2 H_{y} & =17,065 \mathrm{l}_{f} \\
2 H=\sqrt{\left(2 H_{x}\right)^{2}+\left(2 H_{y}\right)^{2}} & =\left(61,800^{2}+17,065^{2}\right)^{1 / 2} \\
2 H & =64,113 \mathrm{l}_{f}
\end{aligned}
$$

$$
\begin{aligned}
& \text { Check } \sum M_{n}=0: R(m-k)+2 H_{y} k=2 H_{x} b \\
& \quad 52,745:(1.76-1,178)+17,065(1.178)=61,800(.822), \quad 50800=50799,6 .
\end{aligned}
$$


3

shear on trunnion ears

Double shear cross -area on ears ( $5 / 8^{\prime \prime}$ din.)

$$
A_{d s}=2 \frac{\pi}{2}(.625)^{2}=0.6136 \mathrm{in}^{2}
$$

Shear Stress,

$$
\tau_{d s}=\frac{P}{A}=\frac{24}{A_{d s}}=\frac{64,113}{.6136}=104,490 \text { psi }
$$

OK

$$
\begin{aligned}
& \text { SEGMENTS: } 4140 \text { at } R_{c} 40 \text { Shear field }=102,600 \text { psi } \\
& \begin{array}{ll}
\& A X L E S \text { STEEL a Sher U1tin. }=111,600 \mathrm{psi} \\
\text { Izod }=35 \mathrm{At}-16 .
\end{array} \\
& R_{c} 42 \text { Shear Yield }=106,300 \text { psi } \\
& \text { Shear Ultimo }=116,000 \text { psi } \\
& \text { Izod }=30 \text { A }-16 \text {. }
\end{aligned}
$$

Shear on AxLe

Double shear cross-aren on axle ( $9 / 16^{\prime \prime}$ cia.)

$$
\begin{gathered}
A_{d s}=\frac{\pi}{2}(.5625)^{2}=0.497 \mathrm{in}^{2} \\
T_{d s}=\frac{\rho}{A}=\frac{R}{A d s}=\frac{52,745}{.497}=106,125 \mathrm{psi}
\end{gathered}
$$

ok

THUS, LOAD CONDITION BORDERING WITH PLUGGED BT T, MAX. PRESSURE AND ONLY TWO SEGMENTS HOLDING LOAD. THIS ALLOW' ADEQUATE SAFETY FACTOR FOR NORMAL OPERATIONS. 
Check $\mu_{\text {static critical value }}$

[4]

$$
\begin{aligned}
& N_{x} b+N N_{y} k=2 H \mu_{s t}+N \mu_{s t} a \\
& r=\frac{.625}{2}=.3125 \quad N=\left(N_{x}^{2}+N_{y}^{2}\right)^{1 / 2}=\left(61,800^{2}+35,600^{2}\right)^{1 / 2}=71,360 \\
& a=k \cos \theta-6 \sin \theta=1.178 \cos 30^{\circ}-.822 \sin 30^{\circ} \\
& \frac{a=.609}{61,800(.822)+35,680(1.178)=64,113 \mu_{s t}(.3125)+71,360 \mu_{s t}(.609)} \\
& 92,831=63,494 \mu_{s t} \\
& \text { critical static }=1.46
\end{aligned}
$$

$-60-$ 
APPENDIX B

CURRENT MECHANICAL BIT RELEASE DRAWINGS 


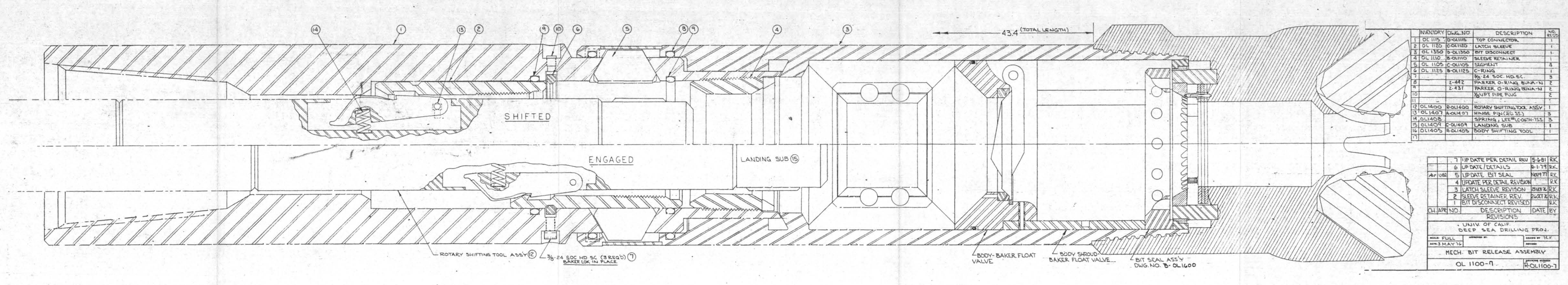




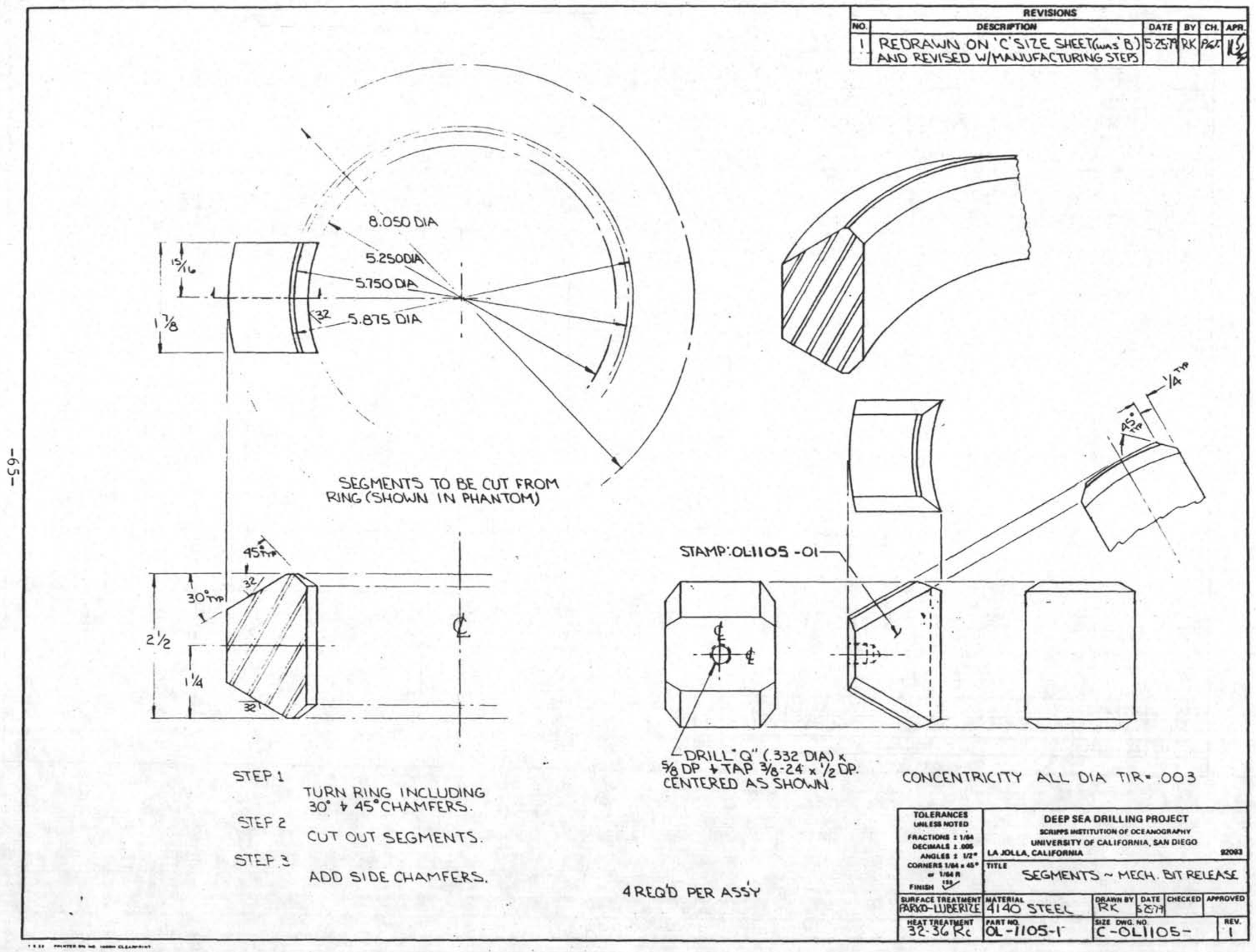




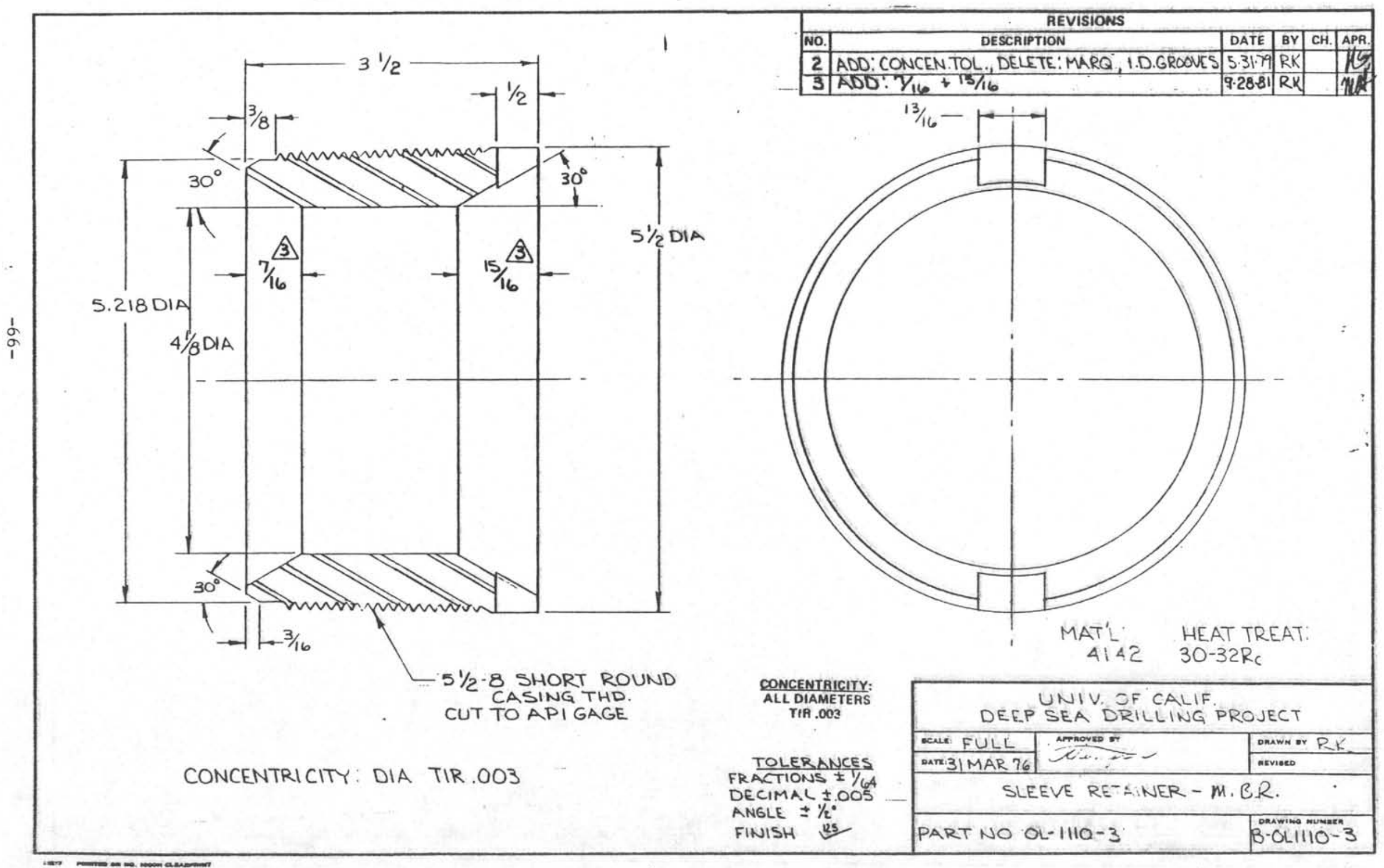




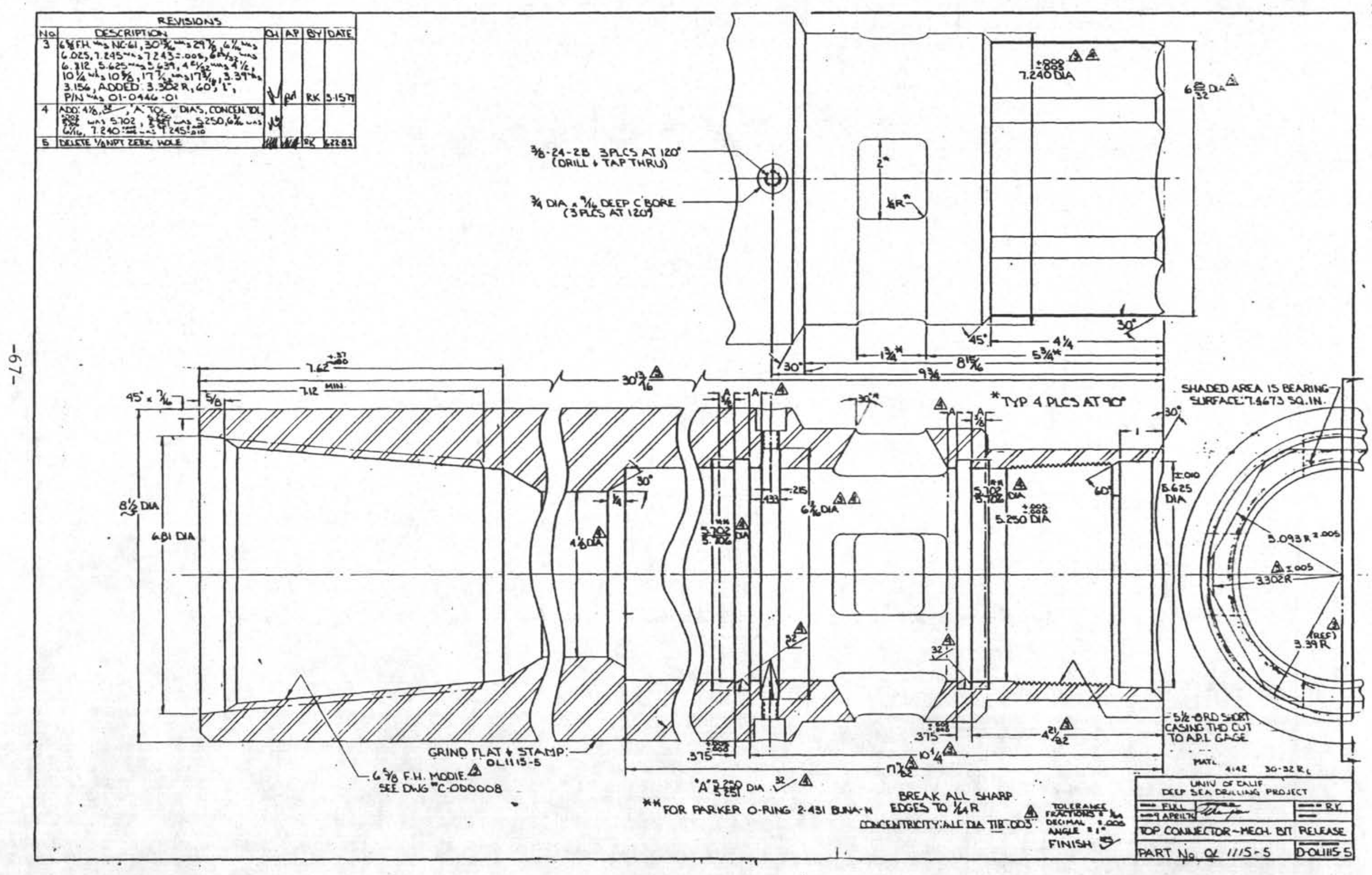




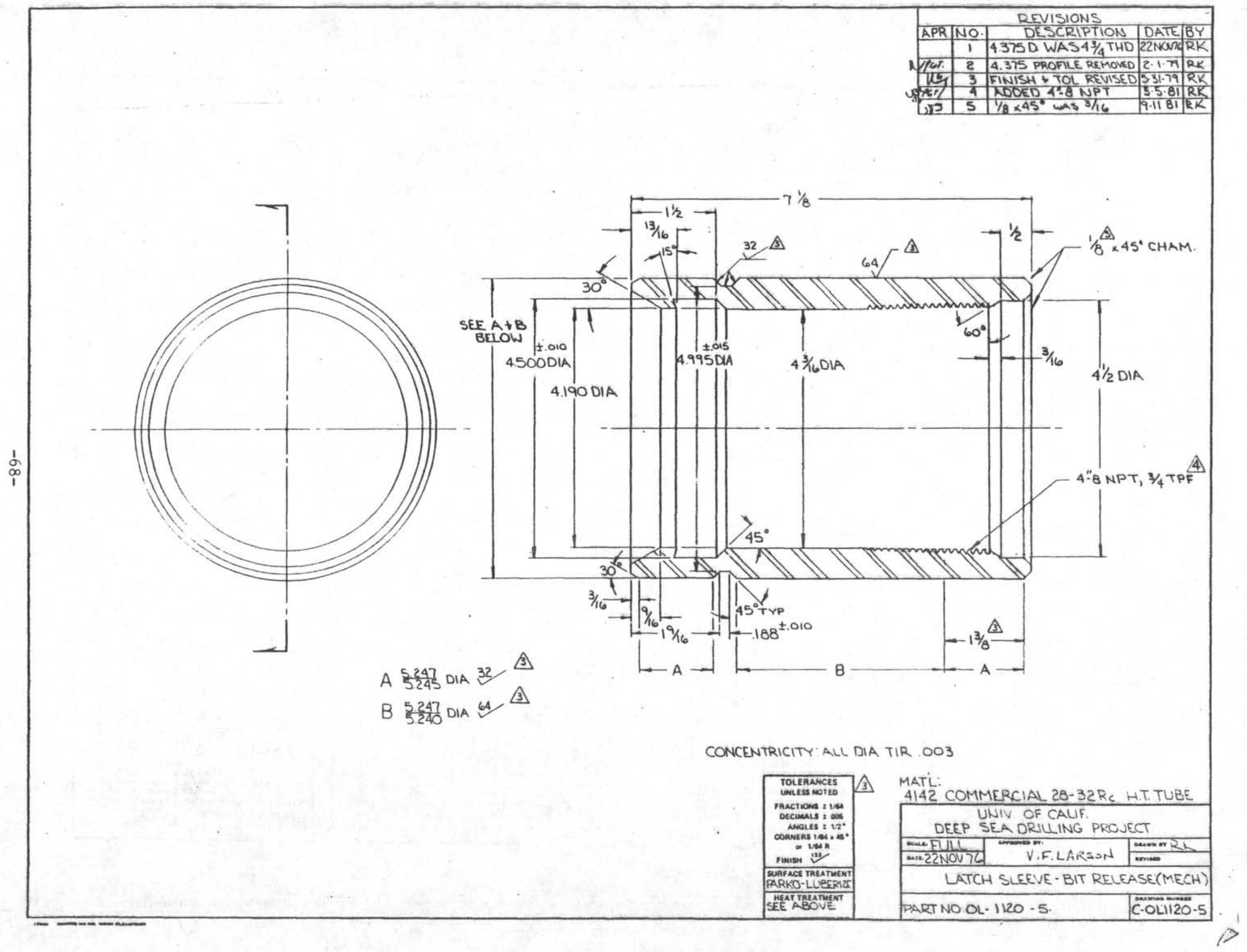




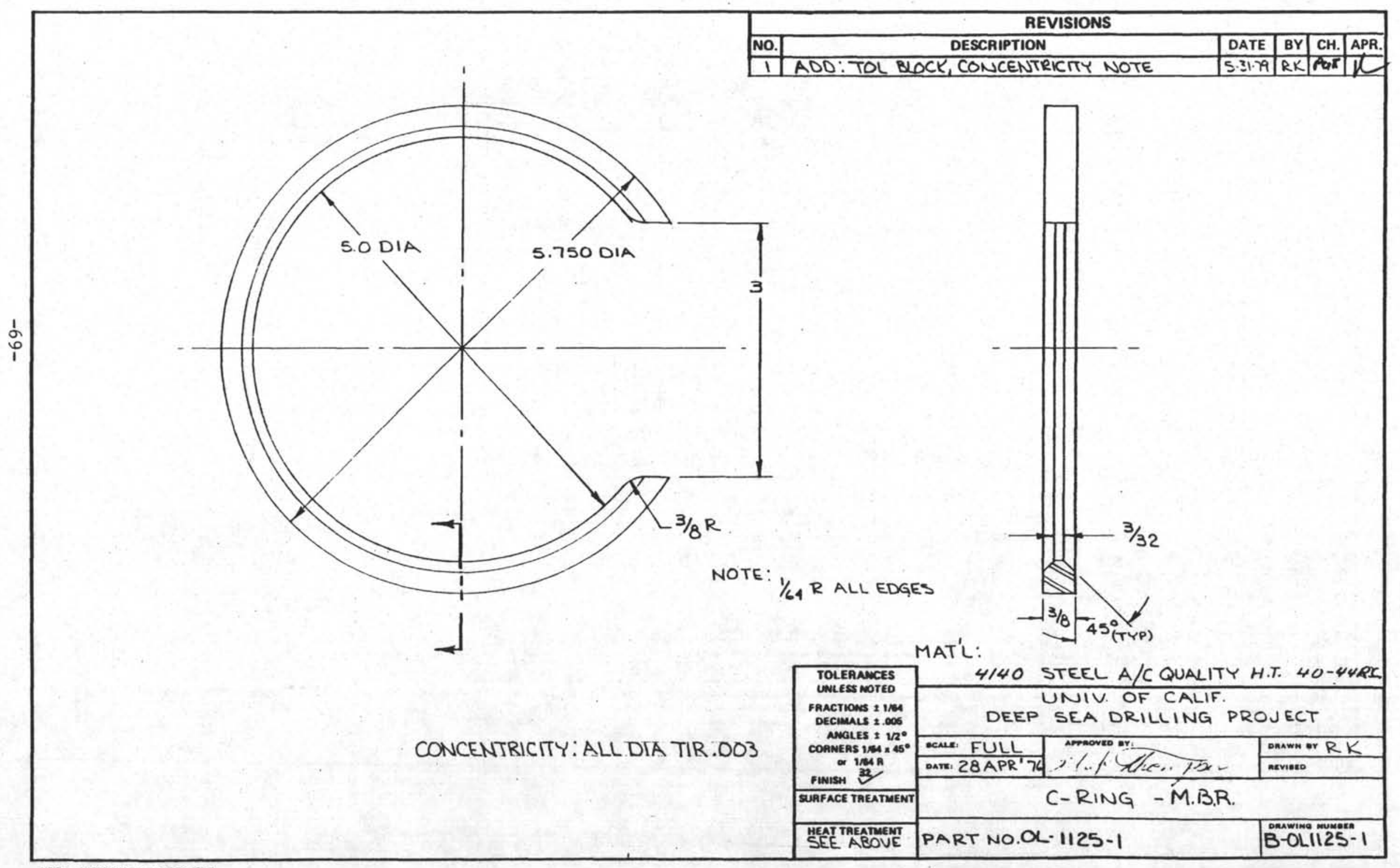




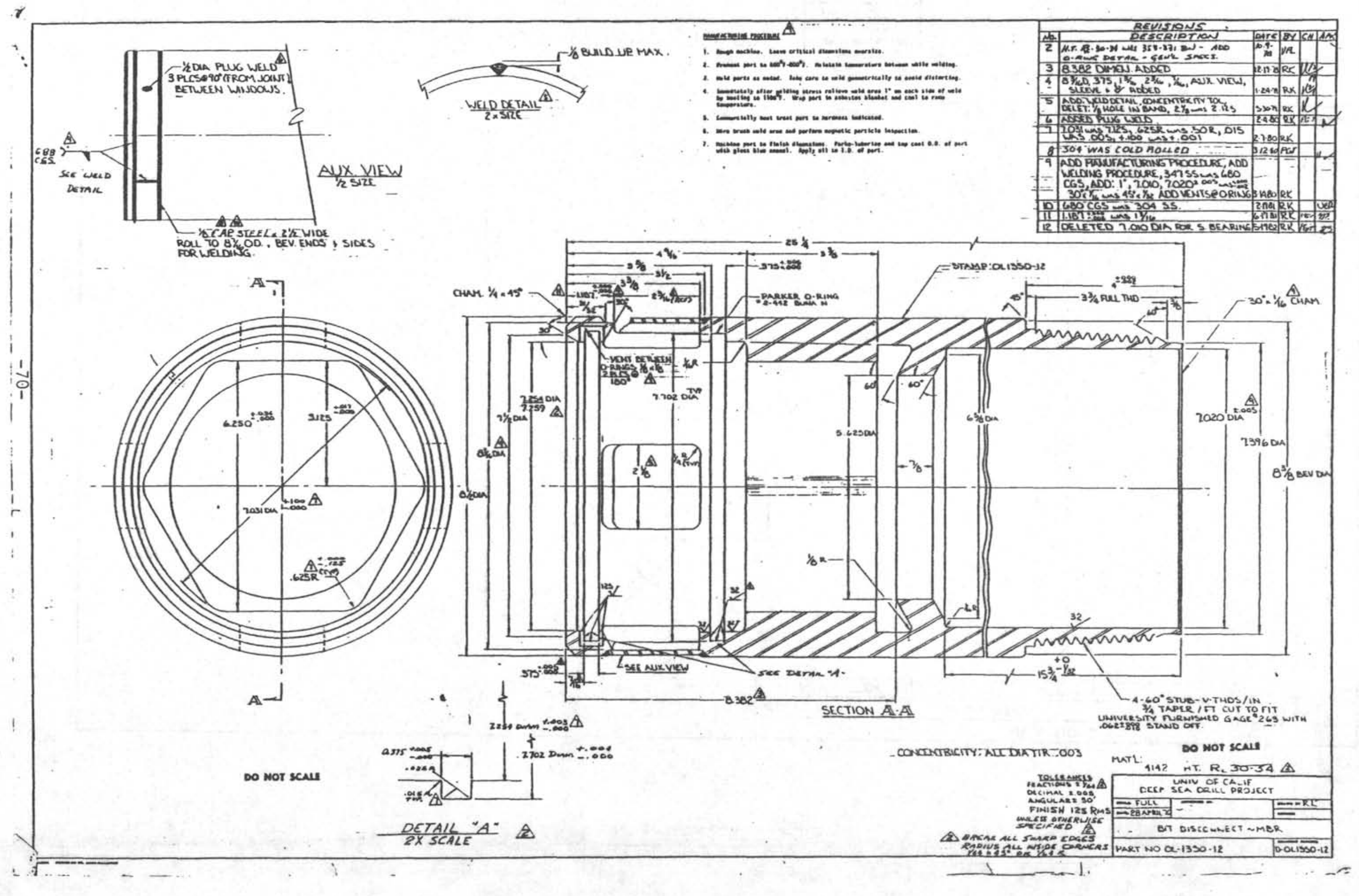


APPENDIX C

CURRENT HYDRAULIC BIT RELEASE (MOD. IV) 



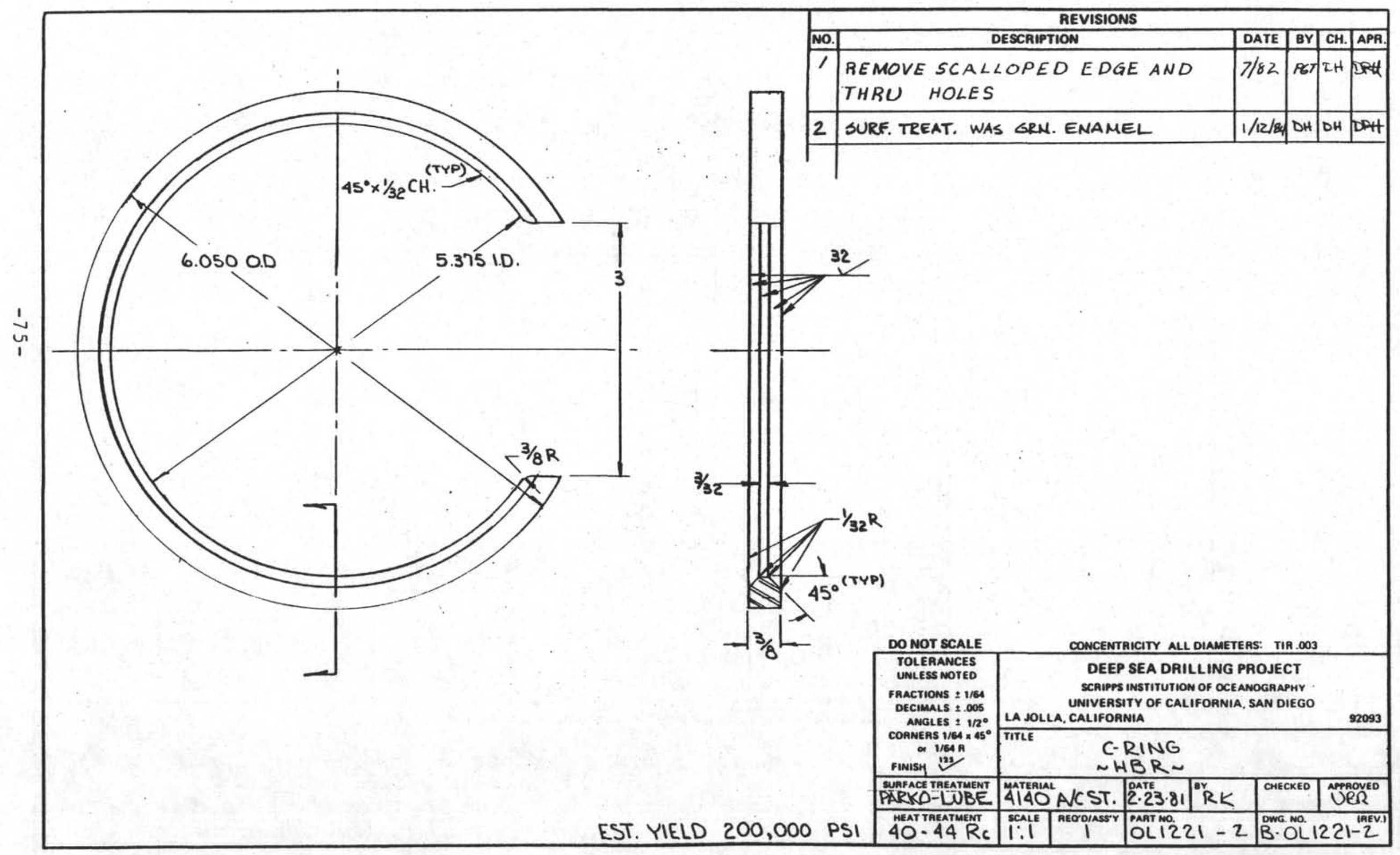


DRILL 5/16 DIA $\times .6 \mathrm{DP}+$ TAP $3 / 8-16 \times 5$ DP, TYP 2 PLC
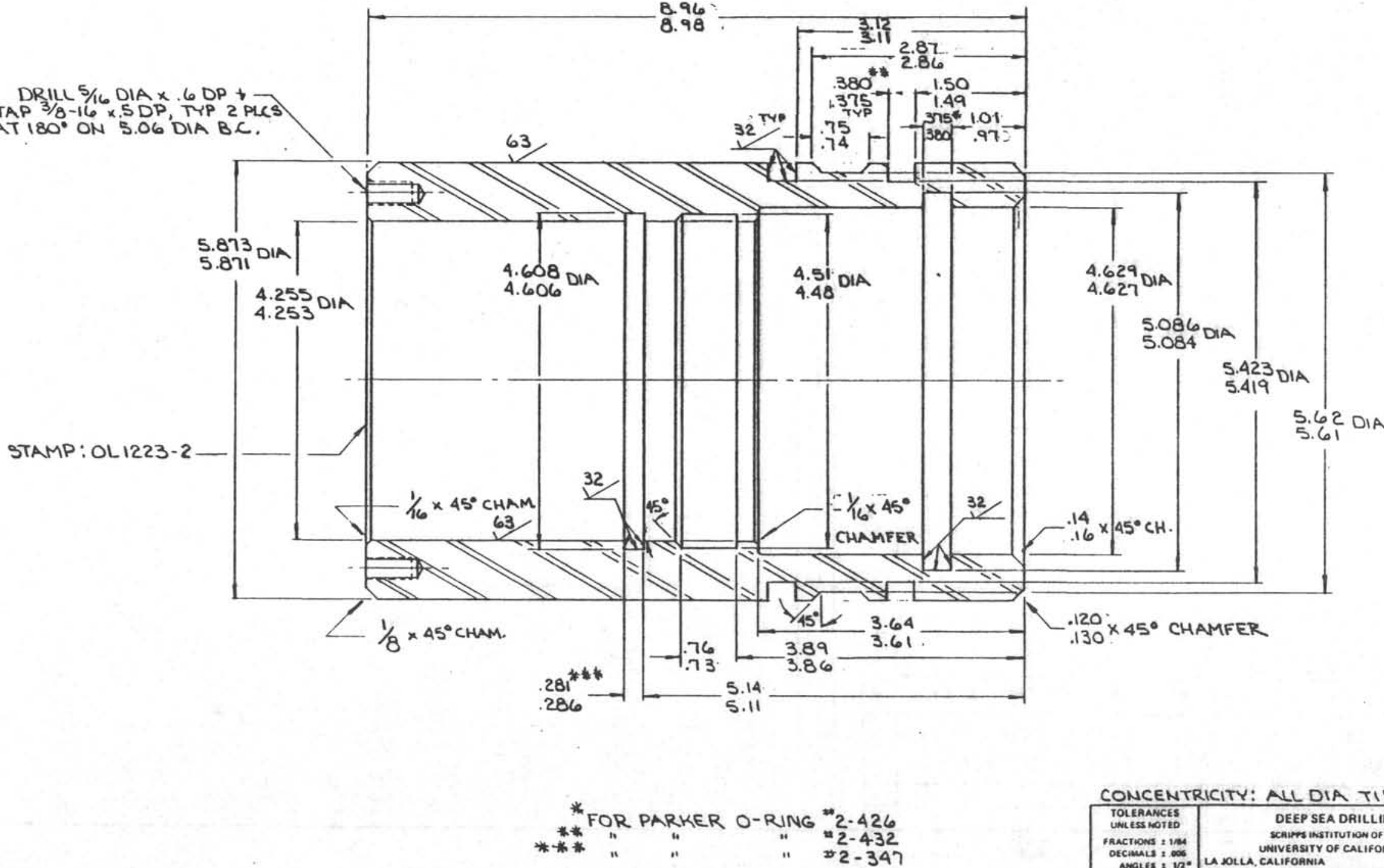

CONCENTRICITY: ALL DIA TIR.003

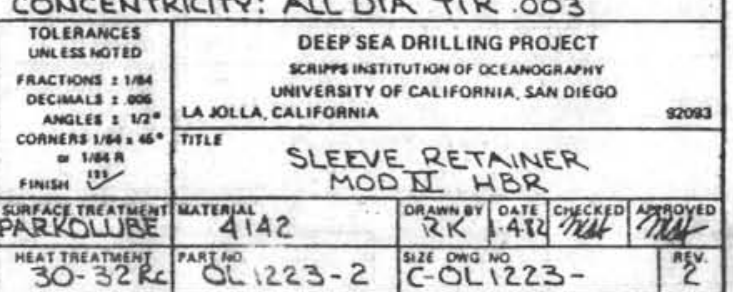




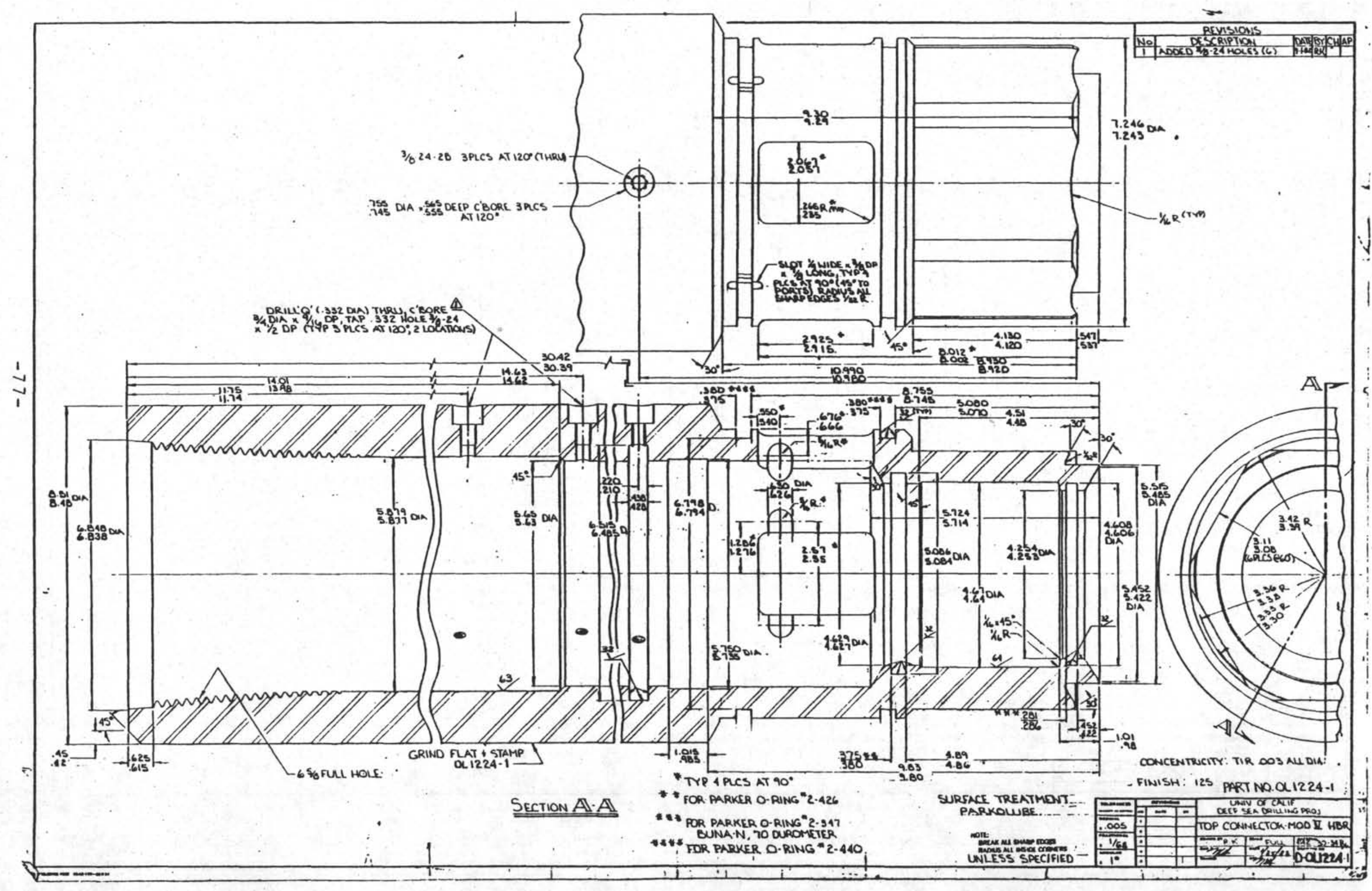




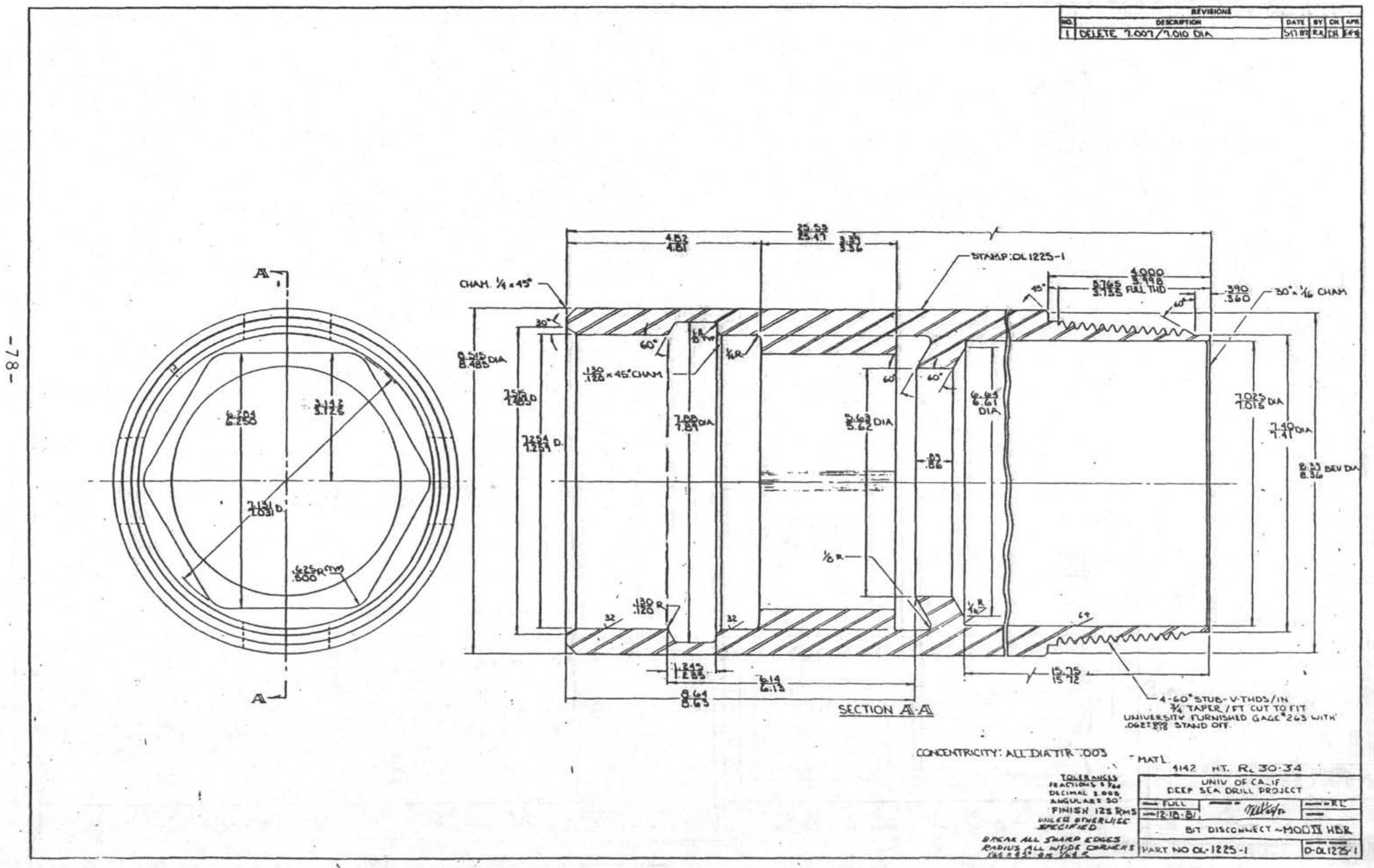




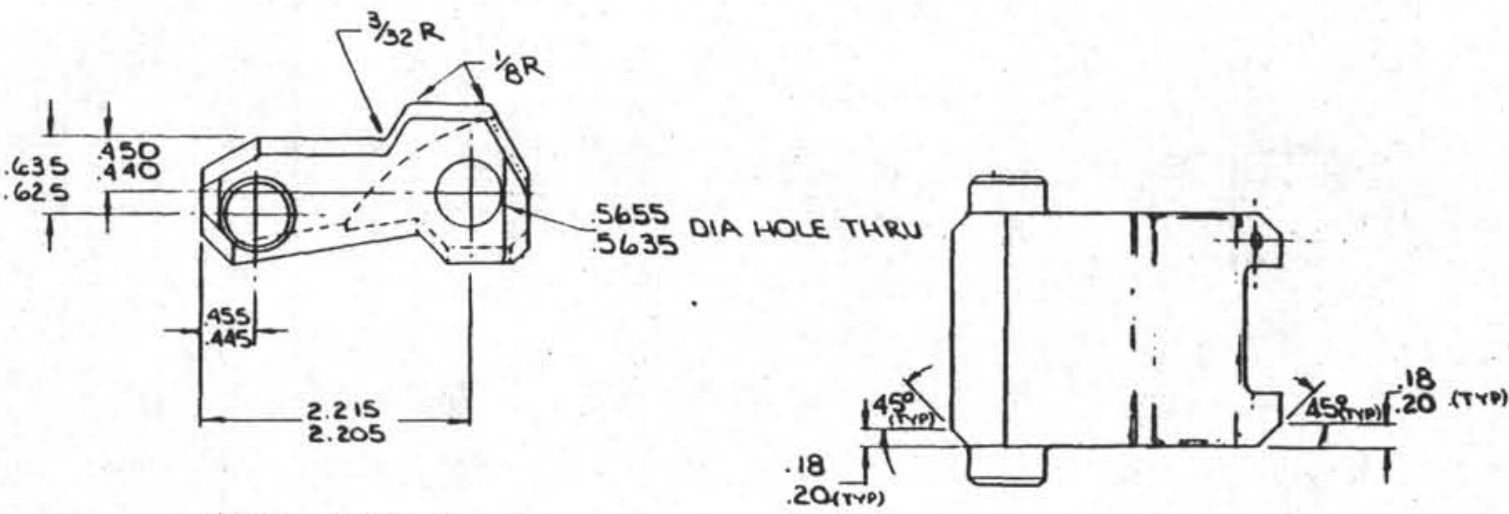

AUX.VIEW
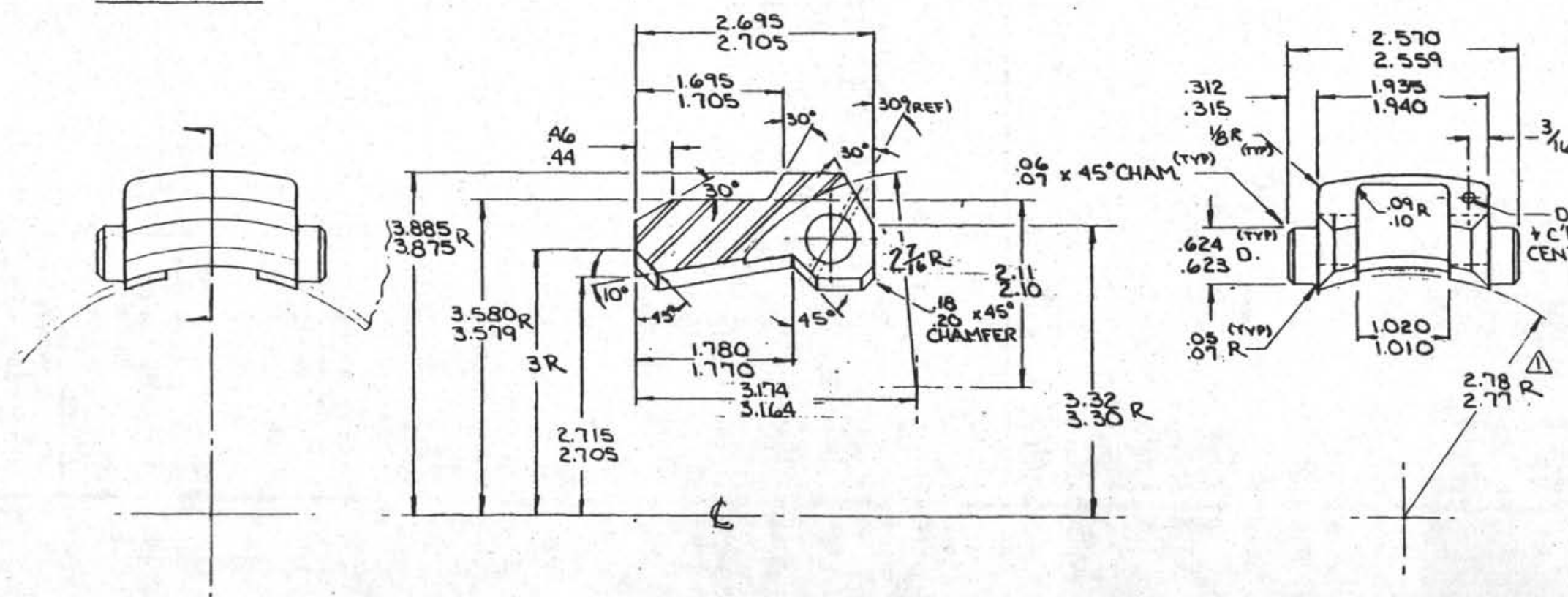

4 REQ'D PER ASSY BRENK NUL SHARP EDGES

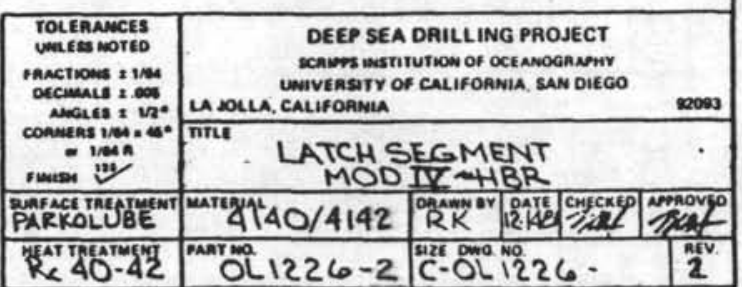




\begin{tabular}{|c|c|c|c|c|}
\hline \multicolumn{5}{|c|}{ REVISIONS } \\
\hline No. & DESCRIPTION & DATE & \begin{tabular}{|l|l|}
$\mathrm{BY}$ & $\mathrm{CH}$. \\
\end{tabular} & APR. \\
\hline 1 & $.5620 / 5610$ WAS $.5635 / .5625$ & $2 \cdot 25,72$ & RKinest & 2044 \\
\hline 2 & T/8 DIA HOLE WAS $3 / 16$ & $2 \cdot 10.83$ & $R \times \mid \mathbb{R H}$ & \pm \\
\hline
\end{tabular}

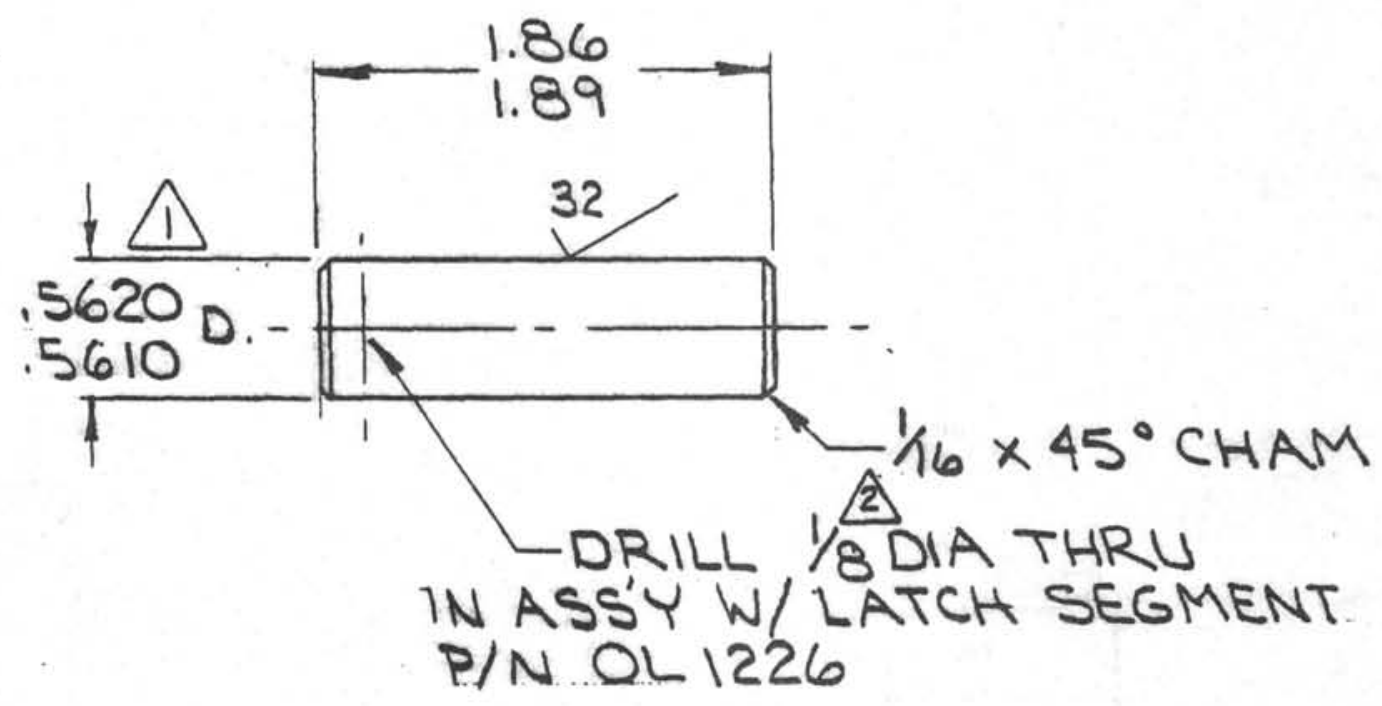

DO NOT SCALE TOLERANCES UNLESS NOTED

FRACTIONS $\pm 1 / 64$

DECIMALS \pm .005

ANGLES $\pm 1 / 2^{\circ}$ CORNERS $1 / 64 \times 45^{\circ}$

or $1 / 64 R$

FINISH

SURFACE TREATMENT

SUAFACE TREATMENT

MEAT TREATMENT

$R_{c} 40-42$
CONCENTRICITY ALL DIAMETERS: TIR 003

DEEP SEA DRILLING PROJECT

SCRIPPS INSTITUTION OF OCEANOGRAPHY UNIVERSITY OF CALIFORNIA, SAN DIEGO

LA JOLLA, CALIFORNIA

ROLLER AXLE MODIV HBR

MATERIAL

MATERIAL

4142 12.14.81

\begin{tabular}{|l|l}
\hline BY & CHECKED \\
\hline
\end{tabular}

234

DWG. NO. (REV.) SCALE $/$ AEQ'D/ASS'Y $Y$ PART NO.

OL $1227-2$ A-OLI227-2 


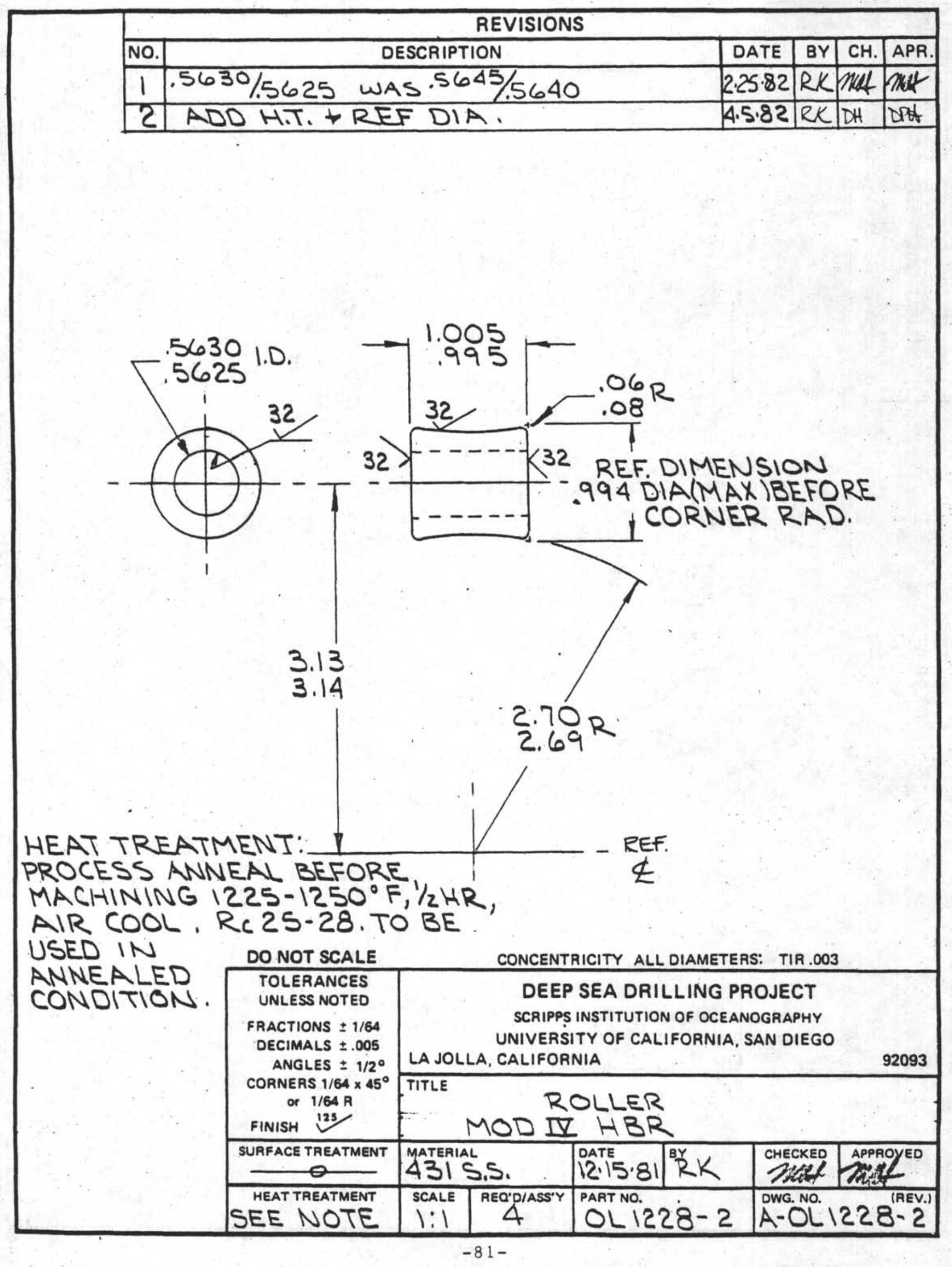




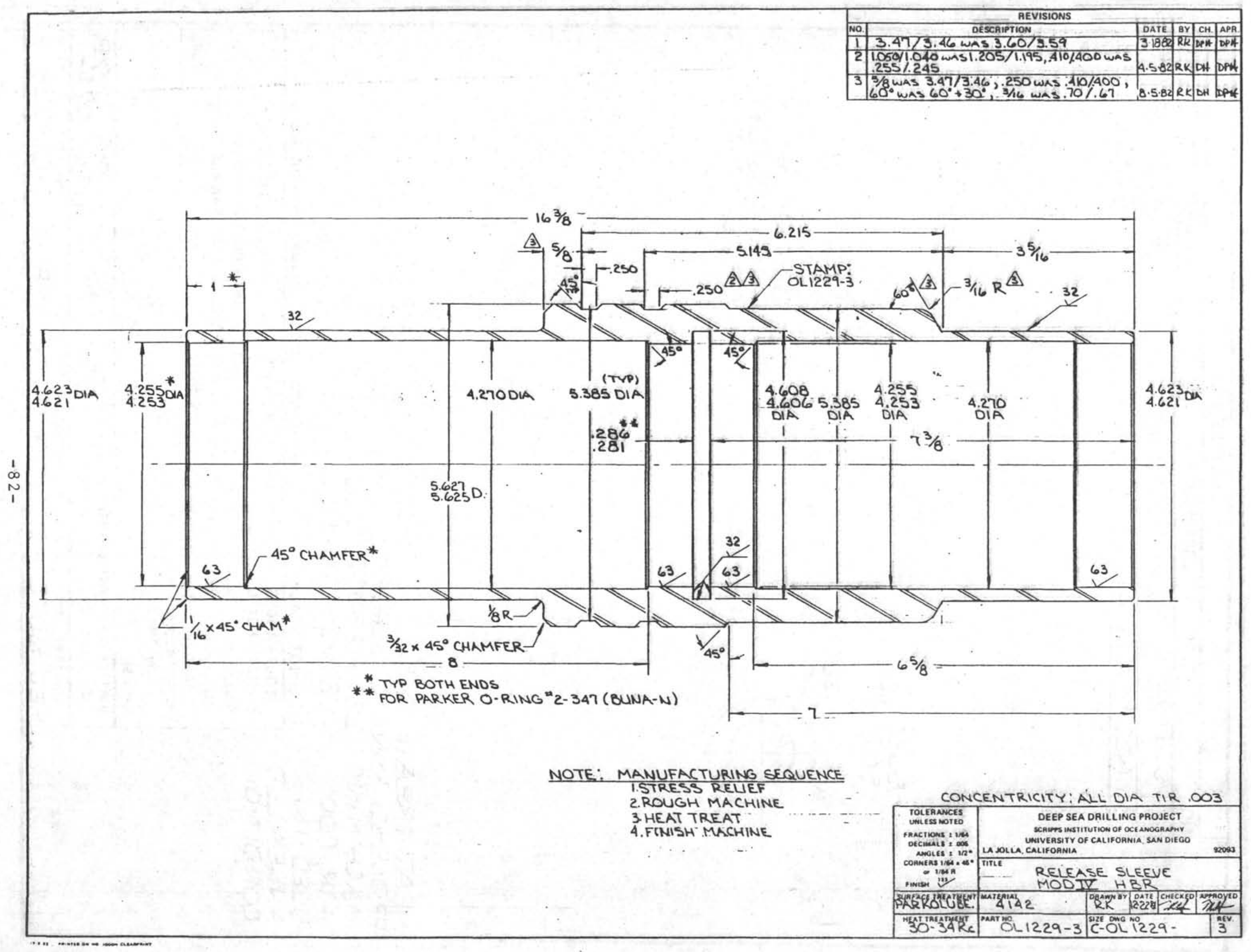




\begin{tabular}{|c|c|c|c|c|c|}
\hline \multicolumn{4}{|c|}{ REVISIONS } \\
\hline NO. & DESCRIPTION & DATE & BY & CH. & APR. \\
\hline 1 & ADDED EXPANSION PIN & 12.2082 & RK & PG & \\
\hline
\end{tabular}

Seal specifications for the Hydraulic Bit Release Top Connector - MOD IV. All 0 -rings to be 70-Durometer Buna-N Rubber. Seals are to be packaged in sets in a waterproof bag - MIL-B-117E. Type 2, Class C - Style 1.

The following labeling information shall be reproduced on the face of the bag:

SEAL KIT - HYDRAULIC BIT RELEASE - MOD IV

\begin{tabular}{|c|c|c|}
\hline Qty & $\frac{\text { Parker }}{\text { No. }}$ & Purpose \\
\hline 2 ea & $2-440$ & Trash Seal between OL1224 \& OL1225. \\
\hline 1 ea & $2-347$ & Pressure seal between $0 L 1224 \&$ OL1233. (0-R1ng) \\
\hline 1 ea & $2-347$ & Pressure seal between OL1229\&011233. (0-Ring) \\
\hline 1 ea & $2-347$ & Pressure Seal between OL1223\& OL1233. (0-Ring) \\
\hline 1 ea & $2-426$ & Pressure seal between OL1224\& OL1229. (0-Ring) \\
\hline 1 ea & $2-426$ & Pressure seal between OL1223 \& OL1229. (0-RIng) \\
\hline 2 ea & $2-432$ & Pressure seal between $0 \mathrm{~L} 1224 \&$ OL1223. (0-Ring) \\
\hline 1 ea & $2-432$ & Trash seal at top of oL1223. \\
\hline 4 ea & & $\begin{array}{l}\text { Expansion Pin, 1/8" dia by } 1 " \text { long in stainless } \\
\text { McMaster-Carp. } 92383 \mathrm{~A} 309\end{array}$ \\
\hline & & $\begin{array}{l}3 / 8-24 \times 5 / 16 \text { long socket head cap screws } \\
\text { in heat treated stainless steel. }\end{array}$ \\
\hline
\end{tabular}

DO NOT SCALE TOLERANCES UNLESS NOTED

FRACTIONS $\pm 1 / 64$ DECIMALS \pm .005 ANGLES $\pm 1 / 2^{\circ}$ CORNERS $1 / 64 \times 45^{\circ}$ or 1/64 R FINISH SURFACE TAEATMENT
CONCENTRICITY ALL DIAMETERS: TIR.003

\section{DEEP SEA DRILLING PROJECT}

SCRIPPS INSTITUTION OF OCEANOGRAPHY UNIVERSITY OF CALIFORNIA, SAN DIEGO

LA JOLLA, CALIFORNIA

92093

TITLE

$O-R I N G \mapsto S E A L$ SPEC. HBR - MODI

\begin{tabular}{|c|c|c|c|c|c|}
\hline$\overline{\mathrm{TTE}}$ & & DATE & ${ }^{B Y} R K$ & CHECKED & APPAOVED \\
\hline & & & & & \\
\hline
\end{tabular}




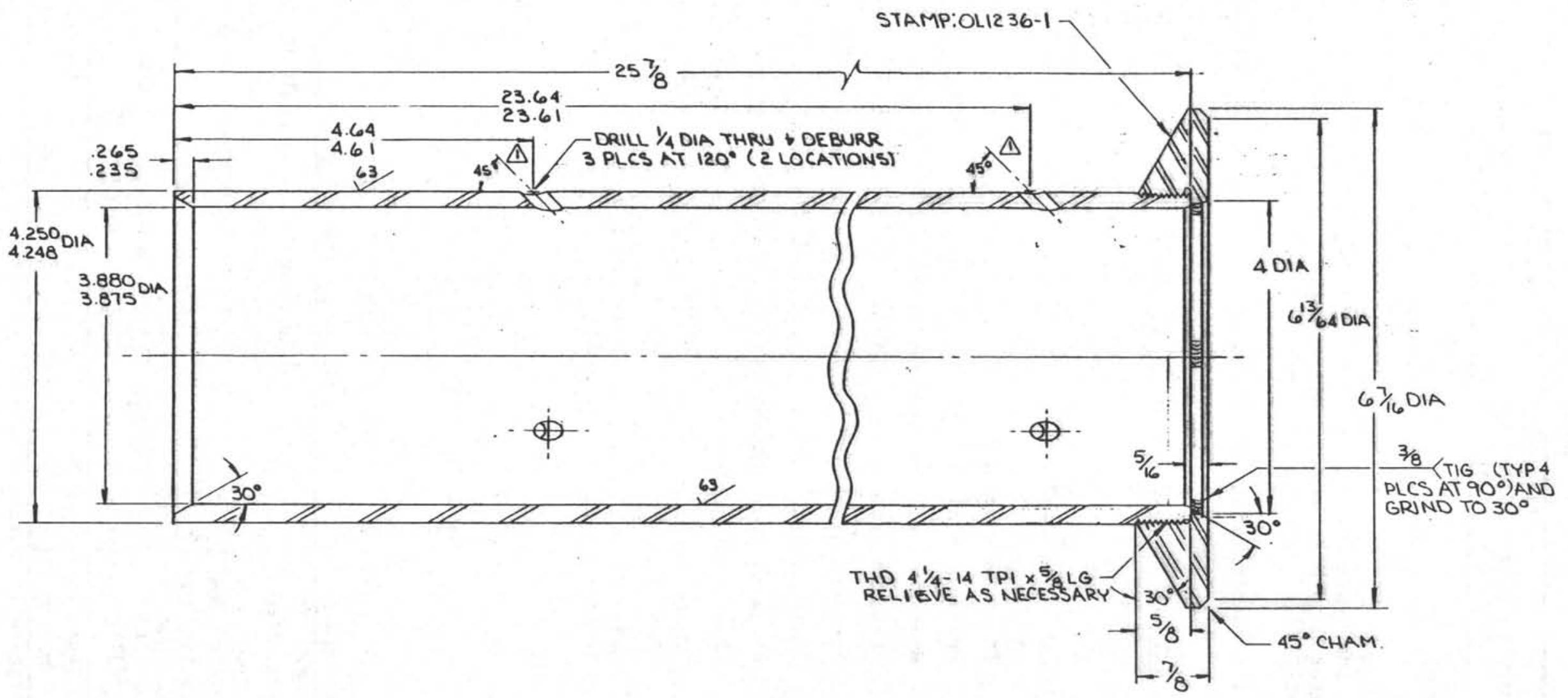

CONCENTRICITY: ALL DIA TIR.OO3

\begin{tabular}{|c|c|c|}
\hline 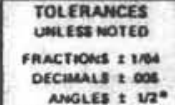 & 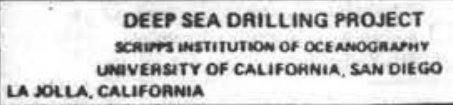 & 20023 \\
\hline 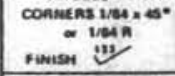 & $\begin{array}{l}\text { TIIIEER / BEARING SPACER } \\
\text { 3BT ID.HBR (MOO I }\end{array}$ & \\
\hline 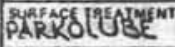 & 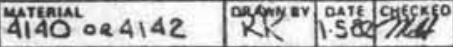 & menes \\
\hline $\begin{array}{l}\text { MEAT TREALERT } \\
30-34 R_{C}\end{array}$ & Mat OL. $1236-1$ & $\frac{m_{E}}{1}$ \\
\hline
\end{tabular}




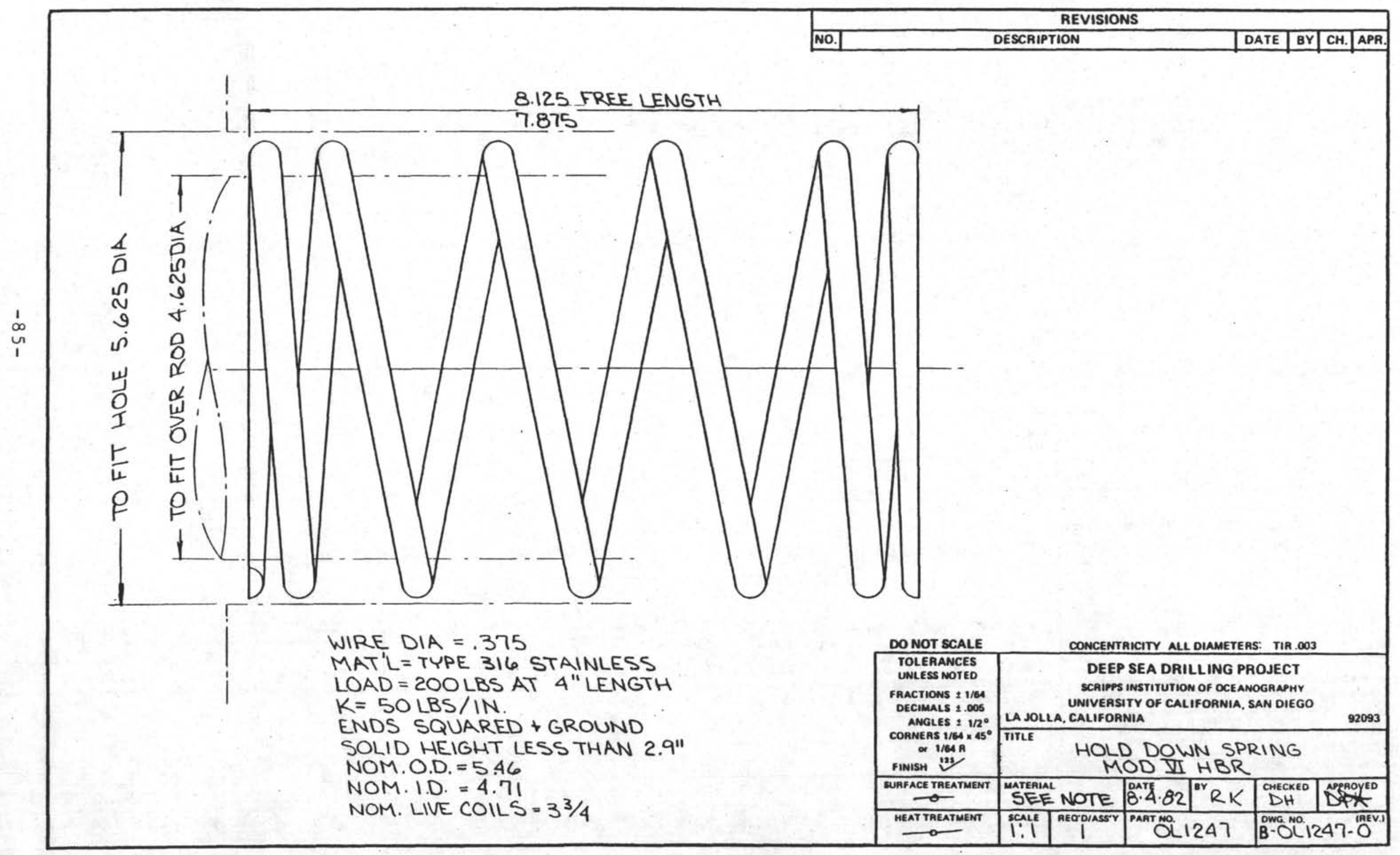




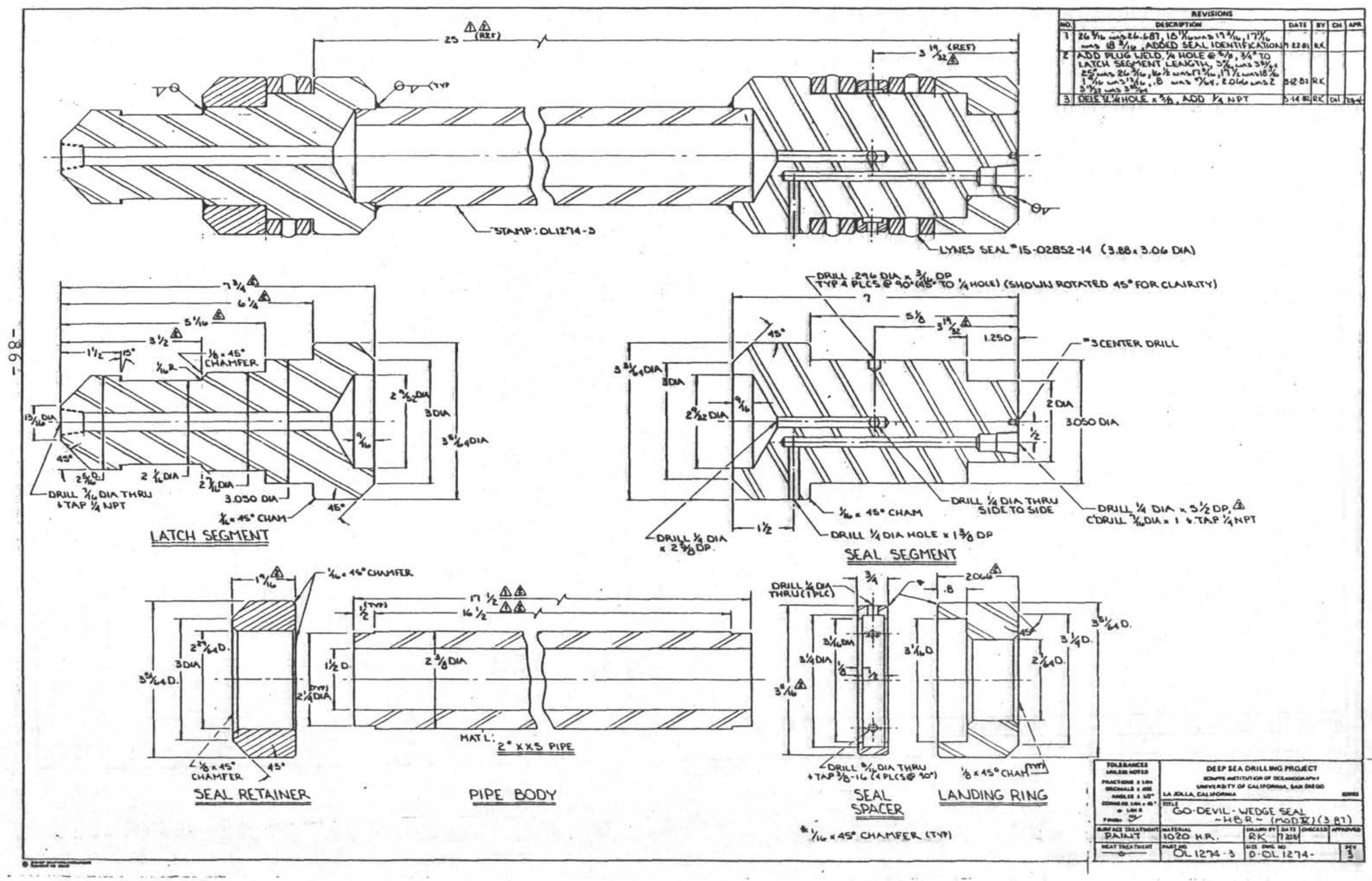




\section{REVISIONS}

NO.

\section{NOTE:}

SEAL MUST ENERGIZE ON A 3.050 SHAFT $\rightarrow$ SEAL IN A 3.878 BORE.

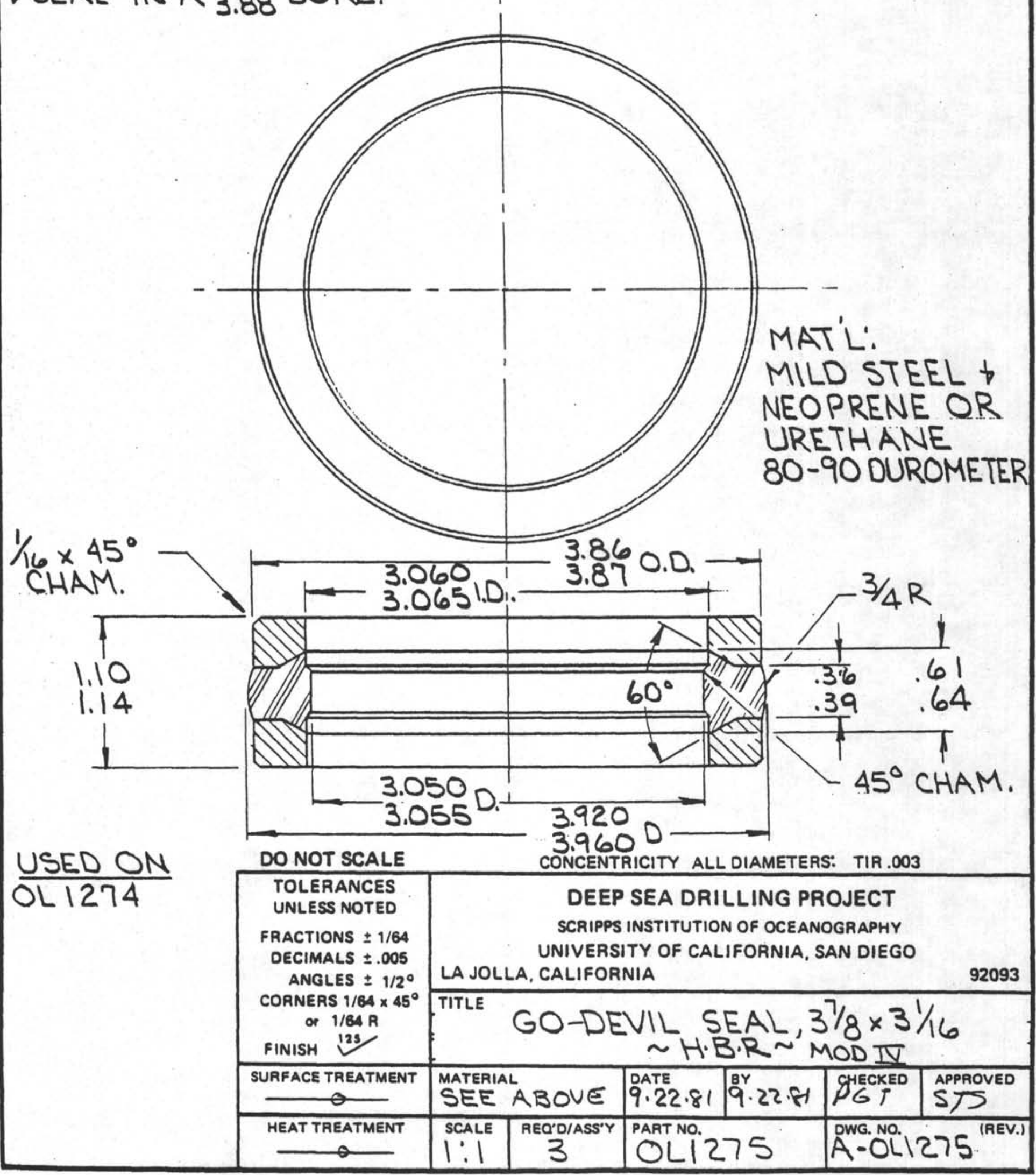




\section{APPENDIX D}

PAST MECHANICAL BIT RELEASE/HYDRAULIC BIT RELEASE AND RELATED DRAWINGS 


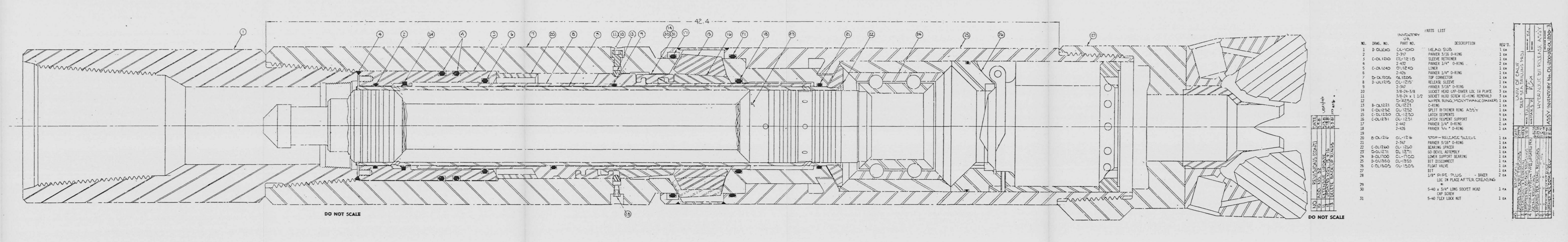




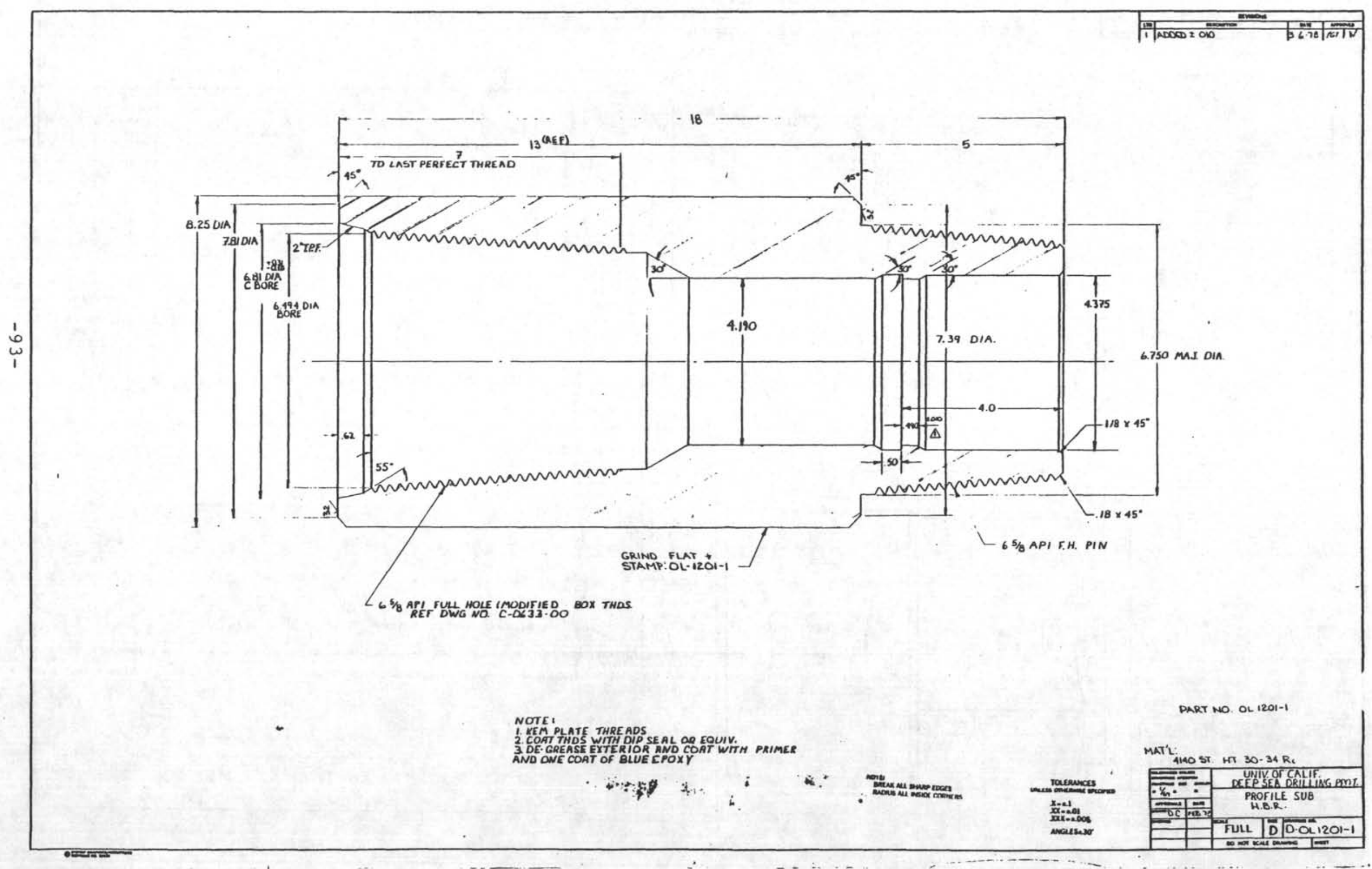




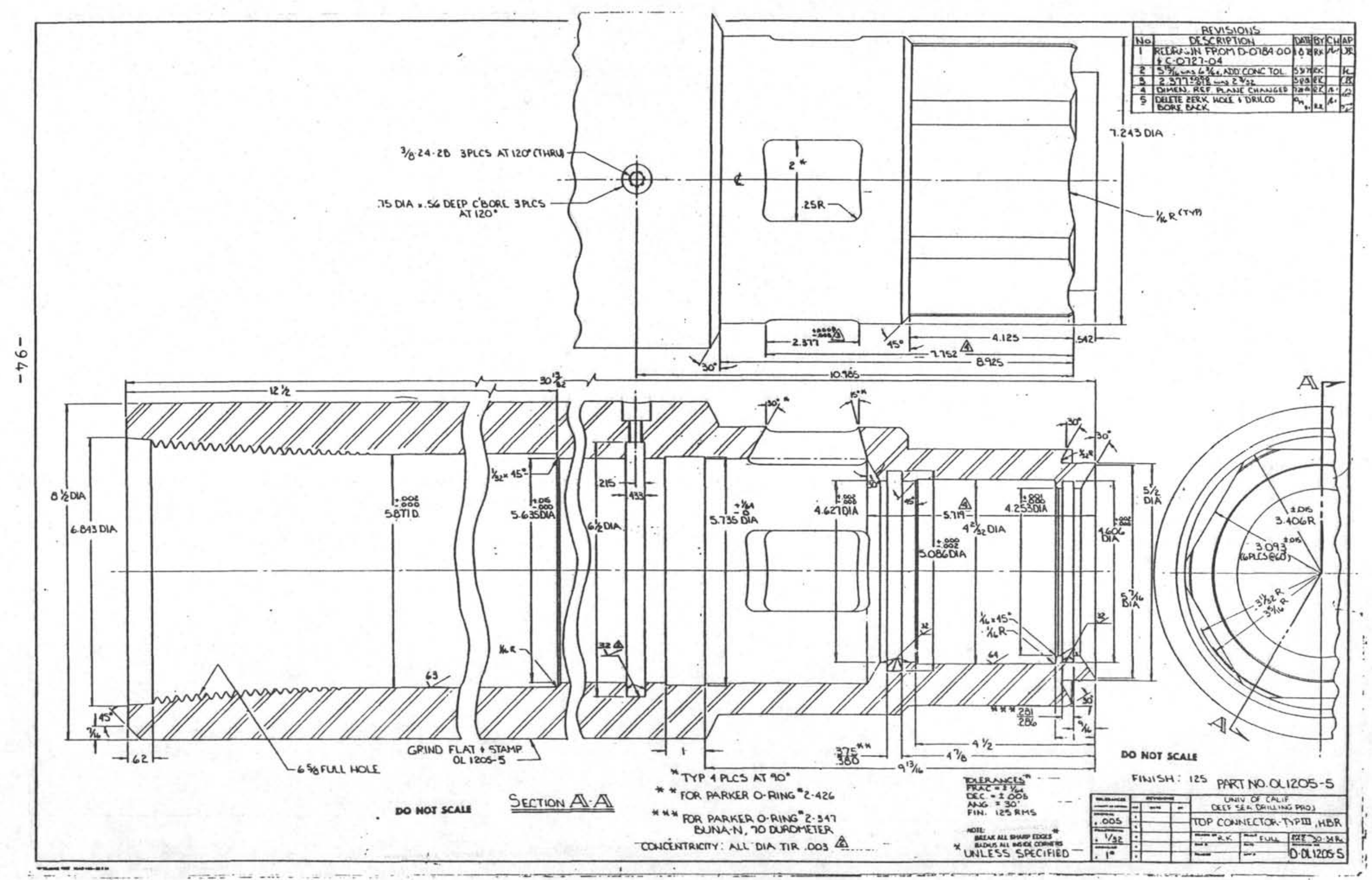




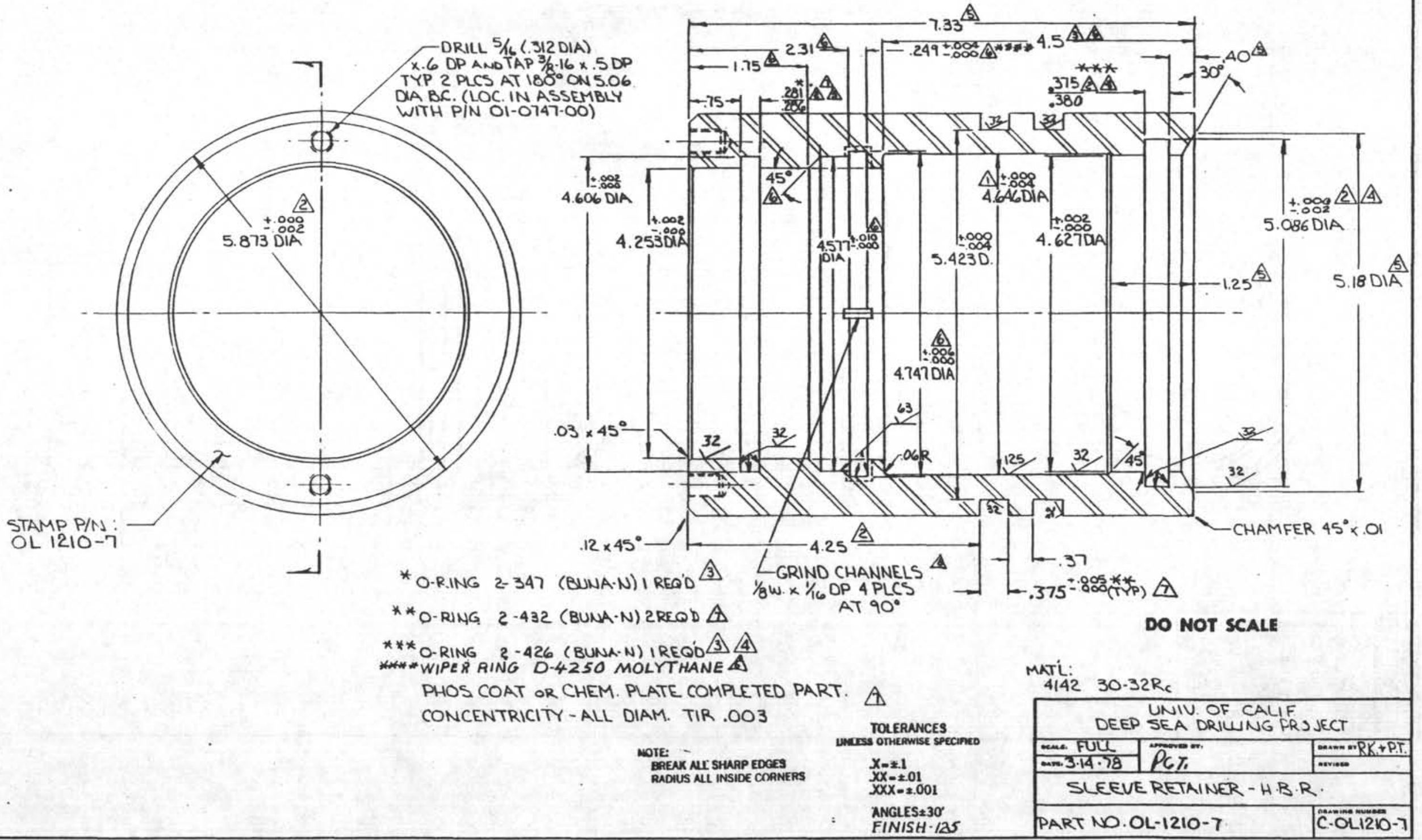




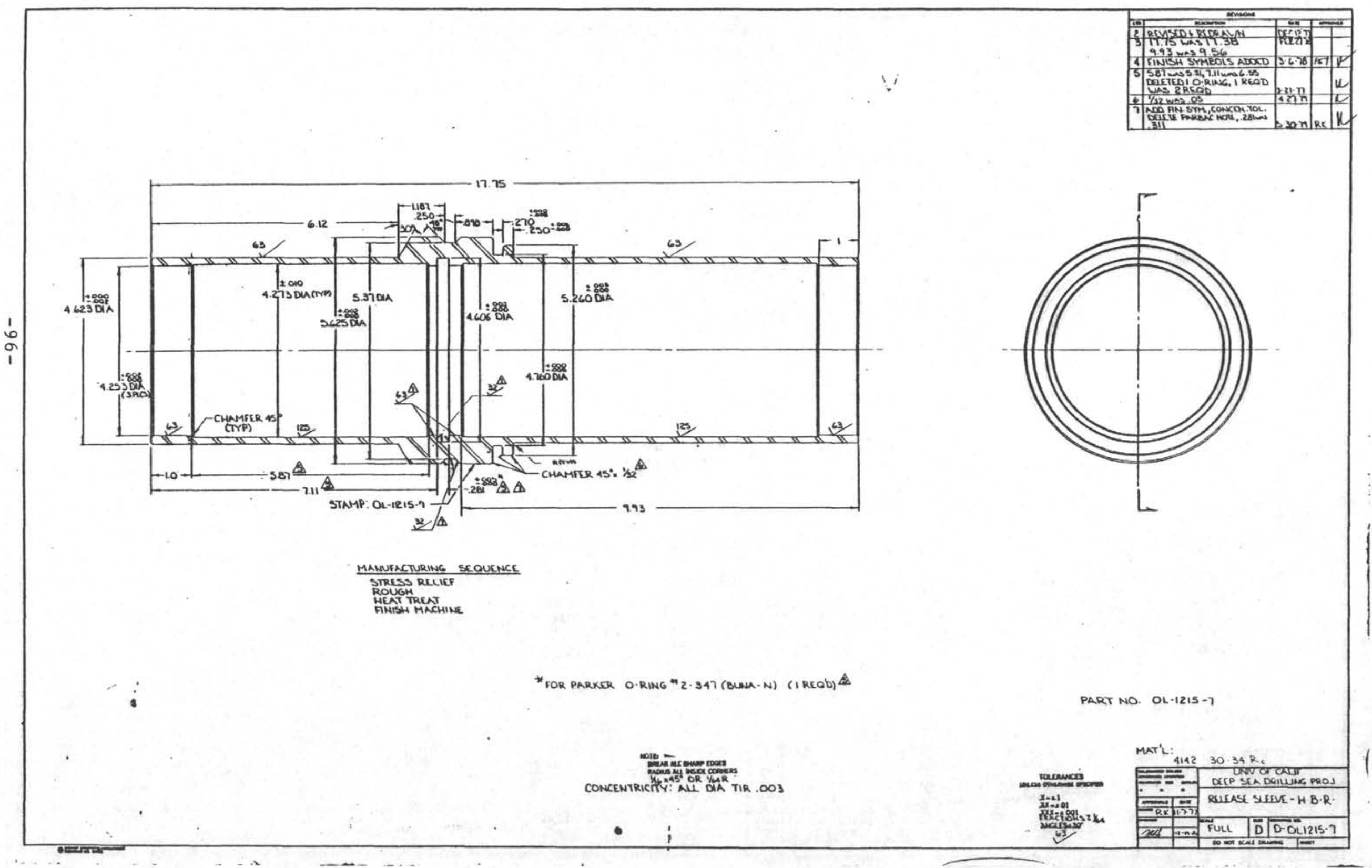





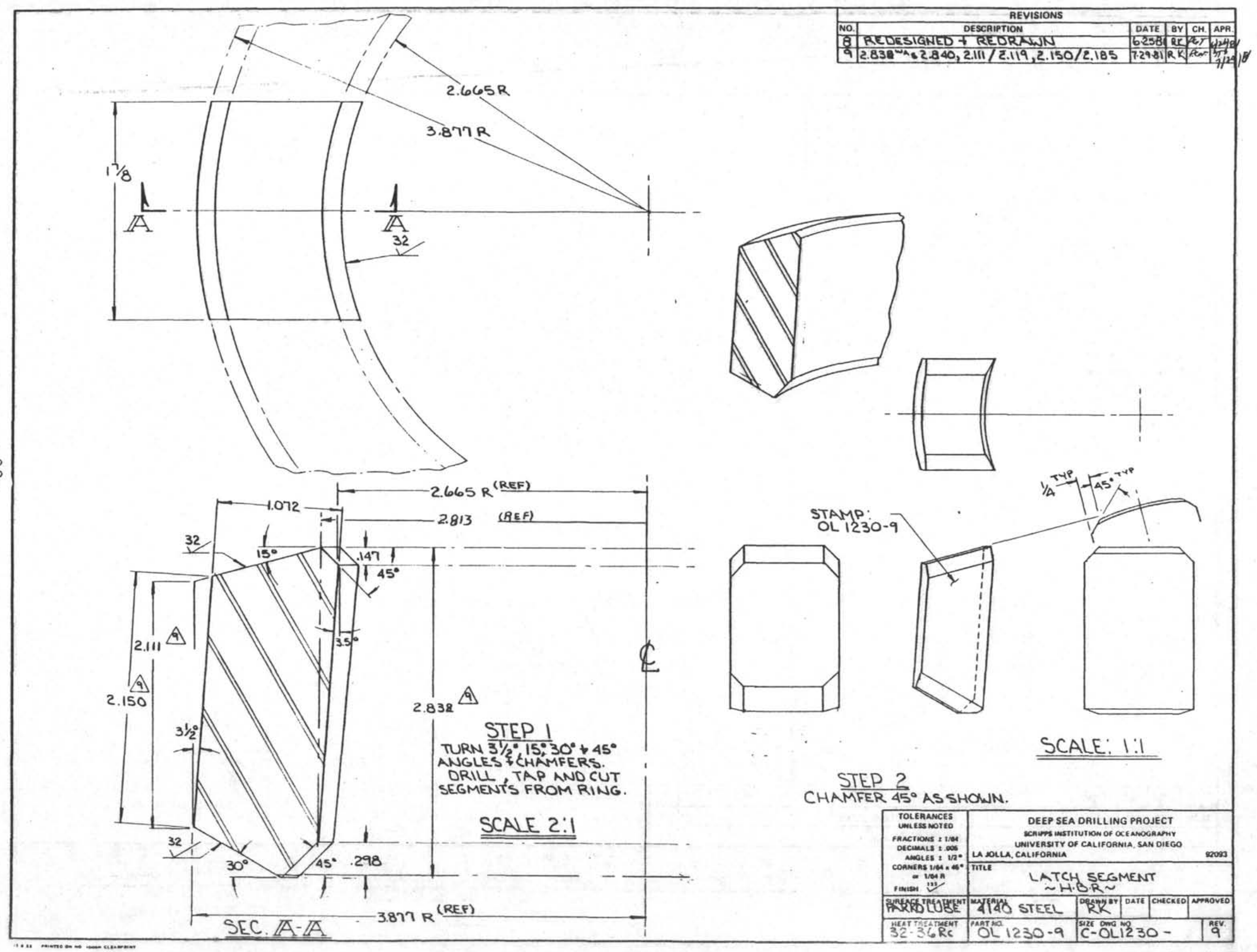



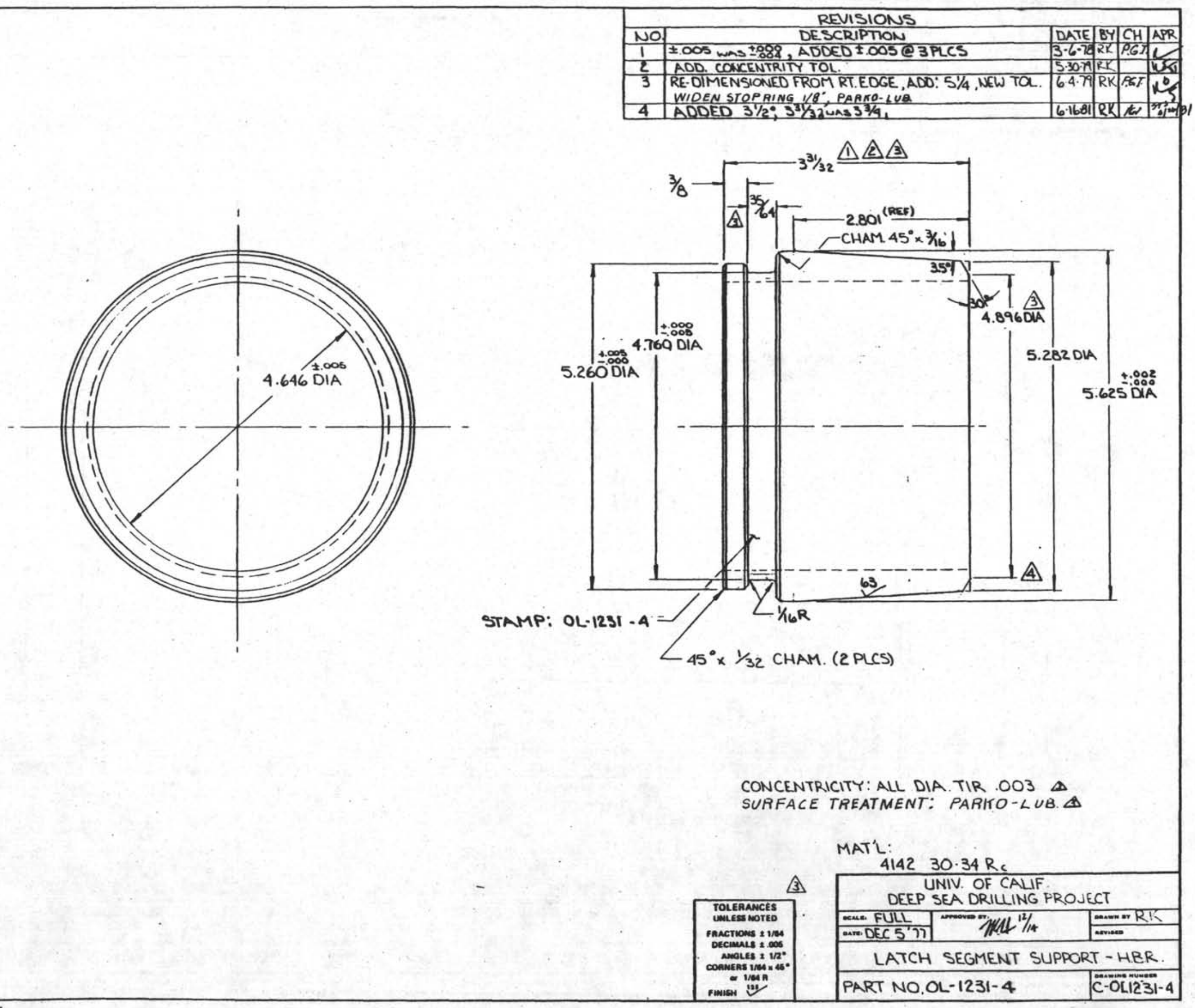

CONCENTRICITY: ALL DIA. TIR .003 $\triangle$ DEEP SEA DRILIING PROJECT

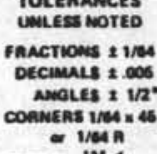
LATCH SEGMENT SUPPORT - HER PART NO.OL-1231- 4 C-OLII231-4 


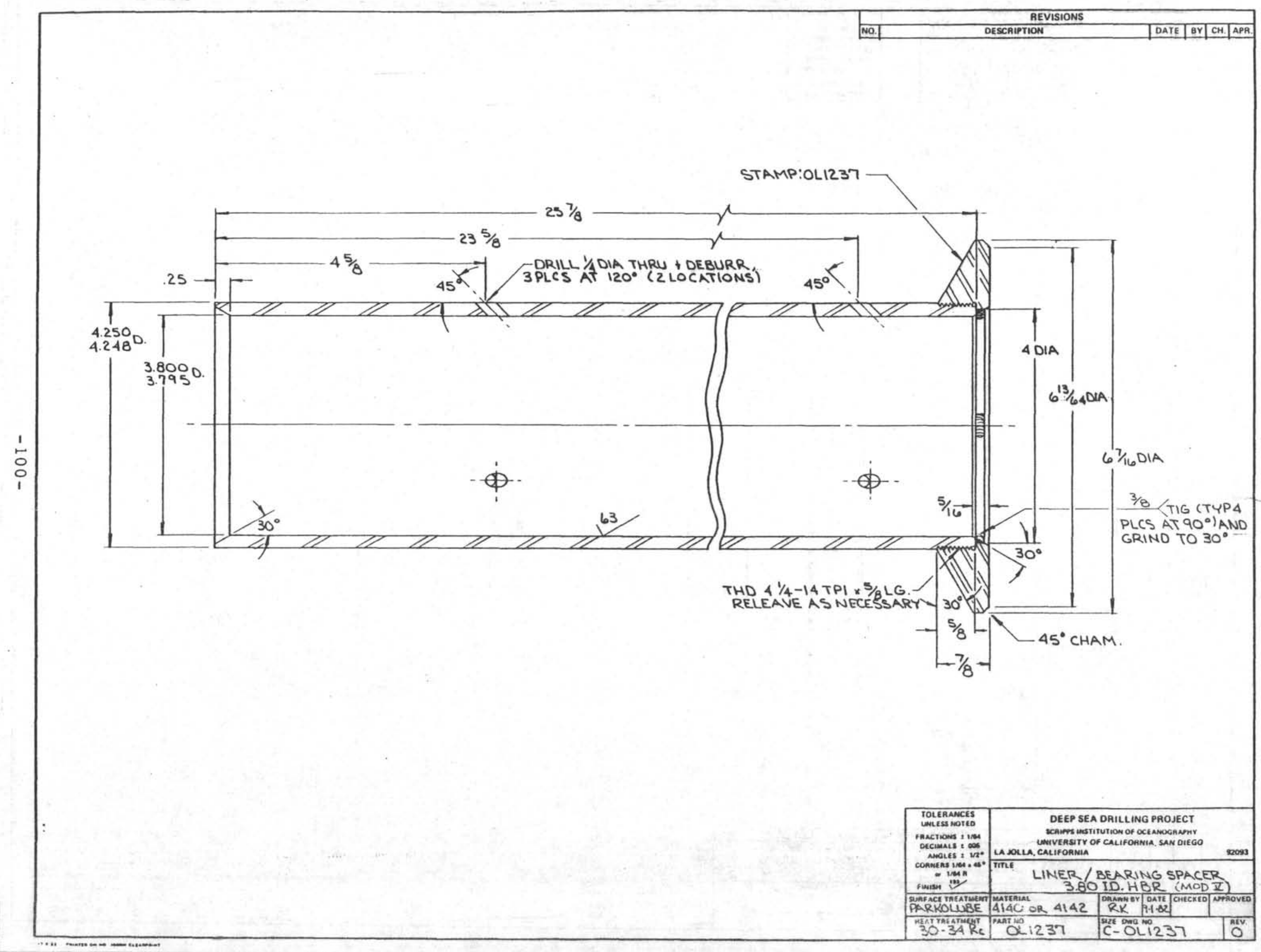




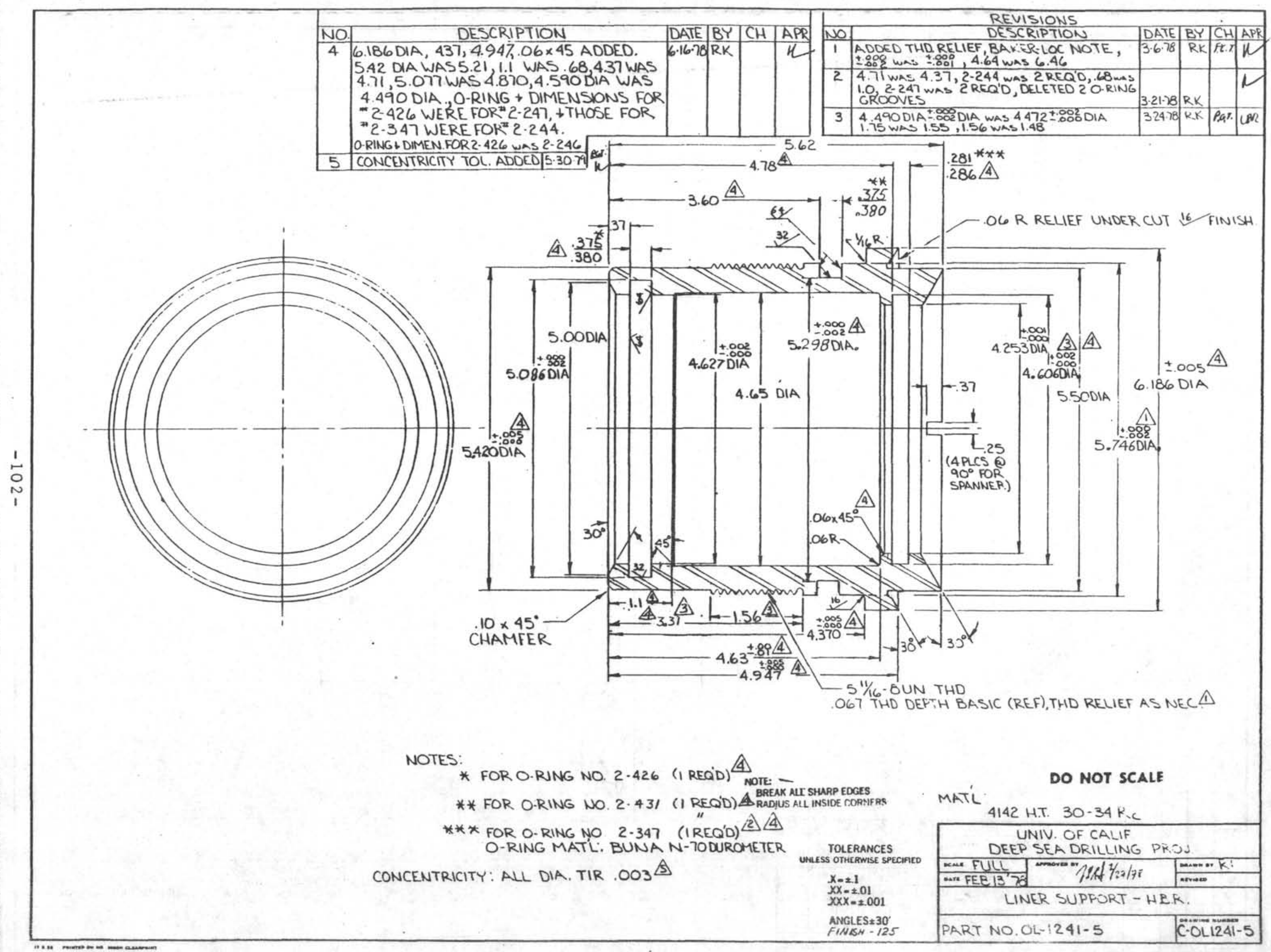




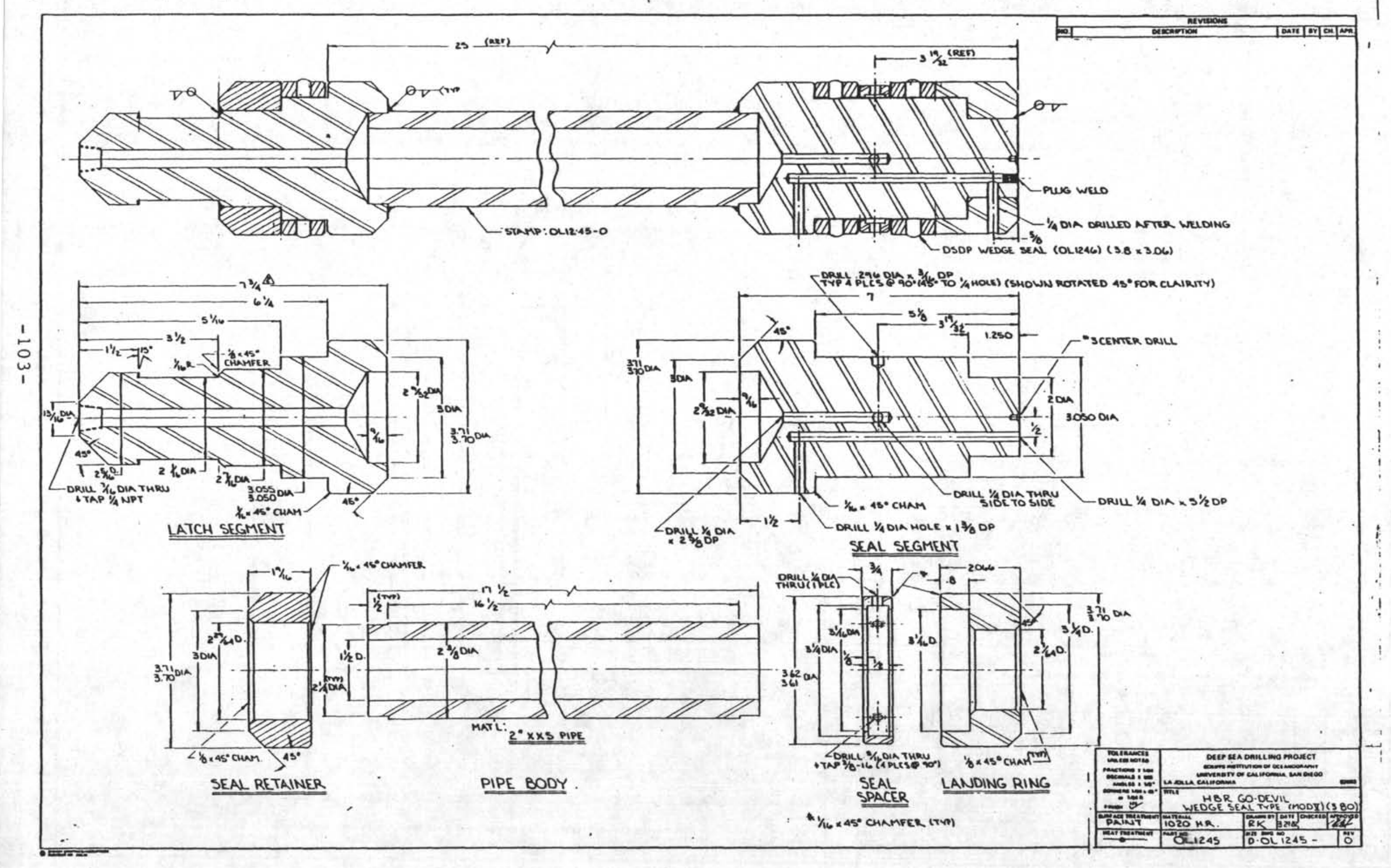




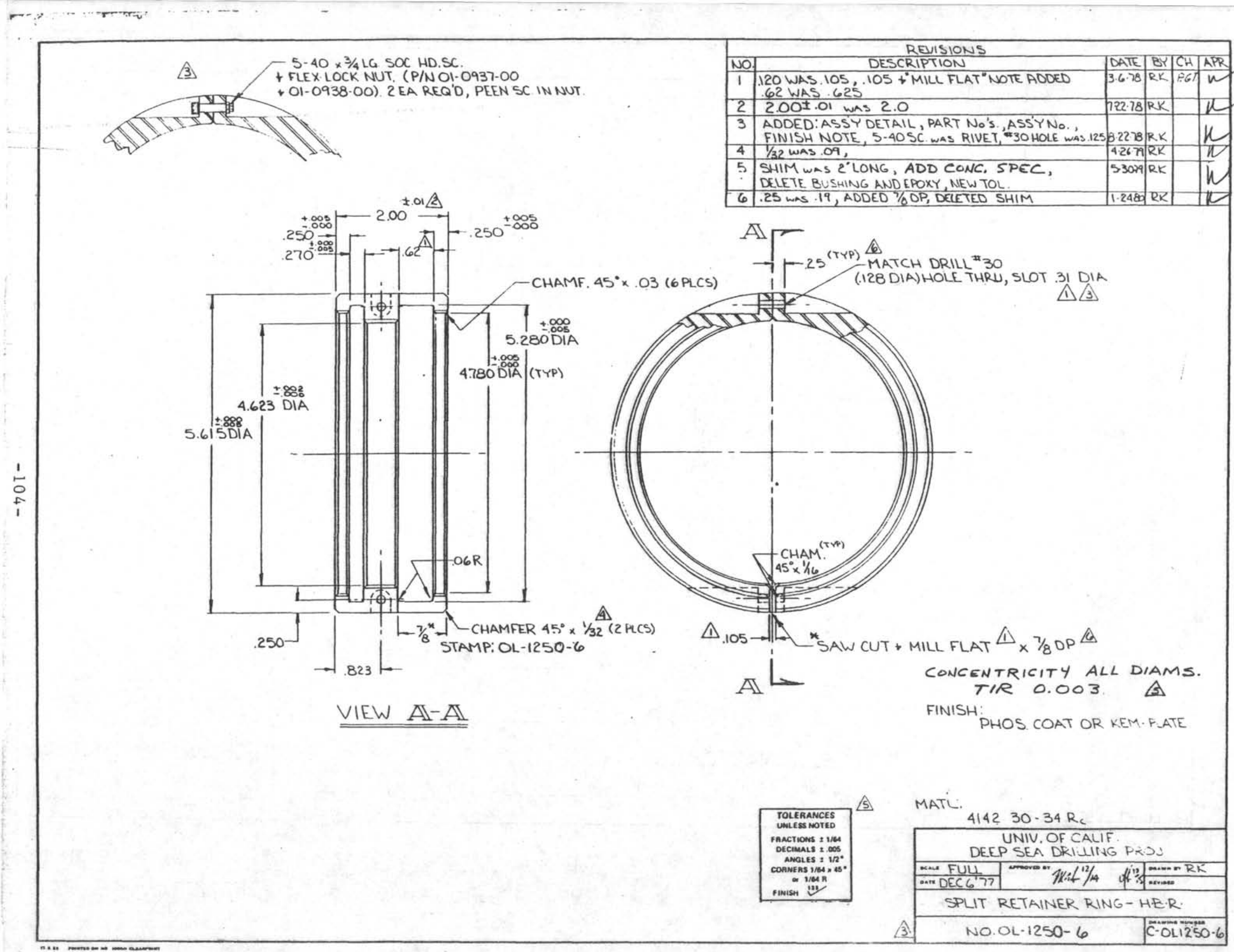




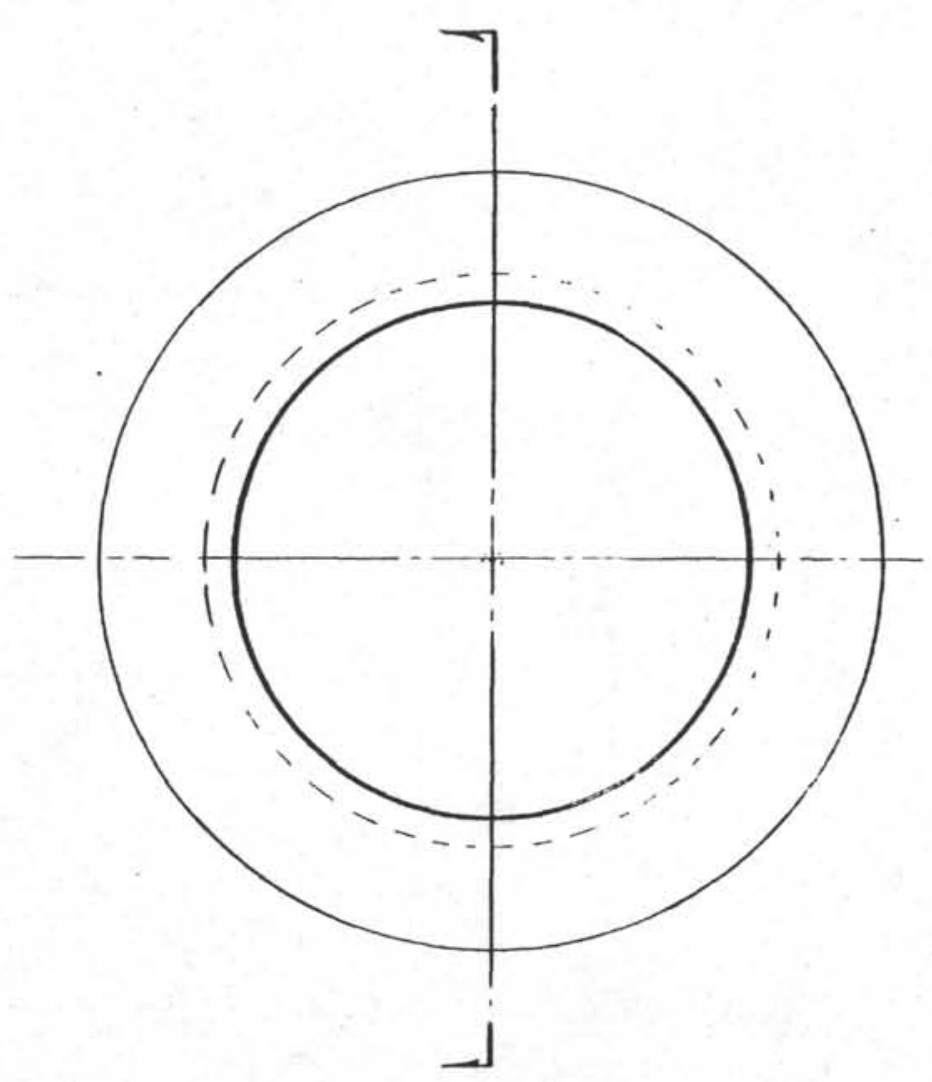

* machine for drtvie fit

WITH PART IMO OL $1240-5$
REVISIONS

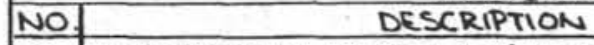
2 RE-DESIGNED + RE-DRAWN (LUGS DELETED) 4 DEIETED 5 "WIDE FLATS

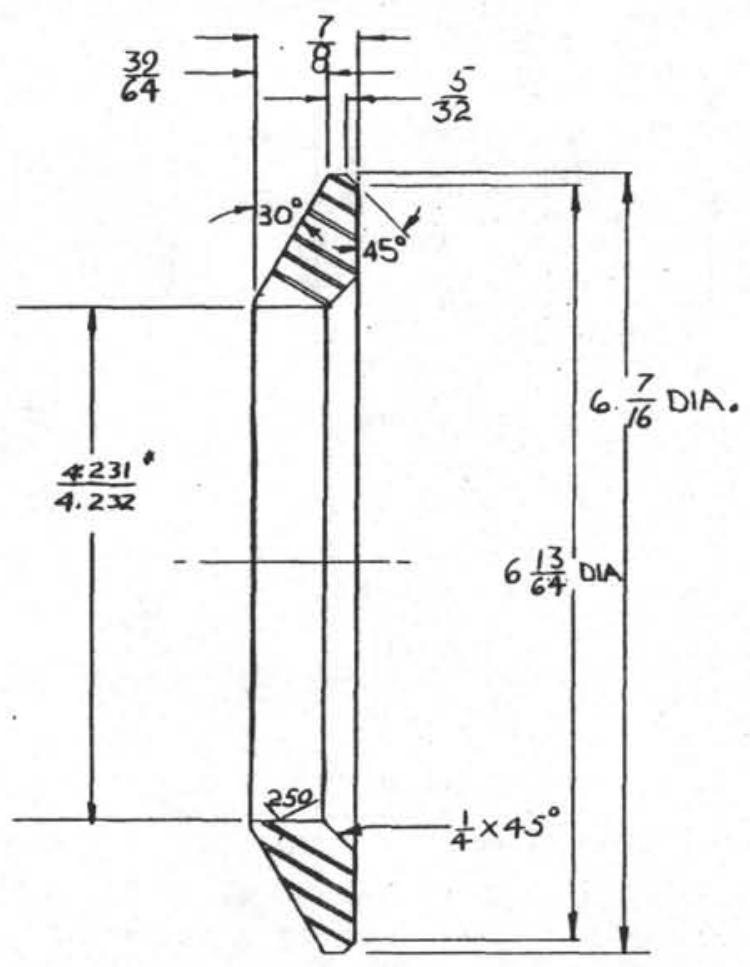

MATL:

MILO STEEL

OLERANCES

DO NOT SCALE UNLESS OTHERWISE SPRCIAD mand

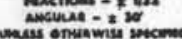

DEEP SEA DRILLING PROJ

\begin{tabular}{|c|c|c|}
\hline ans FUL & someonsen & 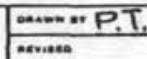 \\
\hline BEA & RING SPhC & $R$. \\
\hline
\end{tabular}




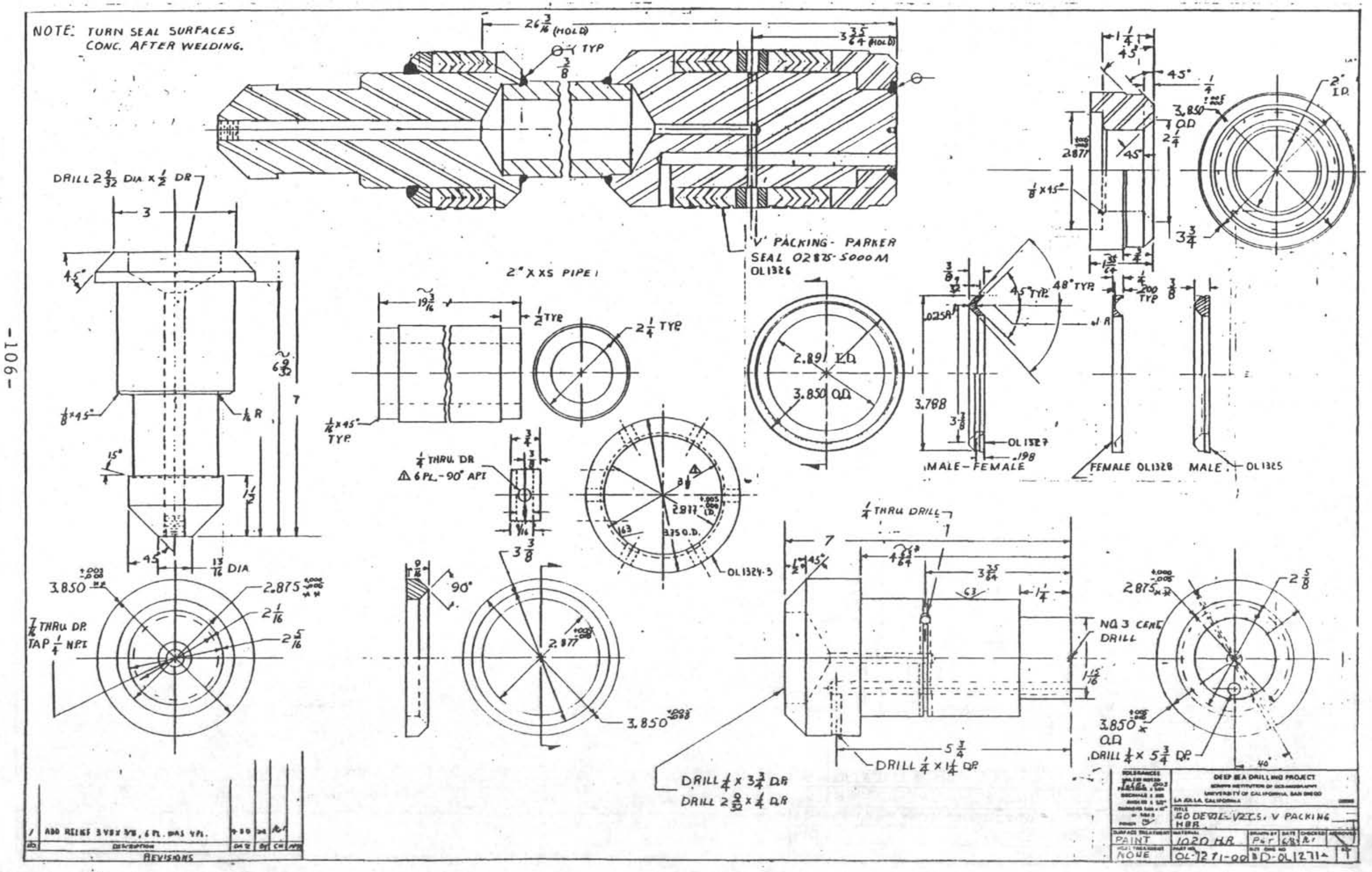




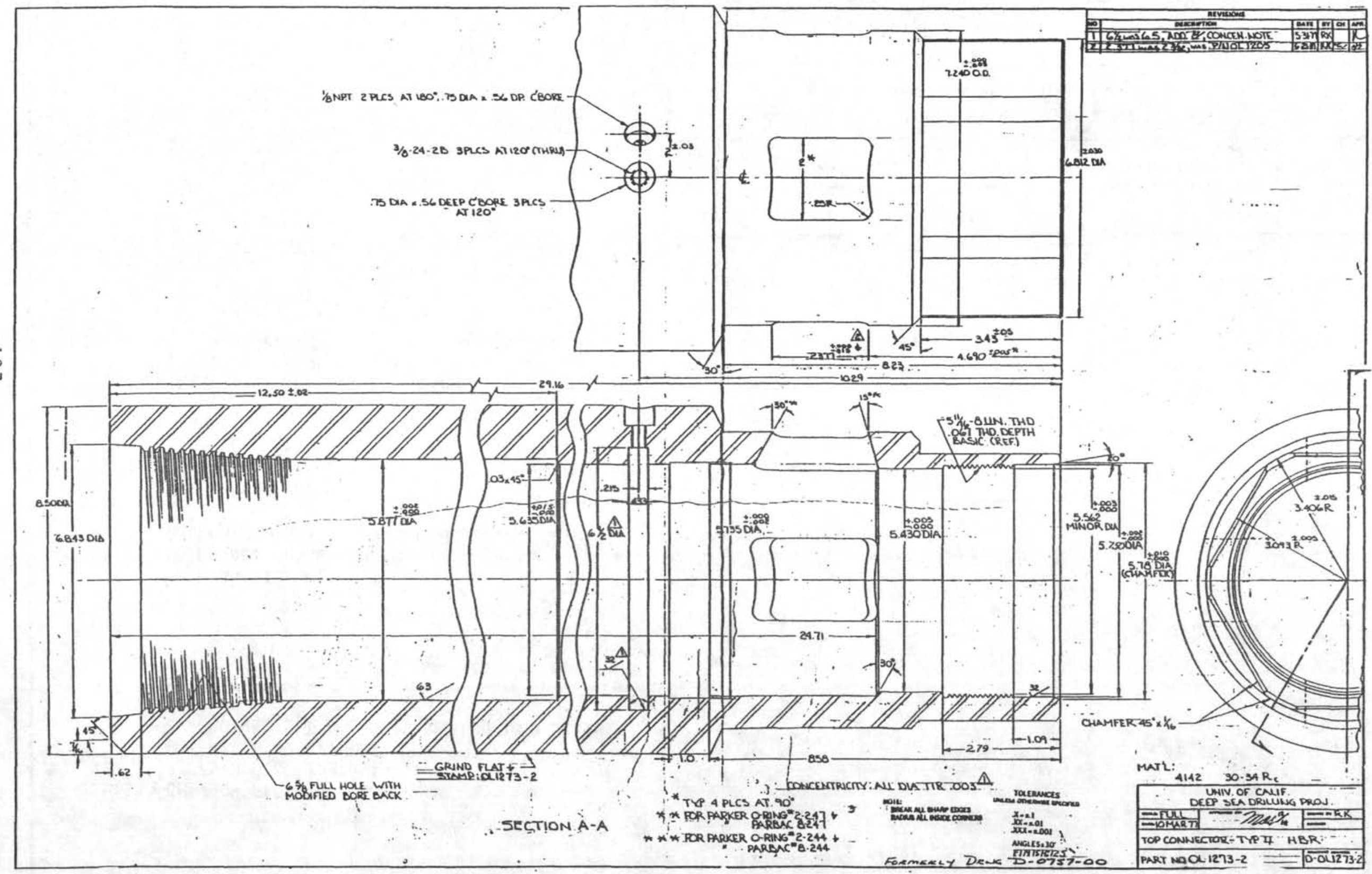


(1) CHEVRON PACKING

3.875 0.D.X. 3.375 I.D. $x .25 \mathrm{C} / \mathrm{S}$

MATERIAL: MOLYTHANE

2 REQUIRED/SET - 3 SETS REQUIRED/GO-DEVIL

TOTAL REQUIRED: 6

(2) MALE ADAPTER FOR (1) ABOVE

MATERIAL: HARD RUBBER

2 REQUIRED/SET - 3 SETS REQUIRED/G0-DEVIL

TOTAL REQUIRED: 6

(3) FEMALE ADAPTER FOR (1) ABOVE

MATERIAL: HARD RUBBER

2 REQUIRED/SET - 3 SETS REQUIRED/G0-DEVIL

TOTAL REQUIRED: 2

MANUFACTURER - PARKER SEAL OR SEARLE

VENDOR: $A B S C O A$

\begin{tabular}{|c|l|l|l|l|}
\hline 01 & $\begin{array}{l}\text { MOLYTHANE MAS FABRIC } \\
\text { CHANGE AMOUNT }\end{array}$ & $10 / 24$ & vflo & U \\
\hline NO. & \begin{tabular}{l} 
DESCRIPTION \\
\hline
\end{tabular} & DATE & BY & A PPreorE \\
\hline
\end{tabular}

UNIVERSITY OF CALIFORNIA

DEEP SEA DRILLING PROJEC

\begin{tabular}{|c|c|c|}
\hline SCALE: NONE & APPRQYED AY: & DRAWN BY PG.T, \\
\hline DATE: 8 & & REVIEED \\
\hline
\end{tabular}

"V" PACKING - GO-DEVIL - H.B.R.

PART NO.

DRAWING NUMEER

$A=0 L 1290-1$ 
SPECIFICATIONS FOR O-RINGS AND BACK-UP RIMGS FOR THE HYORAULIC BIT DISCONNECT, SEE DRANING R-OL 1200 ALL O-RINGS TO BE 70 DUROMETER BUNA-N RUBBER ALL BACK-UP RINGS TO BE 90 DUROMETER BUNA-N RUBBER.

O-RINGS ARE TO BE PACKAGED IN SETS IN A WATERPROOF BAG WITH SUFFICIENT O-RINGS AND BACK-UP RINGS TO REDRESS ONE ENTIRE ASSEMBLY (DOES NOT INCLUDE GO-DEVIL).

\section{KIT NO. ONE}

LABELED: "COMPLETE O-RING SET FOR HYORAULIC BIT OISCONNECT"

CONSISTS OF THE BELOW LISTED SEALS AND KIT NO. 2 AND KIT NO. 3.

QUANITY

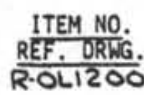

PARKER

PURPOSE R.OL1200

$\begin{array}{llll}2 \text { ea } & 17 & 2-442 & \text { TRASH SEAL FOR ITEM } \# 25 \\ 1 \text { ea } & 9 & 2-347 & \text { PRESSURE SEAL BETWEEN ITEM } \# \text { ANO ITEM \#5 } \\ 1 \text { ea } & 4 & 2-432 & \text { TRASH SF.AL AT THF TRP OF ITEM } \# 3 \\ & & & \end{array}$

KIT NO. THO

LABELED: "SLEEVE RETAINER"

INCLUDES THE FOLLOWING SEALS:

$\begin{array}{ccc}\text { QUANITY } & \frac{\text { ITEM NO. }}{\text { REF. ORLGG. }} & \frac{\text { PARKER }}{\text { NO. }} \\ 1 \text { ea } & \frac{\frac{R \cdot O L I 200}{2}}{2} & 2-347 \\ 2 \text { ea } & 4 & 2-432 \\ 1 \text { ea } & 6 & 2-426 \\ 1 \text { ea } & 12 & 0-4250\end{array}$

PURPOSE

PRESSURE SEAL BETWEEN ITEM 3 AND ITEM \#5

PRESSURE SEAL BETWEEN ITEM \# AND ITEM \#3

PRESSURE SEAL BETWEEN ITEM \#3 AND ITEM \#8

KIT NO. THREE

LABELED: "LINER SUPPORT"

INCLUDES THE FOLLOWING SEALS:

\begin{tabular}{|c|c|c|}
\hline QUANITY & 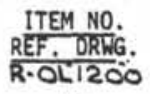 & $\frac{\text { PARKER }}{\text { NO }}$ \\
\hline 1 ea & 18 & $2-426$ \\
\hline $1 \mathrm{ea}$ & 29 & $2-431$ \\
\hline 1 ea & 21 & $2-347$ \\
\hline
\end{tabular}

PURPOSE

$\frac{\infty}{1}$

of

$山 D$

\& 3

iI

㟧

ป

HIPER RINGS BETWEEN ITEM $\$ 3$ AND ITEM 15.

PRESSURE SEAL BETWEEN ITEM \#19 AND ITEM \#8 PRESSURE SEAL BETWEEN ITEM 77 AND ITEM $\$ 19$ PRESSURE SEAL BETWEEN ITEM \#19 AND ITEM \#5

\begin{tabular}{|c|c|c|c|c|c|}
\hline 2 & DELETE BACK-UP RIIIGS, ADD TPASH SEAL ITEY \#4 & 5.30 .29 & & P\&. & 18 \\
\hline 1 & AUD TRASH SEAL ITEH & & & & \\
\hline NO. & DESCRIPTION & DATE & $\mathrm{BY}$ & CH. & APR. \\
\hline
\end{tabular}



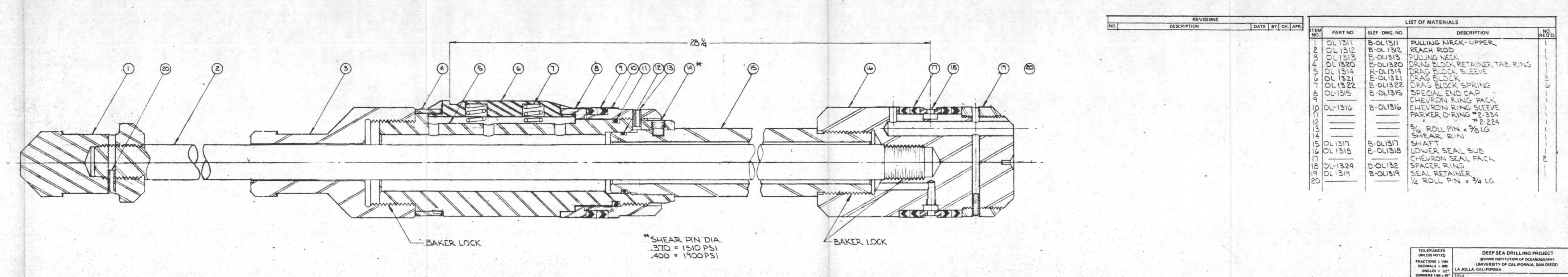

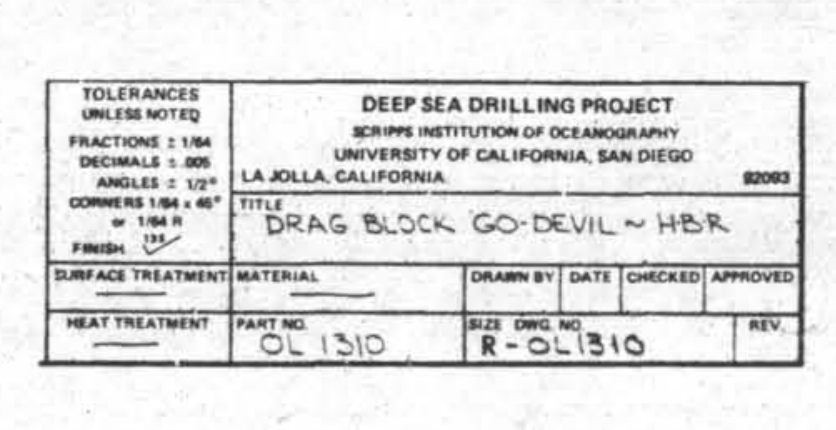




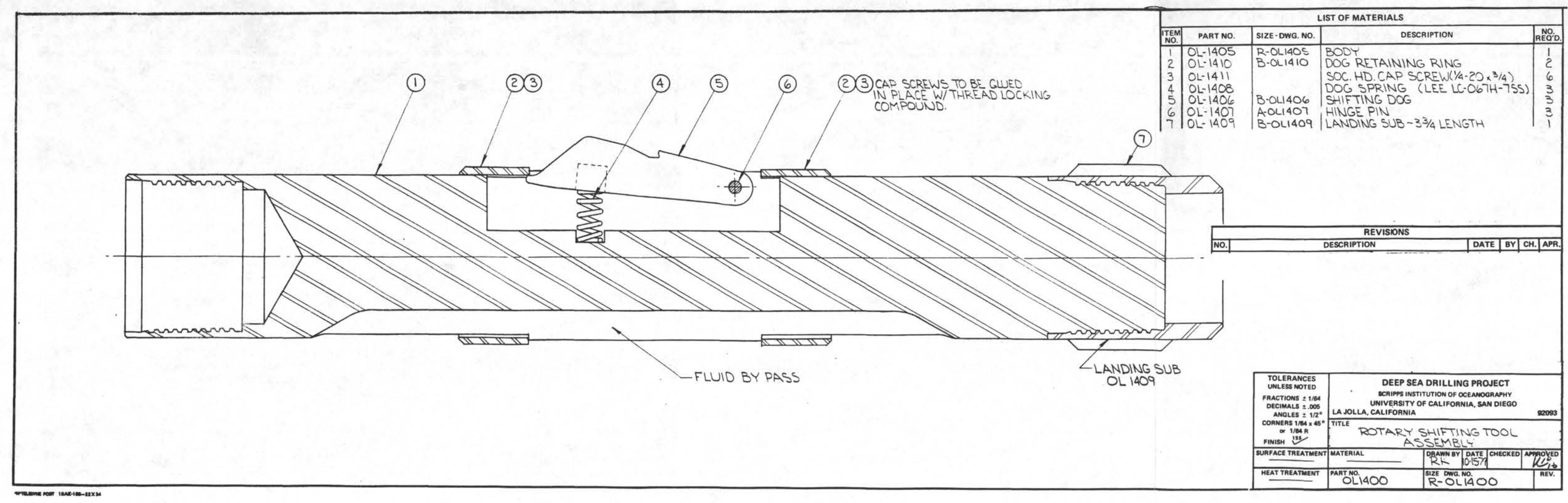




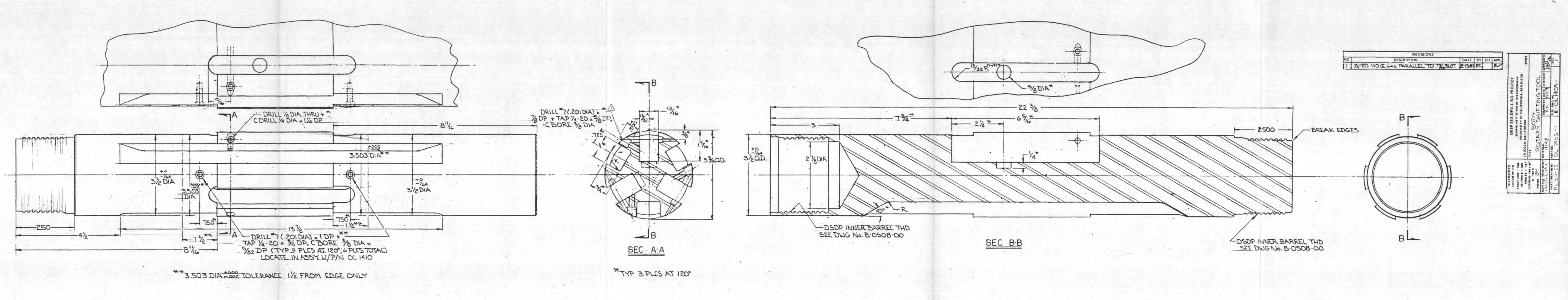




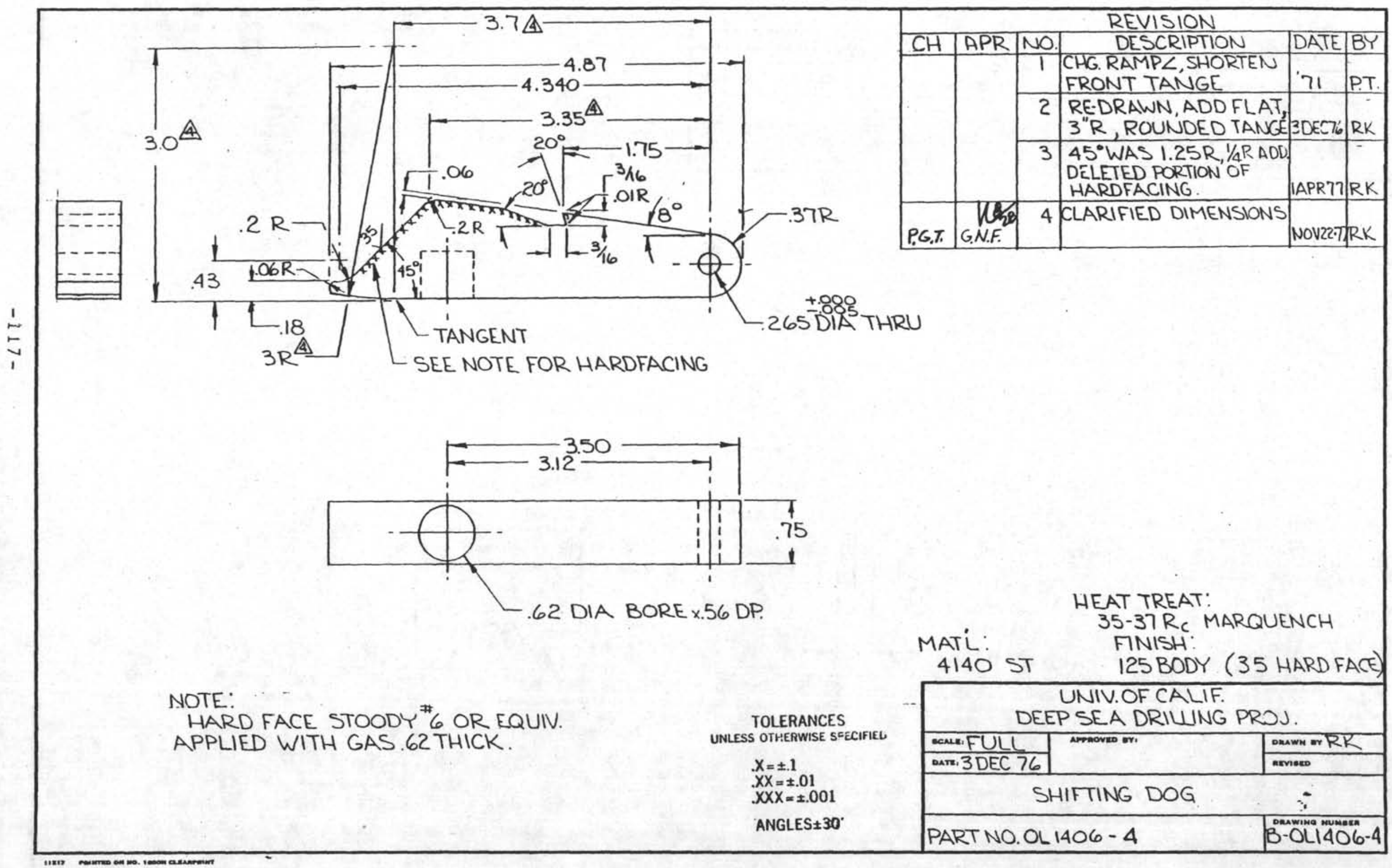




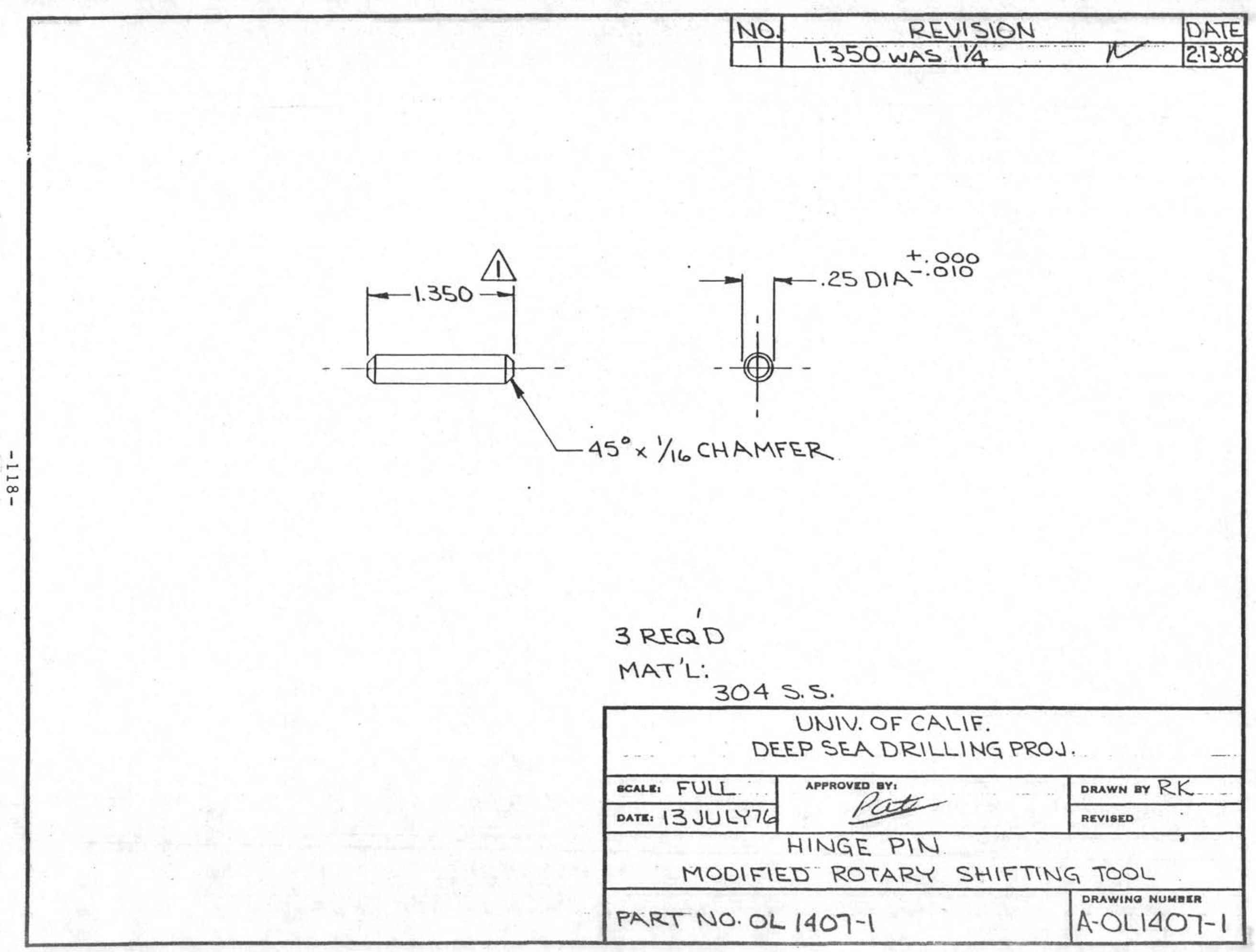




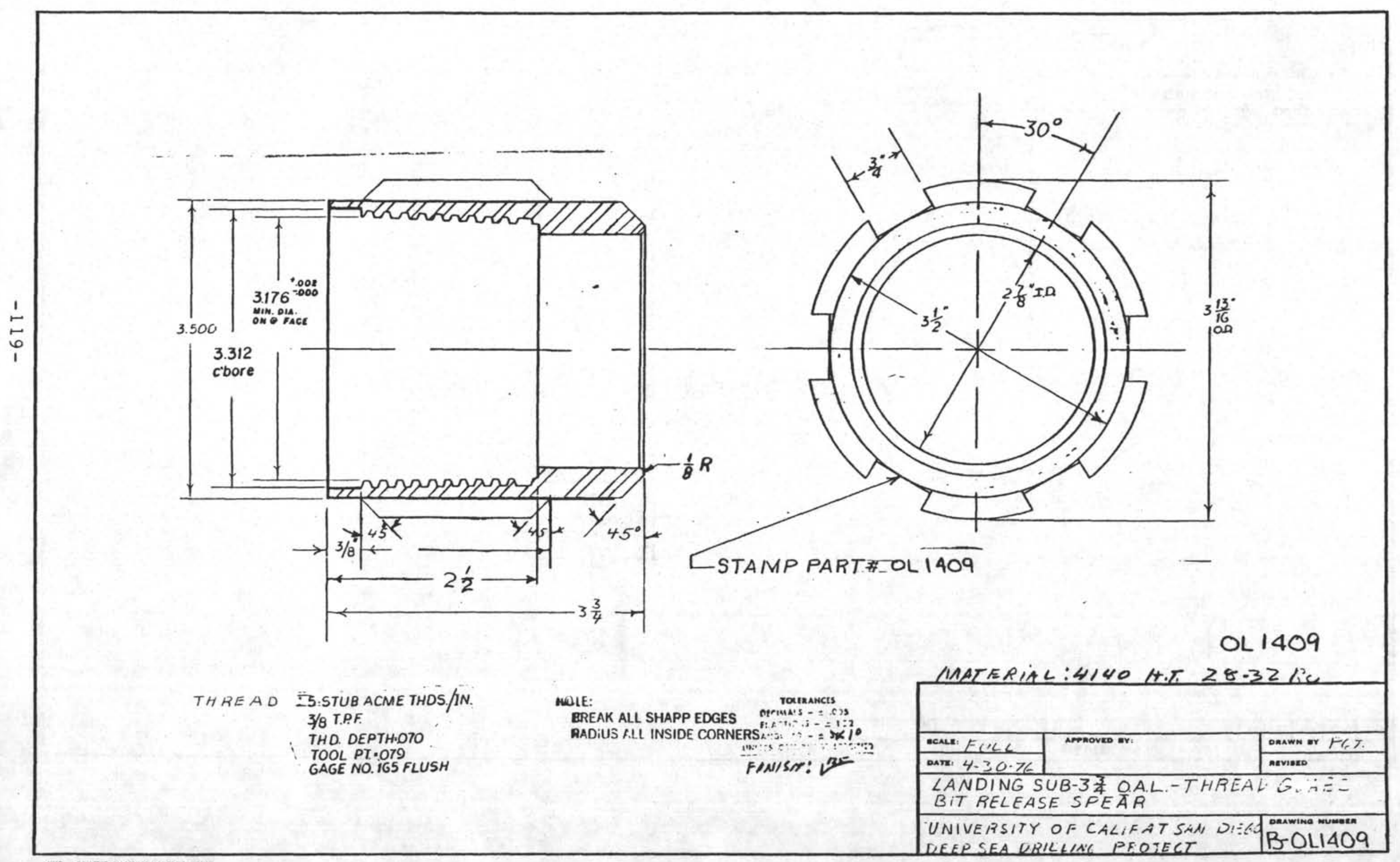




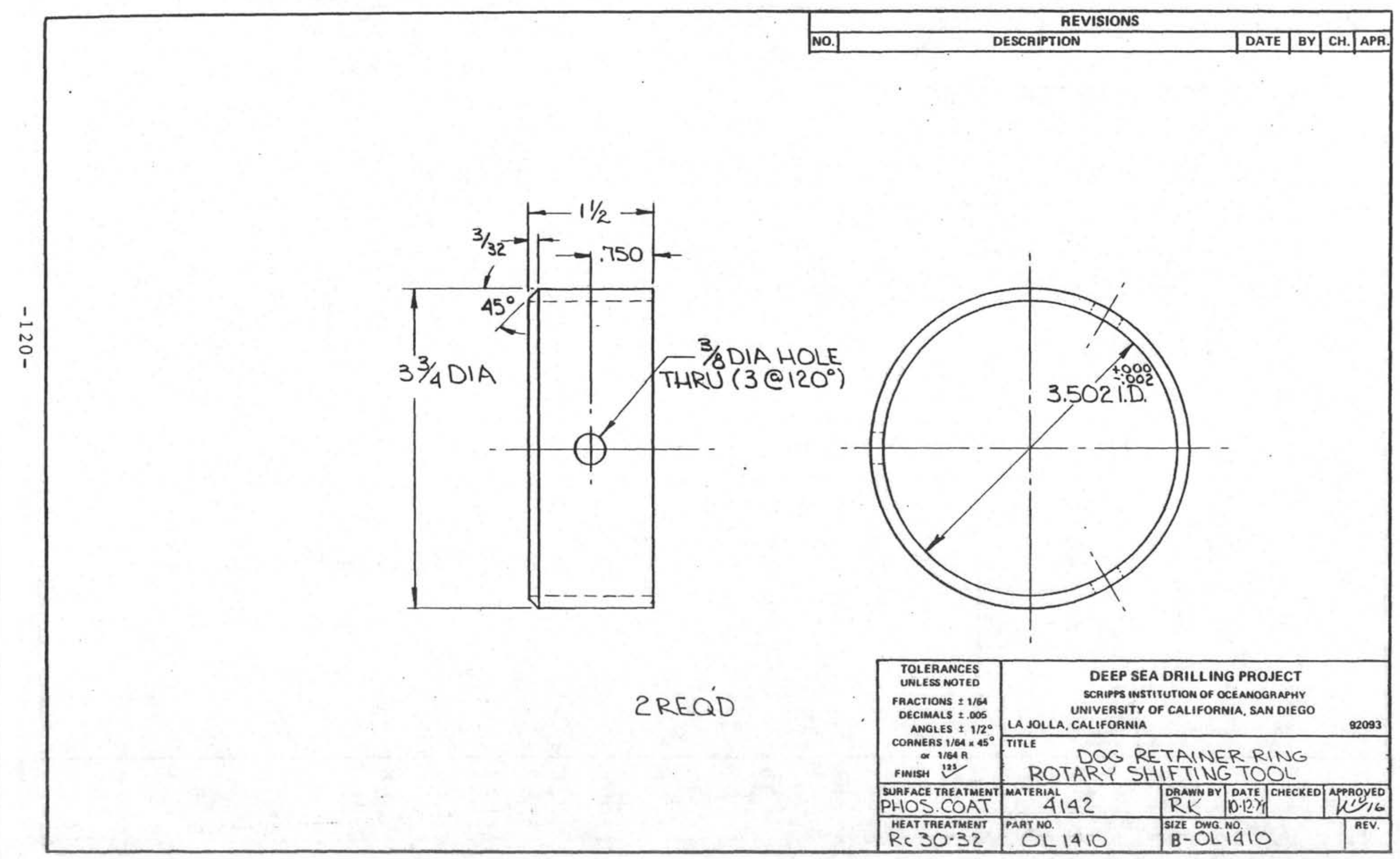

